\title{
A MODEL OF MIDWIFERY CARE AS AN INTEGRAL COMPONENT OF A MULTIDISCIPLINARY PRIMARY HEALTH CARE SERVICE
}

By

Siobhan Mary Connor

A thesis submitted to the Victoria University of Wellington

in fulfilment of the requirements for the degree of

Master of Midwifery

Victoria University of Wellington

2012 


\section{ABSTRACT: A Model of Midwifery Care as an Integral Component of a Multidisciplinary Primary Health Care Service}

This research describes the model of midwifery care embedded in Newtown Union Health Service (NUHS). This model of care is different from the way most midwifery services in New Zealand are organised. The main New Zealand midwifery services are provided by selfemployed midwives and hospital midwives. NUHS was set up to provide accessible health services to a low income population. Pivotal to the service is the employment of a multidisciplinary team which aims to meet most of the health needs of its registered population. As the NUHS midwifery service was set within the larger organisation the case study research method was chosen as it is a method which stresses the importance of understanding the context of a case. It permits the use of several sets of data to capture the complexity of a case. Data collection included interviews with five midwives and seven multidisciplinary team members including managers working at NUHS. An unsuccessful attempt was made to gain access to and interview pregnant women who had used this service. Other data came from several documents about the Newtown community and the service. Data analysis revealed that the NUHS model of midwifery care was made up of five interrelated and interacting components: the community, NUHS, the midwives as integral to the multidisciplinary team, the midwives and the women in the care of the midwives. A discussion of the model includes what was extrapolated as three distinctive features of the model: their philosophy, the union influence and the midwives in the multi disciplinary team. The NUHS model of midwifery care is then related to other national and international models where its distinctiveness is supported.

Key words: midwifery, model of care, model of midwifery care, multidisciplinary team, primary health care 


\section{ACKNOWLEDGEMENTS}

To the people who have assisted this research come to fruition I appreciate the time and effort that you have put in to assist my endeavour.

To all the NUHS participants, thank you for your time in your busy work schedules

To Mum and Dad for their endless support and encouragement and editing

To Joan Skinner, my thesis supervisor, for her experience, guidance and advice

To Kathy Nelson, for early support and encouragement

To Sean, Steve and Simon for IT support

To Kate, Jenny and Andrew for graphics support

To Elisa, Eleanor, Chris, Chris and Brigid for assistance with editing

To all my friends and family who have supported, encouraged me and tolerated the constant decline to invitations, over the period of this research. yet have continued to include me. 
ABSTRACT: A Model of Midwifery Care as an Integral Component of a Multidisciplinary

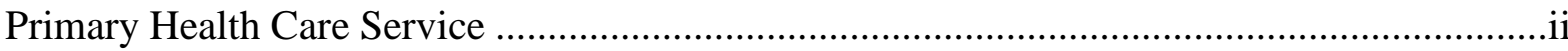

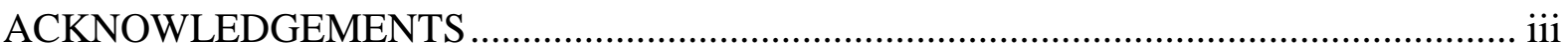

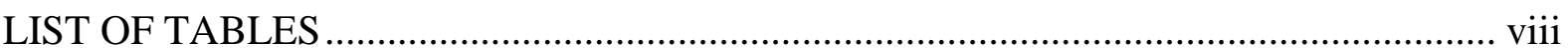

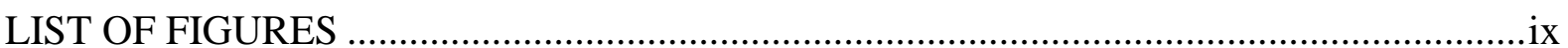

CHAPTER ONE: INTRODUCTION and BACKGROUND ............................................

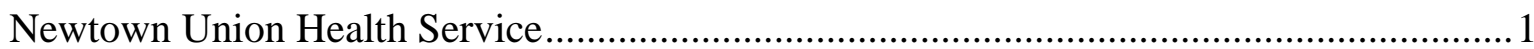

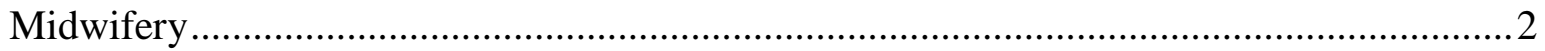

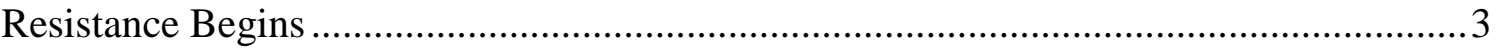

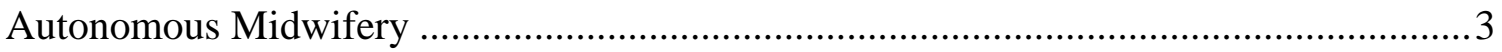

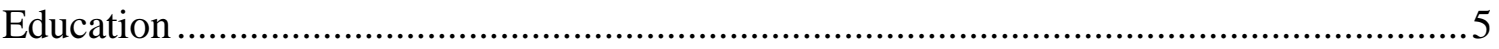

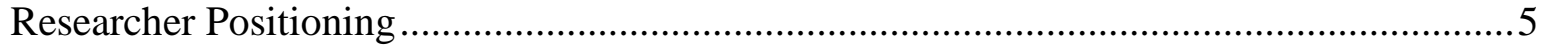

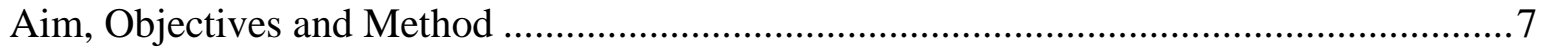

Overview of Subsequent Chapters .............................................................................

CHAPTER TWO: BACKGROUND LITERATURE …................................................

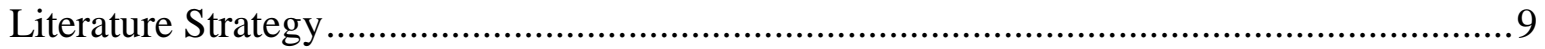

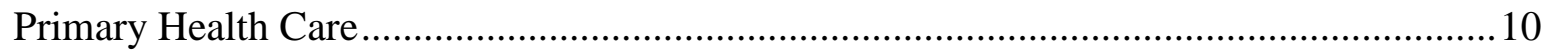

The History and Organisation of Primary Care Services in New Zealand........................ 11

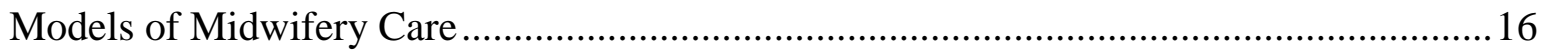

Current Models of Midwifery Care in New Zealand …................................................ 18

Models of Midwifery Care in the United Kingdom .................................................21

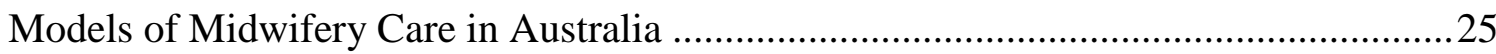

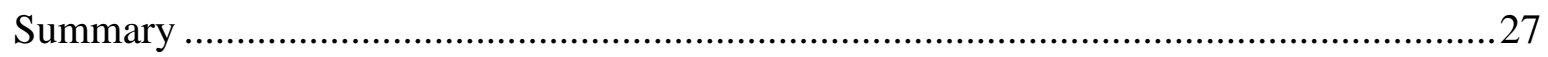

CHAPTER THREE: STUDY METHODOLOGY and DESIGN …...................................2

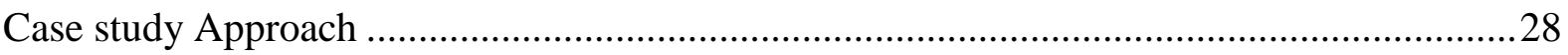

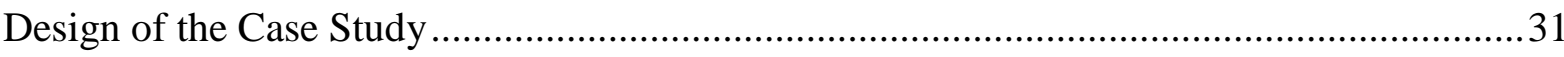


Selection of Case. 31

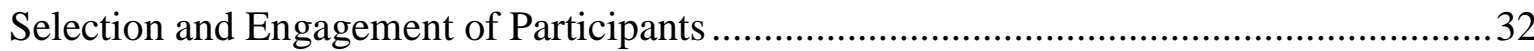

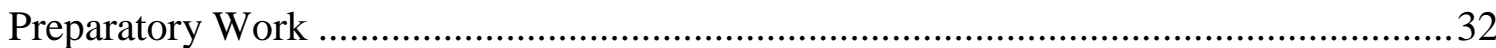

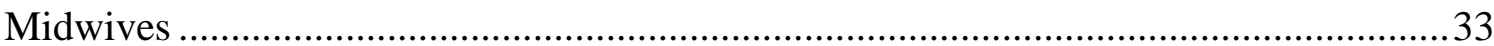

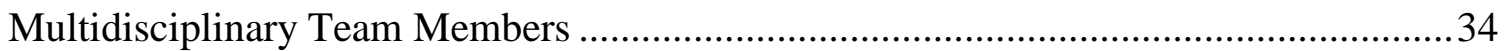

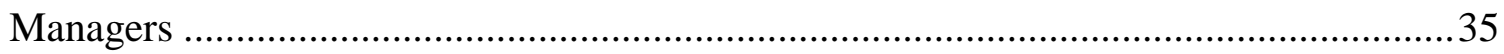

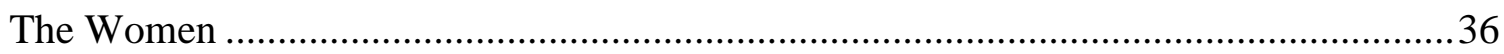

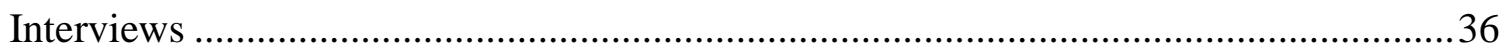

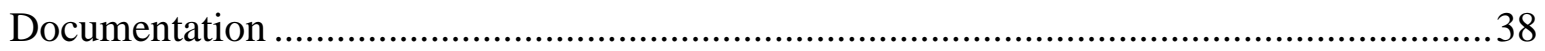

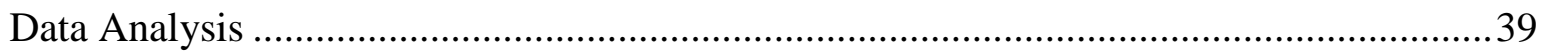

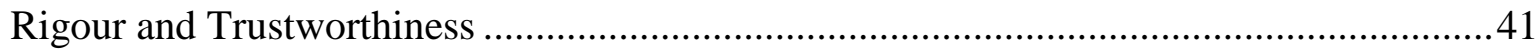

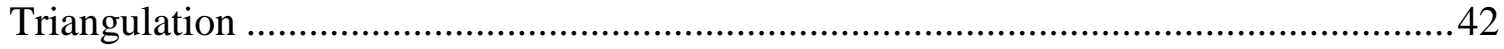

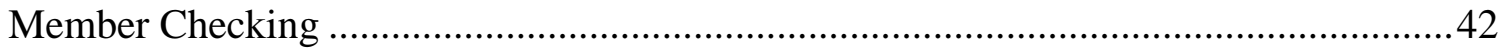

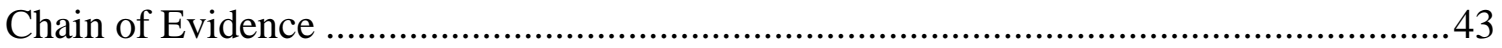

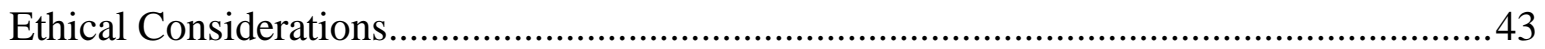

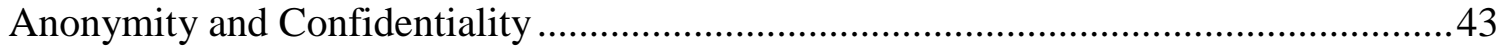

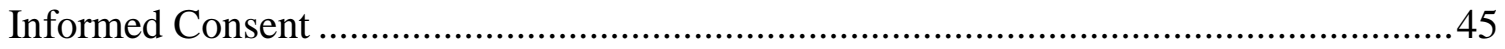

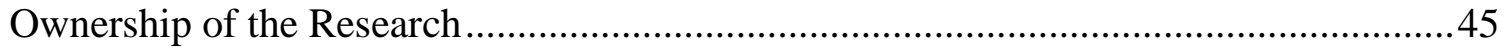

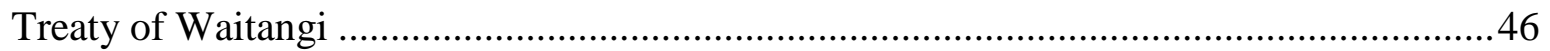

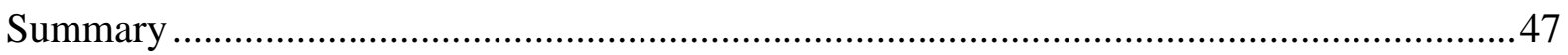

CHAPTER FOUR: FINDINGS - The NEWTOWN UNION HEALTH SERVICE MODEL of

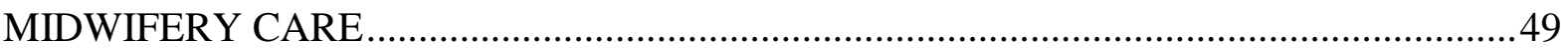

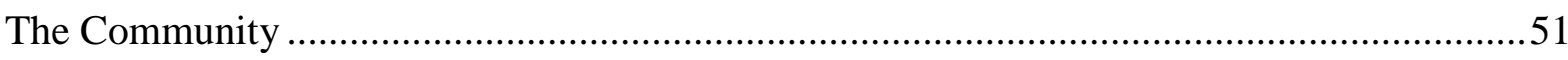

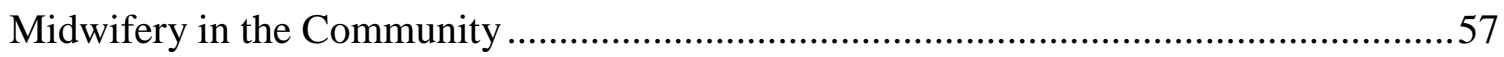

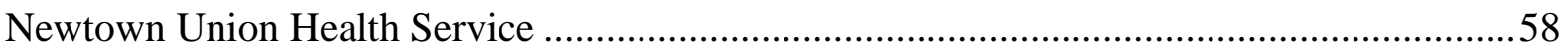

The Origins and Development of Newtown Union Health Service ...................................59 
Newtown Union Health Service in 2011

Kaupapa

Structure

Future of Newtown Union Health Service .66

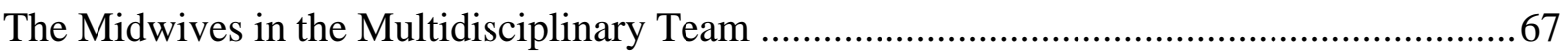

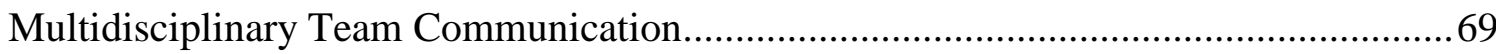

Choosing to be Part of a Multidisciplinary Team............................................................. 71

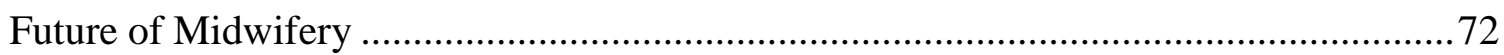

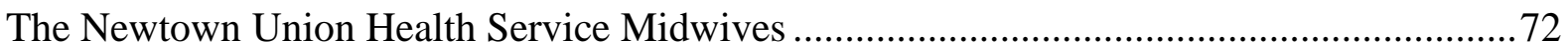

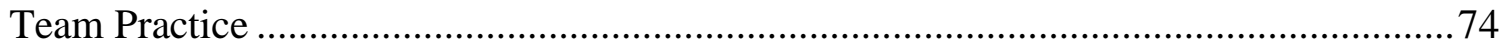

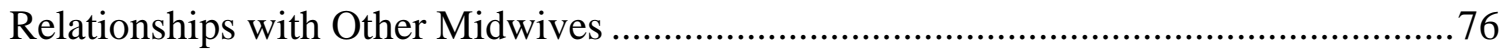

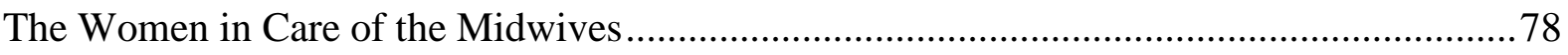

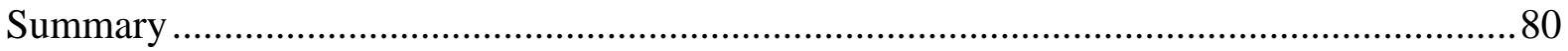

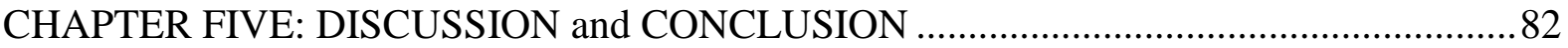

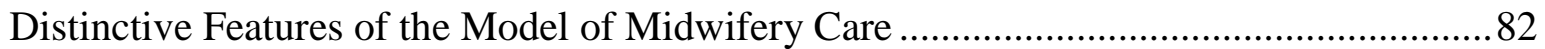

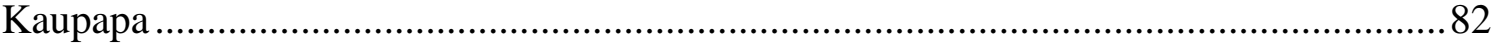

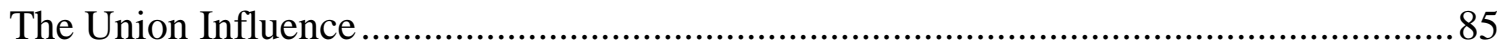

Midwifery as an Integral Discipline in a Multidisciplinary Team ................................8 86

The Relationship of the Newtown Union Health Service Model of Midwifery Care to other

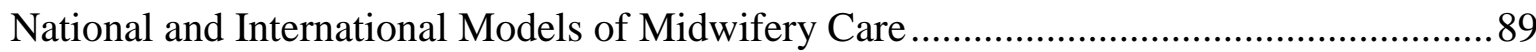

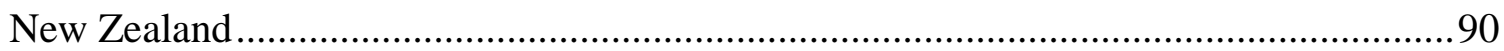

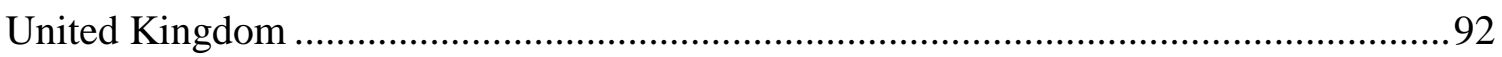

Australia

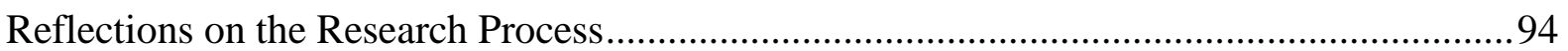

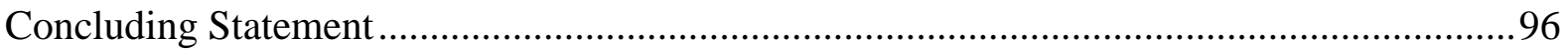

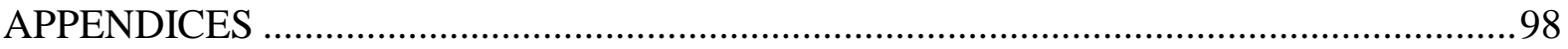




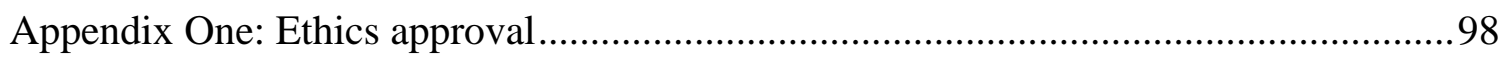

Appendix Two: Midwives Information Sheet with Questions and Consent Form ........ 100 Appendix Three: Non-Midwives Information Sheet with Questions and Consent Form 103

Appendix Four: Contract Between NUHS and Myself to Undertake Research............. 106 Appendix Five: Research Summary and Agreement Between NUHS and Myself ....... 109

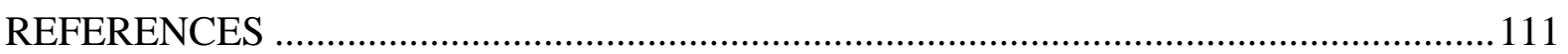




\section{LIST OF TABLES}

Table 4.1: Key to Interviewee Vignettes...................................49

Table 4.2: Ethnic Population...................................................... 55 


\section{LIST OF FIGURES}

Figure 4.1: A Representation of the Newtown Union Health Service Model of Midwifery Care. 51

Figure 4.2: Map of Newtown and its Surrounding Suburbs. .52

Figure 4.3: Income for People aged 15 years and over for Newtown West and Wellington Region 55

Figure 4.4: Income for People aged 15 years and over for Newtown East and Wellington Region. 55 


\section{CHAPTER ONE: INTRODUCTION and BACKGROUND}

The term model of care entered the health service literature in the 1980s. Generally this term refers to how a service or organisation manages the way it operates in relation to the clientele it serves and how it embodies a particular philosophy of practice (Libberton, 2007). The value of the term lies in the way it better articulates a service allowing people to see what is going on more clearly than in the past. Early uses of the term were in relation to medical and nursing services and focussed on how the practice of the practitioners in these disciplines was informed by particular theories. It gradually changed to incorporate the structure and funding of different services (Davidson, Halcomb, Hickman, Phillips, \& Graham, 2006).

This research describes a particular model of midwifery care that developed in New Zealand in the 1990s. I have not found any evidence of this Newtown Union Health Service model of midwifery care documented in either scholarly literature or general writing. This particular midwifery service is located within the Newtown Union Health Service (NUHS) which is a primary health care (PHC) service incorporating a multidisciplinary team (MDT). The midwives in this service are part of this MDT and have responsibilities to the service. (Permission has been given to use the actual name of the service). The NUHS model is different to the main midwifery service in New Zealand which is practised by self-employed midwives who adhere to a practice philosophy known as the 'partnership model' (Guilliland \& Pairman, 1995).

This chapter addresses the background of the study context. It examines the history and context of NUHS followed by a brief overview of midwifery in New Zealand. The history of midwifery is significant as it sets the scene of how midwifery is practised today thus providing a context in which the NUHS Model of midwifery care is situated. This is followed by my positioning as researcher in the study which leads into the research aim, objectives and the study method chosen. The chapter concludes with an overview of subsequent chapters.

\section{Newtown Union Health Service}

NUHS was set up by a group of labour unions to cater to a particular population of low income patients who were the families of union members and beneficiaries. These groups of people were, at that time, having difficulty accessing PHC services (Ryall, 
2009). During that period New Zealand general practitioners (GPs) were the main providers of PHC services on a fee for service basis. They received a general medical subsidy (GMS) for each patient visit from the Ministry of Health $(\mathrm{MoH})$ but were able to charge an extra fee per visit. In most areas, there was no ability for people on low incomes to access a low cost service. The unions, on behalf of their members, approached the then Minister of Health requesting a free health service which would accommodate the health needs of the group they represented. This proposal was declined yet after much negotiation between the unions and the Minister, and outright resistance by the medical profession, a successful outcome eventuated. This was a low cost health service that employed GPs. Newtown was a community that had a local health group operating at the time. They were keen to support this new service which would have significant community involvement. NUHS was set up in 1987.

In seeking out appropriate GPs to employ, NUHS attracted a husband and wife team who had worked in Africa and in a low income area of New Zealand (Ryall, 2009). These GPs were familiar with the Alma Ata Declaration (World Health Organisation, 1978) which spelt out the principles of PHC- accessibility, availability, affordability and appropriateness, and how these should be implemented to achieve health for all. The unions saw the importance of these principles, and with the community already involved, worked with the GPs to achieve a service modelled on them. It became a model primary health care service in New Zealand. NUHS included a midwife from the late 1980s and, by the end of the 1990s, there was a team of midwives. These midwives work under the present regulations that govern the work of all New Zealand midwives.

\section{Midwifery}

Regulation of midwifery in New Zealand commenced with the introduction of the Midwives Act in 1904 (Donley, 1998). It was motivated by the desire that all women have a safe child birth experience (Guilliland \& Pairman, 2011). According to Donley after this legislation, many midwives established their own maternity nursing or 'lying in' homes. Yet the majority remained domiciliary or independent midwives. Subsequent to the 1904 Midwives Act the state funded St Helen's Hospitals were established. They became birthing centres for the wives of working class men and for the education of midwives (Donley; Guilliland \& Pairman, 1991, 2011). 
Paradoxically, the professionalisation of midwifery eventually led to increased control by the medical profession which was accompanied by the medical argument that hospitals provided the safest place for birth (Donley, 1998). This move to hospitalisation diminished the traditional role of midwifery. Midwives had learnt to be both independent and dependent: independent when attending working class women, and dependent and accountable to the doctor when involved with paying woman and in accordance with midwifery regulation. A new Act in 1925 brought nurses and midwives together with regulation administered by the 'Nurses and Midwives Board' (Burgess, 1993). From this period until the 1960s, midwifery became increasingly under the control of nursing and medicine.

\section{Resistance Begins}

This weakening of midwifery led to a resistance movement by both women and midwives (Benn, 1999; Fleming, 2000). These groups riled against medicalisation and techniques of control. Thus began the formation of pressure groups where the message was 'information is power' (Donley, 1986, 1995; Fleming, 1998; Guilliland, 2004). The main consumer group was the Natural Childbirth Group formed in 1951 which eventually became known as Parent Centres (Donley, 1998; Fleming, 2002; Papps \& Olsen, 1997). Educating women about their rights, services available to them and about their own bodies influenced wider perceptions about relationships between pregnant women and health professionals. Midwifery autonomy and accountability gained ground following active lobbying for 'natural birth' from both the consumers and midwives. Yet antagonism between the domiciliary and hospital midwives had begun to emerge and the medical and nursing professions continued their fight to control midwifery (Donley, 1986).

\section{Autonomous Midwifery}

By the end of the 1980s the consumers' voice was growing. Women wanted more engagement in how and where they gave birth. Both midwives and women were encouraged by the WHO definition of midwifery. This was a comprehensive definition that included:

The midwife must be able to give the necessary supervision, care and advice to women prior to and during pregnancy, labour and the post-partum period, to conduct deliveries of her own responsibility and to care for the newborn 
and the infant. She may practise in any setting including the home, hospital and community.

(International Confederation of Midwives, 2005)

The consumers stimulated the public debate that opposed the New Zealand Nurses Amendment Bill of 1983 which undermined all midwives (Burgess, 1993). As a result the 'Save the Midwives' Society birthed itself (Papps \& Olssen, 1997; Donley, 1998; Fleming 2002) and the ongoing protests resulted in changes to the subsequent Act (Donley, 1998). More significantly it led the hospital and domiciliary midwives coming together in order to save the midwifery profession (Donley, 1986).

By 1986, the Midwives Section of the New Zealand Nurses Association (NZNA) had recognised the power of combined political activity of midwives and women (Fleming, 2002; Guilliland \& Hassenn, 1990; Guilliland \& Pairman, 1995, 2011). This Midwives Section ratified the WHO definition of midwifery and used it as part of their lobbying (Donley, 1986). The midwifery profession began to listen to and to identify with women, rather than with medicine and nursing. In 1988 New Zealand College of Midwives (NZCOM) had formed and the decision was made by midwives to involve consumers as partners within the organisation (Benn, 1999; Donley, 1986, 1998; Guilliland \& Pairman, 1995, 2010, 2011).

Under the sponsorship of Helen Clark, Minister of Health, the 1990 Amendment to the 1977 Nurses' Act was enacted. She had the support of all women members of parliament in both political parties and of consumers and midwives (Clark, 1996; Donley, 1998; Fleming, 2002; Papps \& Olsen, 1997; Stewart, 2001). This amendment gave New Zealand midwives autonomy of practice and statutory equivalence to doctors providing maternity care. Equivalence included self-employment, equal pay, hospital privileges, prescribing rights, laboratory access, and educational, disciplinary and regulatory powers (Fleming, 2002; Guilliland, 1998b; Stewart, 2001). The most meaningful factor was equal pay, or the 'fee for service' concept (Engel, 2000). However, midwives continued to face constant opposition and challenges from the medical and nursing professions (Guilliland, 1998b; Fleming, 2002).

Over-expenditure of the maternity service budget was evident in New Zealand by 1993 as the same episode of care was being claimed for by more than one health professional (Engel, 2000). The solution came in a change from 'fee for service' to a fixed or capped fee per birth, claimable as modules of care were completed. With the introduction of 
this system came the concept of 'lead maternity carer' (LMC). The responsibility for the provision and management of the woman's entire pregnancy experience belonged to an LMC. The woman could choose a midwife, GP, or obstetrician as LMC. Guilliland (1998b) acknowledges that the implementation of the LMC was a positive move towards better co-ordination of the woman's maternity care. This shift resulted, over the following years, in a major withdrawal of GPs from maternity care (Guilliland, 1998b, 1999; Stewart, 2001). Self-employed midwives continue to work as LMCs receiving the set capped amount per woman per module of pregnancy. The number of women they care for determines their income.

\section{Education}

Pairman (2011) outlines the changes in midwifery education. Midwifery education remained at St. Helens Hospitals until the late 1970s. From its inception in 1904 it had changed from being a direct entry course to a post-registration nursing course. As nursing education shifted into tertiary educational institutes, midwifery became a postbasic nursing programme within these institutes. Resistance soon arose to this form of education that lacked a clinical component. Within the changes in the 1980s, the midwifery section within the Nurses Association began to lobby for direct entry midwifery again, and a midwifery taskforce was set up in 1986 to achieve this. By 1989, a new one year midwifery programme was approved which was to be run in particular technical institutes around the country. Medical resistance to changes in midwifery education was similar to resistance to other changes. After the change of the 1990 Amendment Act direct entry midwifery was on the table again as the Act had opened the way to experimental educational programmes. These began in 1994 and 1995. These programmes led to a Bachelor of Midwifery which remains the current entry to practice criteria.

\section{Researcher Positioning}

I undertook my midwifery education at the University of York in England and have not been through the New Zealand midwifery education system. Following two and a half years of midwifery practice in the United Kingdom, I returned to New Zealand, and commenced employment in a secondary care hospital. I felt this was an appropriate environment to learn about the unique New Zealand midwifery system. 
After gaining some hospital experience I was initially seconded to and then accepted a permanent position at one of the 11 'Union Health Service' practices in New Zealand. At the time three of these included a midwifery service. The one I worked at is not the one described in this research. Union Health Service midwives were employed and salaried working in a MDT within a PHC service. I believed that working in this team would assist me in experiencing the autonomy that New Zealand midwifery had achieved in the 1990s. I had the support of a team, the security of a regular income and did not have to start up my own self-employed practice. Whilst practising autonomous midwifery in this service I realised there were several differences from those midwives working in self-employed practice. Not only was the position salaried with regular time off, but the majority of women I cared for came from a low socioeconomic background. Further, working collegially with a MDT and with community agencies, to resolve the issues of these high needs women, was integral to my practice.

I enjoyed working in this service and came to value the concept of a midwifery team being included in a multi-disciplinary team in a primary health care service - a one stop shop for integrated family care. I also believed that it was a valid alternative way of practising midwifery in New Zealand. As my exploration of the literature found no documentation on this model of midwifery care I wanted to study the distinctive features of this model. I believed such a study would provide a description of this model for those midwives already working in it and for those who might be interested in working in it. Further, the research would be available to the wider national and international midwifery profession as a distinctive model of midwifery care. Moreover, its description would also provide a basis for anyone wanting to do future research on this midwifery service. My research on the NUHS model of midwifery care began while I was employed by the other Union Health Service. Sadly, after more than four years of employment in this Union Health Service, the midwifery team was dissolved due to a lack of midwives and an inability to recruit more at this time. Those of us remaining were made redundant. The NUHS midwifery service did not experience such changes. 


\section{Aim, Objectives and Method}

This research aims to describe midwifery as practised within NUHS. In doing this it will describe how it functions as a model of midwifery care embedded in a PHC service. I set two objectives to be included in the description:

- To determine how this model of midwifery care is shaped by working in a PHC multidisciplinary team

- To examine the challenges and benefits for midwives working within a specific community and PHC service.

To achieve this aim and these objectives I chose to use case study method as set out by Stake $(1995,2005)$ and Yin $(2003,2008)$. Stake, in particular, sees case study as a qualitative research method that provides descriptive data which would allow me to achieve a comprehensive description of the NUHS model of midwifery care. Yin's approach complements Stake's work providing a guide to the steps needed to be taken in the research. Stake stresses that in qualitative research the researcher brings all that has influenced how they are in the world to the research. To be true to this view I use a 'first person' approach throughout the research.

This chapter introduces the topic of the research. It provides a historical overview to NUHS and New Zealand midwifery in order that this model of midwifery care be understood within its context. Further, this chapter has set out the position of myself, the researcher, and the aim and objectives of the research.

\section{Overview of Subsequent Chapters}

Chapter Two provides a discussion of the literature related to this study. Two areas are explored. The first section is PHC from an international perspective and its connections with the New Zealand context. The second section focuses on models of care. Different concepts of what constitutes a model of care are presented before exploring examples including hospital and self-employed midwifery within New Zealand. It then examines international models from the United Kingdom and Australia.

Chapter Three sets out the research method informed by both Stake's (1995, 2005) and Yin's $(2003,2008)$ case study method. The design incorporates selection of the case, selection and engagement of the participants, documentation, data analysis, a section on rigour and trustworthiness and ethical considerations. This is followed by a 
brief discussion on the Treaty of Waitangi (the founding document of New Zealand between Māori and the Crown).

Chapter Four records the research findings as the NUHS model of midwifery care. A graphic illustration of circles within circles is set out to demonstrate the relationship of the five main components. These include the community, NUHS, the midwives as integral to the multidisciplinary team, the midwives and the women in the care of the midwives.

Chapter Five discusses three distinctive features of the NUHS model of midwifery care and the relationship of the model to other national and international midwifery models. The three distinctive features of the NUHS model are; their philosophy, the union influence and the midwives in the MDT. Following this discussion I include a short reflection on the research process. The thesis then closes with a concluding statement. 


\section{CHAPTER TWO: BACKGROUND LITERATURE}

Case study method which is discussed by Stake (1978, 1995, 2005) and Yin (2003, 2008) does not require a literature review. Nevertheless, both authors talk about the necessity of providing context to the case which background literature can identify. The aim of my research pointed to two sets of literature that would be helpful for me in exploring the NUHS model of midwifery care. They are 'primary health care' and 'models of midwifery care'. This chapter provides an exploration of literature to provide the background to this case study. It does not present a formal systematic literature review on these two areas. The data bases examined were CINAHL, Medline and Cochrane. My search also included textbooks, books, newspaper articles, government reports and full $\mathrm{MoH}$ publications. This examination found no articles reporting on the midwifery component of NUHS. However, I did find some general writing on NUHS. There was literature on PHC and models of midwifery care which I explored.

\section{Literature Strategy}

Two main foci were identified from the PHC literature. Firstly, international documents, mainly from the World Health Organisation (WHO), as the NUHS philosophy and direction were influenced by this perspective. Secondly, PHC in New Zealand as NUHS is placed within its development. I selected relevant material to construct an understanding of how PHC influenced NUHS.

From the literature I identified four aspects of midwifery care models. These were its conceptual development and specific models of midwifery care in New Zealand, United Kingdom (UK), and Australia. I found minimal theory on models of midwifery care. However I did find some literature on general health system models of care and models of nursing care. Some theory from these can be applied to midwifery. New Zealand models provide the national context in which the NUHS model is situated. I chose midwifery models from the UK because development of midwifery in New Zealand was originally influenced by midwifery in the UK and the health systems are similar. Australia was selected because it is a neighbouring country with mainly reciprocal midwifery registration and an ongoing mutual exchange of working populations. I undertook a more detailed examination to establish if a model similar to NUHS existed. Although there were some similar models, the context and several organisational details 
were different. All the material identified pertaining to New Zealand models of midwifery care is used. There were numerous articles on the UK and Australian models. I chose a sample of each model from each country in order to avoid repetition.

\title{
Primary Health Care
}

The concept of PHC arose with the development of the World Health Organisation (WHO) in 1948 (World Health Organisation, 1985). WHO acknowledged that by the end of the two world wars health care was lacking in most countries, particularly, in developing countries and those heavily affected by war. At the international level WHO was the first organisation of its kind with a philosophy that valued the right of all people to be well of mind and body and free from disease.

The Declaration of Alma Ata (World Health Organisation, 1978) was a significant document giving PHC a dominant focus. The term PHC then became internationally known and used. It signalled the birth of an integrated international movement. The name "community care" was commonly used prior to this declaration but it was never as explicit as what was spelt out in the declaration. According to Basset (2006, p. 1) this document was a "transformative step for the World Health Organization" which ultimately "linked health to community action, intersectoral cooperation, and the broader goal of social justice". The Alma Ata Declaration document defined PHC and this has remained the most quoted definition since this time. It reads;

\begin{abstract}
Primary health care is essential health care based on practical, scientifically sound and acceptable methods and technology made universally accessible to individuals and families in the community through their full participation and at a cost that the community can all afford to maintain at every stage of their development in the spirit of selfreliance and self- determination.
\end{abstract}

(World Health Organisation, 1978, paragraph VI)

The 'Health for All' movement (World Health Organisation, 1985) was declared at the 1981 World Health Assembly (WHA). Initially this was to be achieved by the year 2000 yet it is still a goal that is renewed at each WHA meeting. The Ottawa Charter (World Health Organisation, 1986), is another significant document which extends the work of the Alma Ata Declaration. The Charter focuses on strengthening community 
actions through health promotion. It believes this is achieved by the community setting priorities, making decisions, planning strategies and implementing them.

WHO publishes annual reports with a different focus each year (World Health Organisation, 1995-2008). Their aim is to assist countries and any international organisations with information to aid funding and policy decisions. A renewed belief in 'health for all' is described in the 1998 report. Its goals and aims for the first two decades of the twenty-first century were re-evaluated. These took into account the global changes of the previous 20 years. One of the four main strategies to achieve 'Health for All' was about bringing together family, community and PHC in hospitals as an integrated system (World Health Organisation, 1998). The 2008 report reemphasises this with the catchphrase 'now more than ever' (World Health Organisation, 2008). These international movements gave momentum to PHC developments already evident in New Zealand in the late 1970s.

\section{The History and Organisation of Primary Care Services in New Zealand}

In the late 1970s the New Zealand health sector was highly fragmented (Barnett \& Barnett, 2005). General practitioners (GPs) provided PHC (interpreted at the time as the first entry to the health services) via small private businesses. This was on a fee-forservice basis and a government subsidy per patient visit. Some populations including low income, high users and children received lower subsidies (Barnett \& Barnett; Hefford, Crampton, \& Foley, 2005). GPs would refer to other primary care providers, for example physiotherapists, and were essentially seen as the 'gate keepers' for referral to the public hospitals (Ashton, Cumming, McLean, McKinlay, \& Fae, 2004). Nongovernment organisations (NGOs) provided a variety of community-based healthcare. These included well health-child care (e.g. Plunket), disability-support services (e.g. social care), and other types of consumer support services (Ashton et al., 2004). New PHC initiatives gained momentum in the 1980s following the Alma Ata Declaration (World Health Organisation, 1978). This led to the setting up of a PHC fund which made it possible to establish groups like NUHS (McGrath, 1989).

From the late 1980s until 2000 the organisation of PHC services in New Zealand was dictated by shifts in funding and the political scene (Ashton, Mays, \& Devlin, 2005; Barnett \& Barnett, 2005; Cumming, Barnett, \& Powell, 2004; Gauld, 2003, 2008). These authors explain that from the mid 1980s, four significant changes occurred to the 
New Zealand health system. Firstly, in 1989 the Labour Government introduced 14 Area Health Boards (AHBs). This brought primary and secondary care together under one administration. Secondly, the National Government elected in 1990, abolished the AHBs and created 23 Crown Health Enterprises (CHEs). Thirdly in 1998, CHEs became Health and Hospital Services (HHS). Finally, in 2000, after election of the Labour Party, 21 District Health Boards (DHBs), were established under the Health and Disability Act (2000).

PHC services changed significantly in 1993 due to funding changes; mainly with the introduction of formula-based capitation budgets. 'Capitation budgets' was the term used to describe a set amount being paid per person enrolled with a provider service (Ashton et al., 2004). The change in funding allowed community based organisations, for example Māori health organisations, to offer services that had not in the past been publicly funded. This change also "enabled some community-based organizations to engage GPs as their employees, to provide services in line with the organization's priorities, rather than having to have the GP as the principal party who collected subsidies for services rendered" (Ashton et al., p. 31). The medical profession responded to these contracting changes by establishing Independent Practitioner Associations (IPAs). GPs believed these associations would help counter the imbalance of reduced bargaining power they felt had occurred. IPAs were organisations set up by General Practitioners to negotiate contracts on behalf of GPs in the arena of general practice and primary care (Ashton et al.; Barnett \& Barnett, 2005; Gauld, 2008; Malcolm \& Powell, 1996).

The next significant change was foreshadowed in the New Zealand Health Strategy (King, 2000). This strategy provided a framework to ensure all people had access to optimal health. It aimed to maintain a good level of health for all New Zealanders throughout their lives by setting out a range of services. These included health promotion and disease prevention that would be available, accessible and affordable. The intention of the strategy was to bring public and personal health systems, including PHC services, together under district area health boards and to focus on the health of particular populations. 


\section{Primary Health Care Strategy}

The Primary Health Care Strategy was published in 2001 (King, 2001). It was a key step in achieving the goals of the New Zealand Health Strategy (King, 2000). According to Hefford et al. (2005) and Gauld (2008) this was New Zealand's answer to fulfilling the Alma Ata Declaration. Barnett and Barnett (2008) argue this strategy could not be classified as a complete primary care approach adhering to all Alma Ata principles. These authors acknowledge however, that it has been a crucial development in producing equitable access to health care for those most in need. The PHC Strategy required the newly formed District Health Boards (DHBs), to set up Primary Health Organisations (PHOs) and fund them (Barnett \& Barnett, 2005, 2008; Boulton, Simonsen, Walker, Cumming, \& Cunningham, 2004; Cumming et al., 2004; Gauld, 2003; Hefford et al., 2005; King, 2001). Barnett, Smith, and Cumming (2009) believed that the six key directions of the strategy, listed below, would be achieved within 10 years:

- Work with local communities and enrolled populations

- Identify and remove health inequalities

- Offer access to comprehensive services to improve, maintain and restore peoples' health

- Co-ordinate care across service areas

- Develop the PHC workforce

- Continuously improve quality using good information.

(King, 2001, p. 6)

\section{Primary Health Organisations}

Primary Health Organisations (PHOs) were the vehicle for the provision of specific PHC services to particular groups of people. These were to achieve the goals set out by the PHC Strategy (Barnett \& Barnett, 2008, 2005; Barnett et al., 2009; Hefford et al., 2005). The DHB funding took into account the characteristics of the enrolled population, for example age, sex and ethnicity (Ministry of Health, 2005b). Funding formulas reduced the cost for GP visits and prescriptions and were to help design and implement health promotion programmes. PHOs aimed to provide more equitable and affordable, available multidisciplinary services to all, but particularly those with high needs (Barnett \& Barnett, 2005; King, 2001; Ministry of Health, 2010a). These services were to include community health workers, physiotherapists, social workers, doctors, 
nurses and members of other health disciplines relevant to the communities they served. Midwifery was not mentioned as an integral part of a PHO. However as NUHS became part of a PHO, the development and structure of the service was influenced by the inclusion of a midwifery team.

In 2003, a 'Minimum Requirements for Primary Health Organisation' document was published (Ministry of Health, 2003). PHO governance boards were to include community members who were to have input into which services their community required. The PHOs were and remain 'not-for-profit', and are still accountable to the $\mathrm{MoH}$ for all funding. PHOs were not to be dominated by any one particular group of health professionals. Lastly, enrolment in a PHO although voluntary was to be strongly encouraged.

PHOs initially had two types of funding formulas. One was termed "interim" and applied to PHOs with a 'lower level of health need', yet provided low-cost access to some of those enrolled in their practice (Barnett et al., 2009; Hefford et al., 2005; Ministry of Health, 2005b). The other was called "access" and applied to any PHO consisting of a population with more than 50\% in a high needs group (Hefford et al., 2005). Additional funding is given to all PHOs for health promotion, management, first level services, Care Plus (high users with chronic conditions) and for services to improve access.

Inequalities of health received a lot of publicity prior to the introduction of PHOs (Barnett \& Barnett, 2008, 2005; Hefford et al., 2005; Smithies \& Webster, 1998). Statistics released by The New Zealand Health Survey undertaken in 2002 revealed that 20 percent of New Zealanders could not afford to pay to attend a GP and 15 percent could not pay for a prescription to be filled (Ministry of Health, 2004).

The first PHO was set up in 2002. Eighty were operating and functioning by 2008 (Barnett et al., 2009; Gauld, 2008). The MoH contracted the Health Services Research Centre of Victoria University of Wellington to evaluate PHOs. They published four reports (Barnett et al.; Croxson, Smith, \& Cumming, 2009; Cumming, 2009; Raymont \& Cumming, 2009; Smith \& Cumming, 2009). A description of PHOs, their establishment, their structure and their services are described in these evaluations. They 
also explore the experiences of the participants, with particular emphasis on what they see as the strengths and weaknesses. These reports were generally positive as was an evaluation undertaken by the MoH (Ministry of Health, 2005a).

Several issues of concern are raised in Gauld's reports $(2003,2008)$. He argues that PHOs were implemented too quickly with no initial pilot carried out to test them. Gauld (2003) believes that the rapid implementation of PHOs could be related to New Zealand's three year parliamentary cycle and the need for rapid planning and implementing of ideas to achieve positive results in order to keep the governing party in power. Gauld suggests there were 'unintended consequences' of the implementation of PHOs; namely that it strengthened the power of the IPAs, ultimately giving the power back to the medical profession. He believes this is related to the government initially consulting with the bigger, stronger IPAs for advice regarding setting up and managing the PHOs. According to Gauld, some PHOs exist in name only. This, he believes, is because they are very small, only just meeting the minimal requirements to be a PHO, and as Barnett and Barnett (2008) suggest, lack the resources to provide health promotion and reduce health inequalities. Nevertheless Cumming et al (2004) strongly believe that New Zealand's new model of health care organisation is 'evolving positively over time' (p. 8), whereas Gauld (2008), Cumming (2009) and Smith and Cumming (2009) describe PHOs as having an unknown future.

In recent years various people in the media have made several references to the overexpenditure on health. One of the solutions is seen as reducing the number of PHOs (Armstrong, 2009). Tony Ryall, the present Minister of Health said "We simply have too many of these PHOs in the country and the resources are too thinly spread. I think we could save several million dollars... which could then be used to improve frontline services for patients" (Armstrong, 2009, p. 1 ). Currently PHOs are merging and numbers are reducing. Recent literature describes consolidation of GP practices and the establishment of Integrated Family Health Centres (IFHC) (Ministry of Health, 2010b). This infers that larger multidisciplinary teams of health professionals will provide more services. These would incorporate some secondary care services with more information technology and new ways of providing these services. 
Midwifery has not had a significant profile within the development of PHC services in New Zealand. Prior to the 1990 Amendment Act of the Nurses Act of 1977, GPs, practice nurses and obstetricians provided the majority of maternity care. A small number of midwives provided a home birth service to women, essentially a PHC service. However they were never nominated in the official documents as PHC workers. After the 1990 Nurses Amendment Act self-employed midwives increased in numbers and GP care of pregnant women decreased. The new midwifery model did have an explicit PHC focus but this was not incorporated into the PHC strategy and did not feature in the PHO development. Midwives joining NUHS with its strong PHC philosophy is an example of integration of midwives in PHC. When NUHS became part of a PHO in 2003 this integration was extended into a PHO structure. The development of PHC in New Zealand has had a significant impact on the way the NUHS model of care is structured. At the same time as PHC was developing in New Zealand new ways of organising midwifery care were also developing.

\section{Models of Midwifery Care}

My search for literature on models of midwifery care elicited several particular examples of the way midwifery services are organised in New Zealand, the United Kingdom and Australia. Definitions or descriptions of how midwifery is structured as a model of care were minimal as previously mentioned. Therefore I broadened my search and examined how the concept of model of care was used in both the health system and in nursing to establish whether the findings of my research would meet the essential criteria needed to be a model of care. Once I had established these criteria I was able to apply them to the description of the midwifery services that $I$ found in the aforementioned countries.

Models of care are described in the literature in a variety of ways. According to Davidson, Halcomb, Hickman, Phillips and Graham (2006) a model of care can refer to how national health systems are organised, for example, a welfare model of care or a national insurance model of care. It can also refer to how smaller services, for example, PHC services are organised or to ways a health discipline arranges its practice, for example, the medical model. The common components covered in these descriptions include the organisation, the funding of a service and the philosophical components of the practice within a service. 
Nursing models often include midwifery because in many countries midwifery is closely connected to nursing. Building on the earlier work of Chinn and Jacobs (1983) Libberton (2007) describes a model of (nursing) care as "a set of concepts constructed to guide practice, generate new ideas and differentiate nursing from other professions" (p. 29). Bowden (2006) makes a specific application of health related models to midwifery and finds that "the term has been adopted a great deal, but not exclusively, to refer to the aspects of care given to women" (p. 37). As Chinn and Jacobs emphasise the practice of nursing in their model, Bowden's interpretation places the stress on the practice of midwifery.

Models of midwifery care in the early $20^{\text {th }}$ century were influenced by the medical model (Cooper, 1999). Another early midwifery model embodying the medical model, according to Rooks (1999) is the obstetric model of care developed within a speciality of medicine.

Today midwifery focuses on normal pregnancy. As Rooks (1999, p. 4) says "Midwives are experts in protecting, supporting and enhancing the normal physiology of labour, delivery and breast feeding". Rooks observes that the medical model and midwifery models of care have merged over time as a result of midwives and doctors working together. Nevertheless, this author states there are important distinctions between the two including the philosophy, relationship between the carer and the pregnant woman and the use of obstetric interventions. Hatem, Sandall, Devane, Soltani, and Gates (2008), published by the Cochrane Database, looked at 'midwife-led versus other models of care for childbearing women'. According to the above authors various models of care were used in different countries incorporating New Zealand, Australia and the United Kingdom. Childbearing women in these countries could choose from the various models including a medical model, a midwifery model or a combination of both.

The most explicit definition of a model of midwifery care I found in the literature involves:

continuity of care; monitoring the physical, psychological, spiritual, and social well being of the woman and family throughout the childbearing cycle; providing individualised education, counselling and antenatal care; continuous attendance during labour, birth and the immediate postpartum 
period; ongoing support during the postnatal period; minimising technological interventions; and identifying and referring women who require obstetric or other specialist attention.

(Hatem et al., 2008, p. 1)

This definition is strong on the practice components of midwifery but lacks any organisational components. As a summary of the features of models of care present in the literature I constructed a description incorporating these to provide a more comprehensive overview. It reads:

A model of midwifery care embodies guidelines and policies for the provision of care to women and their families. Such a model includes the structure of a service designed by a group and the way it is funded. It can be set within a larger organisation which can be broader than the work of midwives. Where this occurs it will influence in overt or covert ways how midwives arrange their work and practice. Midwifery practice then either takes its values from the larger organisation or, if the structure permits, creates its own particular philosophy which shapes the interactions with women. A mixture of these combinations can exist.

Such a broad definition of a model of midwifery care will cover the NUHS model as my preliminary understanding indicates that the midwifery service is shaped by the influences of the structural components and the philosophy of the whole service.

\section{Current Models of Midwifery Care in New Zealand}

\section{Self-Employed Practice and Partnership Model of Care}

Prior to 1990 most midwives worked in hospitals. An exception to this was a small number of midwives facilitating homebirths (Donley, 1986). The Amendment to the 1977 Nurses Act in 1990 changed the way midwives could work (Clark, 1996; Donley, 1998; Fleming, 2002; Flemming, 1998; Guilliland \& Pairman, 1994, 1995; Hendry, 2008; Papps \& Olsen, 1997; Stewart, 2001). Following this amendment, midwifery as a profession in its own right, was recognised and gave New Zealand midwives autonomy of practice and statutory equivalence to doctors providing maternity care (Engel, 2000; Fleming, 2002; Guilliland, 1998a, 1999; Stewart, 2001). Independent practice within small groups was the initial description used for this change in the way midwives work. 
The term 'self-employed' midwives is now unofficially preferred to 'independent midwives' because the term 'independent' implied that midwives were set apart without support from, or dialogue with, other disciplines.

Initially it was Section 51 of the Health and Disability Services Act 1993 which determined the way maternity services would be structured and funded. A review took place which resulted in Section 88 of the Health and Disability Services Act 2000 (New Zealand Statute). Further updates in 2002 and 2007 culminated in the Primary Maternity Services Notice 2007 (New Zealand Statute) which was a notice of the New Zealand Health and Disability Act 2000 (New Zealand Statute) (Hinton, 1999). The latter was seen to have more of a primary care focus. Soon after the initial changes to midwifery practice a new model of care with an emphasis on practice emerged.

In the first half of the 1990s Guilliland and Pairman (1995) introduced the 'midwifery partnership' as a model of practice. This model fitted well with the newly formed selfemployed structure. It was designed to shape the midwife-woman relationship. The philosophical underpinnings and principles of the partnership model, identified by these authors, include viewing birth as a normal life event; the provision of a total child birth service and woman-centred care. Continuity of care was a key principle in the partnership model. According to Guilliland and Pairman their concept of partnership was influenced by the Treaty of Waitangi (the founding document of New Zealand), where partnership is a key concept. It became the main model of midwifery practice written about and it shaped the standards of practice established to govern midwifery (Flemming, 1998; Guilliland, 2004; Lauchland, 1996; Wynn-Williams, 2006).

Within the partnership philosophy the role of the midwife is to support and provide clinical expertise and information to the woman to allow her to make informed choices about her care. A small number of births are home-births. By monitoring the women throughout their ante-natal care midwives can detect any deviations from the normal. If these deviations persist the woman is referred to secondary or tertiary services. Midwives are available for the women they care for on a 24 hour a day, seven day a week basis. This availability and the practise of this philosophy is achievable due to the requirement of a named back up midwife who becomes responsible for the woman if the primary midwife is sick, on holiday, requires breaks, or if two women require the midwife's care at the same time. 
There is some debate in New Zealand about the centrality of the partnership model. One of the authors of this model, Pairman (1998), states that unless midwives follow the partnership model, 'real' midwifery is not being practised. This claim was critiqued by several writers (Benn, 1999; Flemming, 1998; Lauchland, 1996; Skinner, 1999). Of particular interest to this research is Skinner's critique. This author argued that the partnership model did not work well for low-income populations.

\section{Hospital Model of Midwifery Care}

After the emergence of self-employed practice, numbers of midwives decided to remain in hospitals to care for women. These midwives who are also known as 'core midwives', give care on a rostered and rotating system on antenatal, delivery and postnatal wards (Skinner, 1999; Wynn-Williams, 2004, 2006). They are employed by the DHB where they work. They are accountable to themselves, the women, their profession and the New Zealand Midwifery Council and their employing DHB. These midwives work more closely with Obstetricians because of their location, often caring for pregnant women with complex needs. Hospital based midwives also carry out the care plans for women in hospital under LMC care. Further, according to WynnWilliams (2004), hospital midwives by default look after women experiencing normal pregnancies if these women have not managed to find an self employed midwife to care for them.

An opportunity exists for hospital midwives to advance their careers via a professional development pathway, or shift into management or education (Wynn-Williams, 2006). The hospital model shapes the midwifery practice in such a way that it can be difficult to provide continuity of care which means that their relationship with women can be disrupted. According to Wynn-Williams (2006, p. ii) midwives working in hospitals are an indispensable part of midwifery because "LMC midwives cannot logistically be present continuously, [therefore] core midwifery has developed an essential role".

\section{Midwifery Within a Multidisciplinary Primary Health Care Service}

The Union Health (UH) Services, providing full family care, developed in the late 1980s in order to overcome the difficulties families had in paying for GP services (Engel, 2000; James, 2009). The early professionals who worked in these clinics brought with them the notion of PHC as set out in the Alma Ata declaration (WHO, 
1978). After the introduction of independent midwifery practice in the early 1990s James discusses how this became established in NUHS. According to Engel, midwifery in PHC took on many of the factors of independent practice. However the three Union Health Services that employed midwives did so on salaries and with principles of PHC that informed the philosophical underpinnings of their practice. Another key feature is the emphasis on family care involving interactions with a service employed MDT. The original intention was that midwives were employed to look after families who were specifically eligible for all their health care at UH services (Engel, 2000; Osten \& McKillop, 2007).

There are $11 \mathrm{UH}$ services in New Zealand. At the beginning of this research three of these included midwifery teams, however, presently only two do so. Maternity funding for the midwives within UH services had been varied over the years. It incorporates claims under 'Section 88'. Another funding stream available for the extra work of caring for at-risk women is captured in a separate contract modelled on the national services specification for the Whanau Ora Maternity Support Services (Osten \& McKillop, 2007). This is a funding stream from the government that is directed to the underserved population where at risk factors are assessed in a family situation and are allocated a particular sum of money. There is no comprehensive description of the model of midwifery care practiced in these services. Hence this research will add to the body of midwifery knowledge. This model of care in a PHC service appears unique to New Zealand but some similar models exist in the United Kingdom.

\section{Models of Midwifery Care in the United Kingdom}

Many English midwives work in the hospital system while others who believe in low technological births and midwifery led services work in Birth Units. Independent midwives, paid directly for their services by the women, are a minority (Bates, 2004). The Changing Childbirth Document of 1993 (Department of Health, 1993) was the impetus for the emergence of groups, teams, and one-to-one models of care. The main concepts promoted in this document are the issues of choice, continuity and control. This was to be achieved in five years (Department of Health; Fleming, 2002; Walton \& Hamilton, 1995). Sargent (2002) believed that the report represented an opportunity for midwives and their managers to make fundamental changes to maternity care ultimately resulting in more autonomy for the midwife (Mander \& Purdue, 2002; Thomas, 2002). 
There are accounts in the literature which infer that these changes have been implemented (Durham, 2002; Mander \& Purdue) and accounts that they have not (Thomas).

For the majority of English women who birth in hospitals, midwives care for them regardless of whether they are low or high risk. Bates (2004) believes that midwives practising in hospitals routinely apply technology to the care of all women and the birthing process. This author adds that career advancement is common with the development of specialist areas such as expertise in diabetes, antenatal screening, risk management and bereavement. Midwives are salaried and tend to work rostered and rotating shifts (Benjamin, Walsh, \& Taub, 2001). They are accountable to themselves, the women, the profession and their employer (Bates, 2004).

This model is akin to New Zealand hospital midwifery where the hospital context shapes the model of care. Therefore the philosophical concepts of choice, continuity and control are difficult to achieve in a similar way that the New Zealand partnership model values are difficult for New Zealand hospital midwives to practice. The literature reveals that prior to the Changing Child Birth Document other midwifery models of care were already developing.

In England team midwifery commenced in the late 1980s. This comprised of a small group of hospital employed midwives providing care for low and high risk women working across the hospital and the community (Benjamin et al., 2001; Homer, Brodie, \& Leap, 2008; McCourt, Stevens, Sandall, \& Brodie, 2000). The belief underpinning this initiative was that all women needed midwifery input (Bates, 2004). The women would meet all the midwives in a team throughout the antenatal period and they would therefore know whoever was to be at their birth.

The 'know your midwife' scheme as a derivative of team midwifery was created by English midwife, Caroline Flint (Flint, 1993a; Flint, Poulengeris, \& Grant, 1989). It was later evaluated and as a result similar schemes emerged. Within the literature there are evaluations on many of these team midwifery groups (Farquhar \& Camilleri-Ferrante, 2000; Hart, Pankhurst, \& Sommerville, 1999; Tinkler \& Quinney, 1998) including a particular group of authors who did an overall review of team midwifery in the UK (Todd, Farquhar, \& Camilleri-Ferrante, 2009). Findings from all authors indicated that 
maintaining the continuity of care was challenging for the midwives often resulting in long hours with high burnout levels and the added difficulty of maintaining a work life balance.

Larger teams of midwives meant less continuity of care. Tinkler \& Quinney (1998, p. 30) were the only researchers to find that "the future of team midwifery at [their] National Health Service (NHS) Trust remains uncertain within this context of differing priorities and preferences of women for continuity of care and service provision in addition to limited financial resources". The model was designed to give women choice, continuity and control. Therefore its structure emerged out of these philosophical components. As it was set up as an innovative way of practising midwifery minimal outside influences shaped the structure and the practice. Evolving models of care led to different ways of organising midwifery care.

Caseload midwifery involves a small group of midwives caring for a particular allocation of women. Each member of the group assists in the care of their colleagues' allocation of women when the colleague has time off (Bates, 2004; Homer et al., 2008; McCourt et al., 2000; Milan, 2005). The goal of this model is to provide continuity of care. Once the allocation of women to a midwife occurs they become that midwife's responsibility and in discussion with the women, the midwife plans and manages their care (Benjamin et al., 2001; Lester, 2005). It is reported by these authors that job satisfaction is high but a consequence is also a high burnout rate. Generally a midwife who takes a caseload of women is directly employed by an NHS Trust. An example of this model of care is the Albany Midwifery Practice (Reed, 2002a, 2002b; Sandall, Davies, \& Warwick, 2001; Sandall, Page, Homer, \& Leap, 2008).

The Albany midwifery group was unique in that they had a contract with an NHS Trust and a budget to cover all their expenses. This contract means that they were the first self-managed, self-employed community based caseloading group of midwives in England (Sandall et al., 2001). The reason for looking at this model of care in particular is that it is the most similar in autonomy and accountability to the self-employed model in New Zealand. It was formed in 1994 as a result of the publication of the Changing Childbirth Document in 1993 (Sandall et al., 2001; Sandall et al., 2008). The group initially consisted of seven midwives and a practice manager. Each midwife took on a primary caseload of 36 women a year and was 'back up' to another midwife within the 
group who also had 36 women. From 1997 they were subcontracted by Kings College Hospital of London. They continued to provide care to a specific number of women living in areas of high deprivation, and those who were referred by local GPs. As with other caseload models the key value informing their midwifery practice is continuity of care. According to Reed (2002a) these midwives believed the way they practice assists in keeping the intervention rates low as well as having a higher than national average homebirth rate. The evaluation (Sandall et al., 2001) commissioned by the Department of Midwifery in the Women and Children's Care Group of Kings College NHS Trust supports their belief that caseload midwifery reduces the rates of caesarean sections and the need for analgesia. Unfortunately the Albany Midwifery group lost their funding late 2009 and the model is no longer in operation (Boseley \& Domokos, 2009).

Using the Albany midwives as an example of a caseloading midwifery practice it is evident that they began with a philosophy of practice including providing womancentred care and continuity of care particularly to women who lived in high deprivation areas. With this they were able to have a contract that gave them their own budget from an NHS Trust. They organised themselves to provide the care without any larger organisational constraints.

Another model of care is termed the 'one-to-one' model. It is most akin to the selfemployed midwifery model in New Zealand but the midwives are paid salaries by an NHS Trust. It was a scheme set up to provide continuity of carer (Flint, Poulengeris, \& Grant, 1989; McCourt \& Page, 1996; McCourt et al., 2000). Sandall (1996) describes this model of care as having more autonomy and allowing more flexibility in how work loads are managed. Examples of this model of care include The 'Guy's and St. Thomas' One-to-One Caseload Project (Berry, 2005) and Manor Gardens Team in London. It was introduced to Queen Charlotte and Hammersmith Hospitals and evaluated by Page, Beake and Vail (2001). Wood (2005) also uses the Albany Midwifery Practice as an example of this style of care promoting its effectiveness in providing care for vulnerable at risk women. In terms of meeting the criteria as a model of care it is closely related to the previous case load model as it is philosophically driven with few institutional restrictions.

A distinct model of care takes place in birth centres (Bates, 2004; Foureur \& Sandall, 2008; Godfrey, 2002). These also have different names including maternity homes, 
midwife-led units, cottage hospitals. Some are funded by the local NHS who pay midwives salaries and some are private. Women see them as a place to go where they can have a natural birth but not a homebirth. Hence they have low intervention rates. If complications occur during labour, women are transferred out to the nearest hospital. Bates (2004) and Godfrey (2002) describe midwives working in birth centres as being able to 'practice to their full potential'. Midwives in birth centres commonly work in shifts. The first one was opened by Caroline Flint and is private due to an inability to secure funding (Flint, 2010). As a model of care it is philosophically driven to support natural birth but because they work in shifts continuity of care is restricted. As they are either funded privately or via NHS Trusts there will be different restrictions according to their budgets and what the funders require of them.

Another privately funded model of care is known as 'independent midwifery' (Milan, 2005). These midwives work outside of the NHS and are paid directly for their services by the women they care for. They predominantly do homebirths but some have 'honorary contracts' enabling them to work in hospitals (Bates, 2004). According to Flint (1993b) some independent midwives are attracted to working in midwifery group practices and some work in partnership with each other. They offer a wide range of care to women on a twenty four hour basis including antenatal, intrapartum and postnatal care. While doing this they provide complete continuity of care (Anderson, 2007; Bates, 2004; Frohlich, 2007; Learner, 2004; Page, 2004). Indemnity insurance is generally expensive for independent midwives and can act as a deterrent to working this way (Dimond, 2002). This model has the least restrictions from outside organisations and is free to organise its practice according to its commitment to providing continuity of care.

I now look at Australia where there is less variety of models of midwifery care available to women, than in New Zealand or the UK.

\section{Models of Midwifery Care in Australia}

In Australia, the majority of midwives work in hospitals, where most specialise in particular areas including antenatal care in wards or clinics, delivery and postnatal care. Brodie, Davis, and Homer (2008) describe this model as obstetric led and they see it as fragmented because of shift work. A small number of birth centres exist and a limited number of independent (self-employed) midwives work privately (Leap, Homer, \& 
Brodie, 2008). These independent midwives can no longer obtain professional indemnity insurance so the women who employ them do so knowing this situation.

Several new ways of working commenced in Australia at the same time as the international shift to new models of care in the 1990s. They predominantly involve team midwifery attached to hospitals. The components are very similar to those of team midwifery in England. Descriptions and evaluations of these are recorded in the literature. For example see; Biro, Waldenstrom, Brown and Pannifex (2003), Cornwell, Donnellan-Fernandez and Nixon (2008), Homer (2005), Rowley, Hensley, Brinsmead and Wlodarczyk (1995) and Walker, Moore and Eaton (2004). The evaluations found that most team midwifery models had a positive effect on women's experiences with less medical intervention and shorter hospital stays. They also found that providing team midwifery care to low and high risk women is very achievable. Brodie, Davis and Homer (2008, pp. 99-100) conclude that "models of midwifery care that support autonomy and recognise the full potential role of the midwife are still rare in Australia".

Rowley, Hensley, Brinsmead and Wlodarczyl (1995) provide an example of team midwifery model of care in Australia and was the first of its kind. Research informed these authors that continuity of care for pregnant women improved consumer satisfaction of care and maternal and foetal outcomes, but predominantly for low risk women. They designed a trial at a large tertiary hospital that incorporated both low and high risk women who were divided into two groups. One received continuity of care and the other received routine care. The outcome was that women receiving continuity of care had improved outcomes and higher satisfaction of care. The research found that providing continuity of care was more cost effective. The care given to both groups was found to be equally as effective. Midwifery teams of various forms continue to emerge in Australian hospitals.

As with other hospital models of midwifery care the institutional restrictions affect the practice of the midwives and how they interact with women. With the onset of team midwifery attached to hospitals there seemed to be fewer restrictions to achieving philosophical concepts, like continuity of care, improved maternal and neonatal outcomes as well as women's satisfaction, for both low and high risk women. 


\section{Summary}

Overall this exploration of the literature extended my knowledge of both PHC and models of midwifery care to make me a more informed researcher. In particular it gave me a more informed approach to design aspects of the research process, construct the interview schedules and carry out the interviews. My reading confirmed that there were no descriptions of the NUHS model of midwifery care in the literature. Ultimately it has provided a context where the findings of the research can be positioned both in New Zealand and internationally.

The term model of care is summarised as an organisational umbrella which includes particular dimensions of practice. The different examples of midwifery models of care both in New Zealand and internationally show that components of organisation can shape the practice. But equally a commitment to a philosophy of practice such as embedded in the New Zealand partnership model can shape how the organisation is constructed. Further the international models demonstrate how their differences are often a result of the different health system context and policies of each country.

PHC acquired more attention in New Zealand in relation to the cost of GP services in the 1980s. In addition increasing awareness of inequalities of health care and the principles of the Alma Ata Document gave momentum to PHC developments which culminated in the construction of the PHC Strategy in 2001.

Also in the 1980s in New Zealand, a ferment of discontent arose in relation to the limited choices available for pregnant women. At that time women predominantly received pregnancy care from GPs and obstetricians and there was a high intervention rate. The consumer voice for change, which included being able to choose a midwife and the option of a home birth funded by the health system, gave rise to the 1990 Amendment to the Nurses Act. From this period on midwives increasingly took over the care of pregnant women within their self-employed and partnership practice model. Both developments in PHC and pregnancy care came together when midwives joined the Union Health Services in the early 1990s.

The next chapter describes the case study method and its implementation to achieve the aim of the research. 


\section{CHAPTER THREE: STUDY METHODOLOGY and DESIGN}

Before choosing a research method to study the NUHS model of midwifery care, I needed to consider the main features of this service. I was aware that the midwifery service was situated within the larger organisation of NUHS. My focus was not on the whole service, but I was conscious of the need to capture the influences of the larger organisation on the midwifery service. NUHS originated within a particular low socioeconomic community that used the services of NUHS because it was more affordable than other PHC providers. The service had developed to meet the needs of this particular population. I felt that obtaining the views of the midwives, the staff who worked within the service and the women who utilised the midwifery service would give me a contemporary understanding of the NUHS model of midwifery care. To achieve this I would require interviews within a qualitative methodology. While a qualitative survey may have worked I felt that it would not be as productive as talking to the midwives and staff. In exploring the case study method I discovered that this approach provided me with the tools to capture the context of an organisation. One of these tools was interviews. I studied this method further in order to increase my knowledge and understanding and concluded that it was the most appropriate method to study the NUHS model of midwifery care.

The first section of this chapter addresses the case study approach. This is followed by the design and processes of the study. The design section discusses selection of the case, selection and engagement of the participants, documentation, data analysis, rigour and trustworthiness, and ethical considerations. A short account on the Treaty of Waitangi concludes this chapter.

\section{Case study Approach}

The two key researchers who have written extensively on the case study method are Stake $(1978,1995,2005)$ and Yin $(2003,2008)$. For Stake, case study is primarily a qualitative research method with an emphasis on understanding the context of the case from indepth description. Yin, in addition, provides useful strategies not covered by Stake.

Stake $(1995,2005)$ differentiates between two types of cases that can be studied intrinsic and instrumental. An intrinsic case is one in which you have a specific interest 
and you want to understand it more comprehensively than what is already known about it. In this sense Stake (2005, p. 450) says 'the case is pre-selected' and intrinsic researchers look for "what is important about the case within in its own world". In an instrumental case study the primary reason for looking at a case is to determine something that is going on in it, that is, to study a particular process or structure that is present in the case. Within this type of case a number of different cases might be equally suitable. My study is of the intrinsic type as I want to learn about the midwifery practiced within NUHS. Stake stresses that 'particularization' is the primary aim of case study rather than 'generalisation'. To this end the purpose is to obtain an indepth knowledge of one case emphasising its distinctiveness in relation to what might be similar cases or well known cases.

Both Stake $(1995,2005)$ and Yin $(2003,2008)$ advise that to study a case the researcher studies setting, background and any other contexts through which the case can be known. Stake believes people who undertake case study research endeavour to find out what is common and unique about the case but ultimately discover more of what is uncommon. For Yin (2003, p. 2) "the case study method allows the investigators to retain the holistic and meaningful characterisation of real-life events - such as individual life styles, organisation and managerial processes, neighbourhood change, international relations, and the maturation of industries". He states there are two important aspects in the scope of a case study. It should:

- Investigate a contemporary phenomenon within its real life context, especially when,

- The boundaries between phenomenon and context are not clearly evident.

(Yin, 2003, p. 13)

Both Yin (2003) and Stake (1995) state that it is necessary for a researcher to enter into the field of the case to obtain the information required. Yin describes six common sources of data collection for the case study method. These are "documentation, archival records, interviews, direct observations, participant observation and physical artefacts" (p.85). Stake focuses on observation, interviews and document review.

Stake (1995, p. 43) describes a broad view of what constitutes a context. He asserts that a context includes "temporal and spatial, historical, political, economic, cultural, social and personal". For Stake "issues are not simple and clean, they are intricately wired to 
political, social, historical and especially personal contexts" (p. 17). The context-laden data alerts me to consider that all the information I will use is derived from a particular time and place. Further, what a participant reveals at the time of an interview is a representation of their previous experience at that time. Notably, the construction of the model of midwifery care from the data gathered at a particular time will be representative of that time although some features will remain constant over many years.

When Stake (1995) describes case study as qualitative research he discusses the importance of knowledge as a social construction, the personal role of the researcher and multiple realities. Stake explains that these three concepts are assumptions within the constructivist paradigm which informs qualitative research. He stresses that knowledge is constructed, rather than discovered. According to Stake the researcher wants to build up "a more sophisticated reality, particularly one that can withstand disciplined scepticism” (p. 101). Therefore I would not be looking for knowledge that is waiting to be found.

The influence of the personal role of the researcher is sometimes described as the knower being present in the knowledge created (Crotty, 1998). This means that the researcher's pre-understandings influence the research process and the interpretations of qualitative data. As Stake (1995) says "given intense interaction of the researcher with persons in the field and elsewhere...given the intention to participant intentionality and sense of self...however descriptive the report, the researcher ultimately comes to offer a personal view" (p. 42). For Stake, the knowledge constructed is experiential and subjective. This statement recognises that I can not erase all the experience and knowledge that I bring to the research. In this situation my experience of working in a similar service to NUHS is acceptable and can be factored in to how the research develops. Therefore my construction cannot be an objective one in the sense that I am unable to set everything aside and commence the research with a clean slate. It also implies that if another person was undertaking this research using the same approach the outcome would be different. It may have many similarities but it would also have differences. 
Multiple realities exist in relation to how individuals perceive and interpret their experiences. This assumption warns me that the midwives and other staff members may each speak differently of similar aspects of the service. As Stake (1995) explains the data are likely to include 'conflictual evidence' which relays the human concerns of participants who are embedded within the case. Some of the participants views may be contradictory but they are all valid and should be incorporated into the findings to demonstrate the complexity of the service. Contradictions can occur because people have different experiences and change their perceptions in relation to their day to day experience and this influences how they remember events and people.

The above exploration of case study method reveals that the study of the midwifery practised at NUHS is an intrinsic case. This method allows me to construct a case weaving the many views from multiple sources of data whilst taking into account the knowledge that I bring to it. In particular, case study method stresses the importance of the context of a case which is paramount in this study. A constructed model of midwifery care within NUHS will pertain only to the political, economical, cultural and social time when the research is undertaken. Nevertheless, it will provide insight into the workings of a midwifery team within a multidisciplinary team in a PHC practice. Further it will provide a description of a model of midwifery care that can become a yardstick that future research can use.

\section{Design of the Case Study}

A design is pivotal to a case study. Stake (1995) and Yin (2003) believe this includes a logical sequence for the research, beginning with setting the question or aim through to the findings. According to Yin (p. 19) "a research design is the logic that links the data to be collected (and the conclusion to be drawn) to the initial questions of the study". Yin also talks about design as the steps in the research, as a 'blueprint' or 'plan'. This might be called the micro-design, which focuses on the strategy for the data collection and analysis.

\section{Selection of Case}

My interest in this topic came from working as a midwife in a UH Service. Practicing midwifery within the UH Service was a different way of working from the more well known model of midwifery care practised in New Zealand. I had been unable to locate 
anything in the literature on the union health model of midwifery. This fuelled my desire to research this topic. When I began this research there were, in my region, three UH Services offering midwifery care. It was therefore practicable to study one of these. I did not feel comfortable doing an indepth study of the service that I worked in and I was aware that some research had already been undertaken on another of these services. Accordingly, NUHS was the only remaining service to study. I was happy to proceed with this option. I approached NUHS and their midwives about this possibility. A preliminary discussion about studying their model of care resulted in their enthusiastic agreement for me to do so. I proceeded to write a proposal ready to obtain ethics committee approval. Continued conversations and negotiations about the roles and responsibilities of the researcher, the academic supervisor and NUHS progressed into a formal contract. This was signed by the Manager on behalf of the organisation and myself (Appendix Four). The agreement incorporates details regarding the research process, the publication and dissemination of the results.

\section{Selection and Engagement of Participants}

The people I wanted to interview were the midwives, a sample of the multidisciplinary team and a sample of women consumers. The midwives were necessary interviewees because they were the practitioners of their model. I hoped to obtain these interviews first in order to keep a midwifery focus when talking to the others. A selection of MDT members was necessary because they both interact with the midwives and care for the same families. In addition I wanted as one of the MDT members a manager who could give me a perspective of how the overall service worked. The women, in my opinion, were important to interview because they were the consumers of this midwifery service and could convey how it worked for them. Altogether these people would provide information about the case as they would reveal different perspectives of the same service. Their views would be influenced by their own experiences and context. Criteria for all of the interviewees required them to be able to participate and be willing to share their experience in a face to face interview. They needed to be able to communicate clearly in English.

\section{Preparatory Work}

Preparatory work for ongoing meetings included writing out an information sheet, preparing interview schedules and consent forms. There were different interview 
schedules: one for the midwives, one for the MDT members and one for the women. I used a mind map to identify areas that I would need to cover in the interviews. The content for this came from my knowledge of the literature and what I already knew about the service. The next step was to construct several questions and ascertain which questions were appropriate for the different participants. I then ordered them into similar subjects and rewrote them as open-ended questions. This reduced the number of questions to four for the midwives and to three questions for the remaining NUHS staff and women. I constructed prompts to go under each question from the earlier list of questions. Appendices Two and Three set out the information sheet and the questions for the midwives, NUHS staff and the women.

\section{Midwives}

Preparations for identifying the midwives included a meeting with the midwifery team leader. I then spoke at their minuted weekly meeting where most midwives were present. As there were only five midwives I invited all of them to participate as midwifery was my focus. I explained the research and gave them a copy of the midwifery information sheet with the questions and consent form attached. Questions to the midwives were;

1. How does Newtown Union Health Service work and how do the midwives work with in it?

2. Why do you work for Newtown Union Health Service?

3. What are the challenges and benefits of working for Newtown Union Health Service?

4. How do you perceive others (for example, midwives and consumers) view you and the way you work?

At this meeting I was informed of the midwives unanimous acceptance of my proposal. All midwives were enthusiastic and happy to be involved. They wanted to be put on the map!' Having several midwives to interview reduced any major influence by one interviewee.

I anticipated that the midwifery team leader would be a key person in assisting me to obtain participants. According to Yin (2003) the researcher can end up with a key interviewee who becomes an 'informant'. A benefit of this is that this person generally knows a lot and is willing to talk, often providing access to otherwise contrary or 
corroboratory data. For Yin a danger is in coming under the influence of what the informant wants you to know about the case. The solution to this is to constantly use other sources to confirm the information. I was correct in anticipating that the midwifery team leader would act as the informant as she alerted me to the movements of the midwives and provided several documents about the service. Two of the midwives present at the original meeting had left the service by the time I commenced the interviews. However they agreed to be interviewed. I believed interviewing these two midwives would be better than interviewing the newer midwives as they had more experience of working at NUHS.

The interviews were challenging because of the work commitments of the midwives and my own work schedule. Three months into the data collection I began interviewing the midwives. I started with one particular midwife who was going on leave. The second midwife followed shortly after. The subsequent two were with the midwives who had left the service. Such moving on of staff indicated the state of flux at the service and reinforces the findings being tied to a particular moment in time. Several months later I achieved the final midwifery interview which was also the last interview.

The locations of the interviews varied. Three midwives were interviewed in their homes, one at the hospital and another in a cafe. After an earlier cafe interview I found the tape recording difficult to listen to and advised the midwife who wanted to meet in a café that this was not the best venue but it was her choice to proceed.

I found asking each of the midwives the same group of questions invaluable in understanding certain aspects of the midwifery model. Different interviewees would give similar descriptive answers in a different way. I continued to question until I felt I really understood what I was being told. As the interviews proceeded and my knowledge and understanding increased I would re-listen to the earlier interviews which provided me with a deeper understanding of what I was being told. Interviews varied from 30 minutes to one hour in length. They were allowed to come to a natural conclusion rather than be time constrained. This was also consistent with the MDT interviews.

\section{Multidisciplinary Team Members}

I decided that a representative from each of the disciplines would be best placed to answer the questions. Each team had a team leader, yet there were also particular MDT 
representatives that worked with the midwives. I began by inviting the team leaders of the doctors, nurses, social workers and receptionists. The first attempt at writing to them did not result in any participants coming forward. I then wrote to and approached the MDT members who worked with the midwives but this was not successful in achieving anyone interested in being interviewed. It was the initial key informant and another member of the MDT, who became my second key informant, who planned access for me to the MDT interviewees. It took several contacts and several months to achieve an interview with one particular MDT member who I considered critical to the study.

Giving the MDT participants the questions prior to the interviews allowed them to reflect on the area of research I was exploring. I endeavoured to keep each interview focussed and stop general distractions that can occur, whilst at the same time not inhibiting reflections which could be significant. The questions the MDT members were asked were:

1. How does Newtown Union Health Service work and how do the midwives work within it?

2. Why do you think midwives want to work for Newtown Union Health Service?

3. What are the challenges and benefits of having midwives working in the Newtown Union Health Service?

Four MDT members were interviewed at NUHS and one interview took place at the interviewee's home. The first nurse I interviewed (who also had a midwifery qualification) had been seconded to the midwifery team to assist them when one of the midwives took a long period of leave. I felt she interviewed from the perspective of both a nurse and a midwife. In view of this I was keen to have a nurse who practised solely nursing and achieved this.

\section{Managers}

Over the period of this research, there were three managers at NUHS. The first manager, who had been at NUHS for five years, and supported the research left before I commenced the data gathering. During the time of data gathering two further managers were appointed consecutively and were interviewed. The third was appointed towards the end of the research. As a courtesy I arranged to meet with him to explain my research. The organisation was, at this time, in the process of organising a protocol for research, and in particular, research where their service was the subject. I was required 
to fill out a 'form in progress' (Appendix Five). This manager was keen to be interviewed and provided a more people orientated perspective compared to the previous manager whose focus was more administrative. Both were useful and complemented each other.

The managers were considered part of the MDT and were asked the same three questions as the MDT members. The interviews began earlier than intended in view of the second manager leaving the service. He was interviewed in a cafe. The second manager was interviewed at NUHS.

\section{The Women}

Many attempts were made to obtain a group of women to interview. I had initially considered a focus group approach yet the midwives informed me the women were not likely to engage with each other. This was perhaps due to the range of cultural groups of women they provided care to. I decided then that I would interview the women individually. I observed that the midwives did not run any 'mothers groups' or 'coffee mornings' from where I may have had the opportunity to recruit. I left letters of invitation to the women to participate, with the midwives, to hand out to the women. Unfortunately this did not achieve any responses. Following this, I further discussed with the midwives, ideas on how to approach the women but to no avail. Ultimately the interviews with the women did not eventuate as despite the multiple attempts to recruit them, no women came forward.

\section{Interviews}

My own work as a midwife includes interviewing the women I care for to ascertain information relevant to the care of each particular woman. This provided valuable preparation for the more formal research interviews. Stake (1995) and Yin (2003) talk of the commitment and the skill set needed before data collection begins. Stake stresses the importance of 'backgrounding' and 'first impressions' (p. 49). He believes the researcher needs to be well prepared before entering the field.

Yin (2003) and Stake (1995) argue that interviews are vital to a case study. Further Stake advises that a small number of research participants is sufficient within the case study method because of the detailed descriptive qualitative nature of the material sought. He calls this 'thick description'. To gather this material Yin discusses three types of interview methods. Common to all of them is following a particular line of 
inquiry whilst asking pre-prescribed questions in a conversational and unbiased manner. The first style of interview uses open ended questions. This can produce a basis for further inquiry as well as suggest other persons to interview. Stake affirms the interview method where open ended questions are asked. Marchant and Kenney (1997) add that this style of interview allows for greater exploration of the topic being researched. All the interviews undertaken were open ended.

The interviews, although time consuming, had many advantages. They enabled me to keep clarifying the material I was hearing in order to eliminate misunderstandings and I achieved a one hundred percent answer rate to all the questions. Observation of body language and other non-verbal communication whilst sitting with the interviewees gave me a good sense of how they felt about the service and the interviews. Stake (1995, 2005), Yin (2003), Marchant and Kenney (1997) and Norr (1994) agree that these are advantages and emphasize that experiences, opinions, views and feelings are more able to emerge.

The greatest disadvantage of interviews for me was fitting them in around my work and the interviewee's work. A lot of time and effort was required arranging and rearranging interview times. These multiple attempts to achieve all the interviews meant that the interviews took longer than I originally thought would be necessary. This disadvantage is noted by Stake (1995, 2005), Yin (2003), Marchant and Kenney (1997) and Norr (1994). However, these authors do not portray all the messiness that I experienced.

A potential disadvantage was my fear that the interviewees might only tell me what they thought I would want to hear and leave out what might be important to the case. Constant clarification was necessary for me throughout the interviews in order to eliminate misunderstandings. I perceived that when interviewing some participants individually there appeared to be an element of trying to ascertain what their colleagues had already told me as a way of guaging what they should say. Participants revealing what they think the researcher wants to know is a common theme in Stake (1995, 2005), Yin (2003), Marchant and Kenney, (1997) and Norr's (1994) discussion on interviews. This can be overcome, according to these authors, by a skilled interviewer using probes to clarify understanding and putting the interviewee at ease. I used several probes following each general question. 
Another potential disadvantage is the possibility of biased data as a result of the interviewer influencing or directing the participant. I was conscious of this in my interviewing technique and always endeavoured to keep to open questions so that I believe I did not unduly influence what was revealed. Further, documentation was available to counter my influence in an interview.

Eleven of the 12 participants agreed to have their interviews recorded. I chose to fully record with a dictaphone and transcribe the interviews word for word because a) being a first time interviewer I did not want to miss anything, b) I wanted to reflect on the content at a later time, and c) I wanted accurate vignettes in my data analysis. Both Stake (1995, 2005) and Yin (2003) discuss methods of recording the interviews; either by taking notes, or by tape recording, whether this is later transcribed word for word or only the key themes. Neither author actually advises recording the full interview. They believe that the knowledge of the interview being recorded can influence the content of the interview. They also comment that the original meanings can sometimes be lost in the word for word translation. I concede that Stake's view of the method of recording the interviews can influence their content as this is what I found. It appeared that in audio recording the interviews the participants were very conscious of the dictaphone, as there were comments like, 'this is off the record' or 'I don't want this to be used'. Others began to talk more freely once the dictaphone was turned off. I wondered if the reticence was related to not being seen as criticising and possibly being identified. If so, greater anonymity might have achieved richer data. I felt that some of these 'off the record' comments could have given the findings more depth. However, I honoured these requests. I felt that in some instances, audio recording the interview was restrictive as it appeared at times to limit what the interviewees revealed.

\section{Documentation}

Over the period of data gathering I obtained the following documents: the latest 2006 Census data (New Zealand Government, 2006), two NUHS Annual Reports (Newtown Union Health Service, 2008, 2009), MMPO data (Midwifery and Maternity Providers Association, 2008, 2009), 'Health for the People' NUHS 20 years on (James, 2009) - a book published on NUHS, a recent small evaluative research project exploring consumer satisfaction of the NUHS midwifery service (Steinmetz, 2011), 'The Union Health Centres Initiative - an evaluation (McGrath, 1989) and a selection of internal 
reports and documents on NUHS. In addition, I found material on websites that aided my description of the community. Different documents were given to me at different times over the nine month period by the second manager and the midwifery leader. Three of these were received on the completion of the data gathering. This included the evaluative research project which had just been completed.

Documentation is used to both inform the interview questions and assist in confirming interview content validity in case study method (Yin, 2003). It is noted by Norr (1994) that there can be two different types of document. These include statistical records like those kept by the organisation as well as more qualitative records, for example, the minutes from meetings. Norr (1994) comments that documents are generally readily available and are low cost to obtain, yet often only reflect the official view which can make it difficult to determine any bias or what is missing. I found the documents I used extremely helpful as they complemented the interview data and filled gaps of knowledge on the political, historical and organisational aspects. According to Stake (1995, p. 68) "almost every study finds some need for examining newspapers, annual reports, correspondence, minutes of meetings and the like." as this data provides information in areas that the researcher is not able to observe or find out in interviews. Generally the documents appeared to give the official view but the multiple realities expressed in the interview data provided other views regarding the organisation of the service.

\section{Data Analysis}

Data analysis is a critical step in the design as research findings come out of this process. I commenced my data analysis by making notes in a log book, immediately after each interview and then again while transcribing the interviews. In doing this I achieved a sense of what was important within the material. Then I began a more formal process of looking for particular themes. Once these were identified the final process involved structuring them into a framework that described the NUHS model of midwifery care.

Stake (1995) describes the analysis in a case study as pulling it apart and putting it back together again more meaningfully. He goes on to say "the nature of the study, the focus of the research questions, the curiosities of the researcher pretty well determine what analytic strategies should be followed...” (Stake, 2005, p. 77). Yin (2003) is more 
specific in his discussion on analytical strategies and I have chosen elements of his approach for my study. Yin suggests that without a general strategy analysis is difficult. Of the five strategies for data analysis described by Yin, the one used in this research is that of a descriptive framework for organising the data. This is appropriate because the purpose of my case is primarily descriptive. As implied this strategy looks for content themes and a way of organising them coherently.

The notes I made within an hour of each interview involved themes, contexts, thoughts and feelings. In transcribing the interviews word for word I believed I was staying true to the interview and interviewee. To keep the context and tone of what was being said, which Stake (1995) and Yin (2003) both comment can be lost in the word for word transcript, I noted areas of importance to each interviewee.

Once the interviews were all transcribed I familiarised myself with the data by reading it several times and dwelling with it. This was a time for what Yin (2003) advises is defining priorities as to what to analyse. In order to work out what is important I devised a mind map. The content for this came from the literature and my sense of the data. Initially three principle areas of interest emerged. These were; the midwifery practice including the women they attended, the multi-disciplinary team and the community. I examined how the midwifery practice was organised to care for their women, how this functioned within a multidisciplinary team and how the community was influencing these aspects. However, after starting to organise data under these headings, another theme of Newtown Union Heath Service as a PHC service became apparent and was added. Once the data were categorised under each of the four themes, I examined each grouping to ascertain what they could tell me about the model of midwifery care and how all four categories were connected. Stake (1995) describes this process as identifying and exploring the issues most relevant to the case. He adds that the researcher should seek out what is common and what is particular about the case.

Yin (2003, p.111) explains that once the researcher has a strategy it will aid in the fair treatment of the evidence, 'produce compelling analytic conclusions' and eliminate 'alternative interpretations'. What he sees as necessary facets to create an exceptional analysis include the following points:

- Attend to all the evidence leaving no loose ends as ignoring evidence can lead to alternative interpretations. 
- Address the most noteworthy aspect of the case study.

- Use 'your own prior', expert knowledge.

(Yin, 2003, p. 111)

I incorporated these points in working with my data. Yin also lists a fourth point about addressing alternative rival interpretations. This is not relevant to my analysis as no other description of this model of midwifery care is available.

Having constructed the framework from the interview material I discovered that I had very little information on the community and the way NUHS had developed. I reexamined my documents and log book and found that these were particularly helpful in expanding the description of these two areas. The MMPO data and the evaluative study were helpful in enlarging the interview data on the midwifery service. The final framework included five main components: the community, NUHS, midwives within the multidisciplinary team, midwives and the women who receive their care. It was then important to examine design processes in order to demonstrate their credibility.

\section{Rigour and Trustworthiness}

It is important that the findings of this research can be trusted. In order to ensure this certain processes need to be adhered to. These include triangulation and member checking addressed by both Stake (1995, 2005) and Yin (2003, 2008). Stake (2005, p. 454) explains triangulation as "a process of using multiple perceptions to clarify meaning, verifying the repeatability of an observation or interpretation". I found three of six types of triangulation measures discussed by Stake (1995) and Yin (2003) to be particularly applicable to this research. They are 'data triangulation', 'methodological triangulation' and 'multidisciplinary triangulation'. In this research data triangulation and methodological triangulation appeared similar and are addressed together. Member checking, according to Stake, is when the study participants are asked to comment on drafts of the interviews and study findings in relation to 'accuracy and palatability'. Another process used is providing a chain of evidence which, according to Yin, (p. 83) is "explicit links between the questions asked, the data collected, and the conclusions drawn". 


\section{Triangulation}

I demonstrated triangulation by using different methods of gathering data; interviewing, and document examination. The common threads between the two forms of data included the context of the service, the descriptions of the multidisciplinary team and the midwifery service. The commonalities of the interviews and the observations, according to my log book, were the busyness of the service, the multicultural element, passionate staff and occasional tensions between staff that these passions engendered. The interviews offered different realities experienced by the team members not evident in the documents or observations.

Contributions from multidisciplinary team members are also a form of triangulation. The use of this is evident in that this research included the input and perspective from a representative of each of the disciplines in the multidisciplinary team. In fact, seven of the twelve interviews were with MDT members of NUHS. Their perspectives are different as could be expected but all complement each other in building up a picture of a team and the service. The common thread in the MDT material is that they each saw the midwifery component as invaluable to the service.

Yin (2003, p. 98) states that the use of multiple sources of evidence is a strong point of case study resulting in a more 'convincing or accurate' piece of research aimed at "corroborating the same fact or phenomenen". Ultimately Yin and Stake agree that triangulation is the common method used to assess the reliability in any case study research.

\section{Member Checking}

An offer was made to the interviewees to review the transcript of their interviews. Only two accepted. One participant made a thorough review by taking out and adding material while the other saw her transcript as satisfactory. This demonstrates what Stake calls the palatability of the material. A draft of the findings was given to NUHS for comment as agreed in the initial contract. The midwifery team leader responded positively stating "it is very heartening to have solid research which validates and supports our clinical practice"; she further commented that the study could be helpful in further development of the service. This process involving feedback from the participants at different levels can be described as co-construction. It contributes to the trustworthiness of the data. 


\section{Chain of Evidence}

A chain of evidence aims to give the reader assurance that there is congruence between the aim of the study, the method chosen, the collection of the data, analysis of the data and the conclusions made. I have endeavoured to set out the aim of the research and discuss how the method chosen applies to what I wanted to achieve. Details of gathering the data and how this data was analysed and described are given. Vignettes from the interviews and material from the documents and observations are present in the findings, as advised by Yin (2003). In providing this material there is a decision trail which imparts evidence for all the steps undertaken in this project. Yin (2003) further states that describing these steps allows for another researcher to follow the same processes used in this study. Included in these steps the ethical nature of the research must be explicit.

\section{Ethical Considerations}

All research has ethical implications. These are particularly important when working in the field with real life situations that depend on the contributions of research respondents (Stake 1995). The ethical principle of 'do good' and 'do no harm' governs how the researcher approaches the field, gathers and analyses the data. In my endeavour to 'do good' I wanted to provide a description of NUHS midwifery for the midwives, the service and the profession. I did not want to harm anyone in the process. This goal required me to adhere to several processes which included attention to anonymity, informed consent and ownership of the research.

\section{Anonymity and Confidentiality}

Early discussions with my supervisor centred on the identifiabilty of NUHS and its participants in the research report. It was established that because 'NUHS' is so unique and thus identifiable, the organisation should be named in the report. The then Manager took the research proposal and the ethics submission, which was approved by the Regional Ethics Advisory Committee (Appendix One), to the NUHS Board for discussion and their gained approval for me to proceed. The Regional Ethics Advisory Committee agreed to the naming of the organisation as did the NUHS Board. Morse (1994) explores the significant issue of maintaining confidentiality and all other agreements made at the time of negotiating the research. Included in this exploration is 
the participants' identity, their organisation and their location. For Morse, the important aspect was that all research participants agree to the level of anonymity that occurs.

Complete confidentiality of the midwives was difficult as there are only a small group of them practising at NUHS and therefore they were easily identifiable. In view of this and with their permission I originally sought to name them. Although to 'save the midwives from any harm' I did not intend to attribute individual comments to them. However, as the midwifery interviews proceeded and individual perspectives were revealed, I felt that protection of their identity was in order. In my opinion, the fact that these midwives practise differently from the majority, and are known to their community and local midwifery population, made them a potentially vulnerable group. I also believed that because their model of midwifery care was being revealed for the first time, there was an element of 'who was telling me what', 'were they divulging too much', or 'was there particular NUHS information that I should not hear about'. This led me to believe that there was some anxiety about the exposure of their model. In view of this I believed I could partially protect them by not using their names. The best way of referring to not only the midwives but all the interviewees was by giving them a number between one and 12. However this would reduce the MDT triangulation component of the findings. Therefore I decided to refer to them as Midwife (MW) $1,2,3,4$ and 5. Although one of the midwives was the team leader, this midwife is only referred to as a number in the group of midwives. For consistency the remaining seven multidisciplinary team members are referred to by their profession only. For example N1 refers to Nurse One. The key to the actual participant's identity, is kept with the transcripts and data, under lock and key.

I transcribed nine interviews and three were done by a professional transcriber who signed a confidentiality agreement about their content. All transcripts had the name of the interviewee removed and they were referred to by their initials in the text. The MDT member's initials on the transcript refer to their profession rather than their name. Further the names of all people referred to in the transcripts, for example references to colleagues and well known people, were removed in order to maintain anonymity.

The tapes, transcripts and computer files were securely stored in a padlocked chest in my home. Only my supervisor and I viewed them. After completion of the research, only information on which the findings of the project depend and which do not identify 
the participants, will be retained in secure storage for the required period of five years. This is so that any published material from this research can be checked if necessary. After the five years, it will be destroyed.

\section{Informed Consent}

The midwives were informed of my research and the demands it would make on them over several meetings. They were given their information sheets (Appendix Two) with the questions attached and consent forms (Appendix Three) at an early meeting so they had these as points of reference throughout the research process. They could also contact me at any time. The managers were approached in the beginning and given a copy of all information sheets so they were aware of what everyone was being asked. The MDT members were approached initially by the midwives about the research and at a NUHS core group meeting where all gave approval. I wrote them letters, which included the information sheet and questions, inviting them to participate and then approached them individually again myself with the information and the consent form. All consent forms were signed either before or at the beginning of each interview. Ownership of the research was a topic discussed at an early meeting with the midwives and the manager.

\section{Ownership of the Research}

It was agreed in the contract between NUHS and myself (Appendix Four) that the findings of the research would be owned by NUHS, with me the researcher holding the data and using the material for my qualification and for publications as agreed to by them. Ownership of the findings by NUHS was considered important as they were the ones most affected and needed to have some control over how the research was used. Further the midwives wanted to be associated with the dissemination of the findings as it was their model.

Permission would be required from both parties if any of the information was to be used for other purposes. An example of this process is when I decided to submit an abstract to present the preliminary findings of the research at the International Confederation of Midwives conference held in South Africa. I wrote to the manager and the midwives of NUHS informing them of my intentions. They were happy with this but wanted to see the presentation prior to my departure for South Africa, 'should any tweaking need to be done'. I presented the paper to the NUHS midwives and my supervisor who attended 
(Connor \& Skinner, 2011a). The manager unfortunately had other commitments. After some suggested alterations that were incorporated into the presentation they were happy for me to proceed. They also gave me photos of themselves and their work to include in my presentation which increased its human interest.

For the (national) Joan Donley Research Forum I adapted the presentation to be appropriate to this audience. I also invited the midwifery team leader to present with me. After reading the presentation, the team leader decided it was more appropriate for me to present it and for her to be present to answer questions. I was happy with this and the presentation was undertaken (Connor \& Skinner, 2011b). Unfortunately due to personal reasons she was at the last minute unable to attend this conference.

The third and final presentation to date was to a local NZCOM midwifery meeting; the content was not changed from the national presentation (Connor \& Skinner, 2011c). My supervisor and all the participating midwives were informed and invited to attend whether NZCOM members or not. Unfortunately none of the midwives were present but my supervisor attended.

All the appropriate ethical processes were addressed and adhered to in studying this case. As a result I am not aware of any harm that was done to any of the participants or the organisation.

\section{Treaty of Waitangi}

The Treaty of Waitangi is the founding agreement between the Māori people and the Crown signed by representatives of both parties in 1840. The governing of New Zealand is based on this document. As the research was undertaken in New Zealand, the Treaty of Waitangi principles of partnership, participation and protection were honoured in all areas of this research. I attempted to have a Māori Advisor view the proposal and make comments on any issues that may be significant to Māori participants. However after inquiring who an appropriate person might be at NUHS to undertake this, no one was forthcoming. Particular attention was paid to the reporting of Māori language in the correct format within this research. A support person was offered to all participants but the offer was not taken up. Two of the interviewees were Māori and although they were offered to have whanau support with them, they chose to be interviewed alone. 
The Māori term kaupapa, which is reported in the findings as their philosophy and way of working, is an indication of the Māori perspective being important and integral to the service. It was the preferred word the staff used over that of philosophy. The word kaupapa appears in the glossary of James (2009, p 187) and is defined as 'principle, underlying philosophy'.

\section{Summary}

Exploration of the case study method enabled me to determine that this method was appropriate for describing the contextual complexity of the NUHS model of midwifery care. These authors recommended seeking multiple perspectives from multiple sources of data which complemented each other to provide a greater breadth in describing the case. The method also allowed me to bring my prior knowledge of the UH Services to this particular case. The analysis of the data led to my being able to describe the NUHS model of midwifery care within the limits of a small research study. I was disappointed that I could not include the voice of the women who received midwifery care as I believed their perspective would have enhanced what I was able to achieve.

In beginning this research I wanted to tell the story of Newtown Union Health midwives, to describe their model of midwifery care and reveal how it was placed within a multidisciplinary team within a PHC service. To achieve this I observed the location and the community and I interviewed 12 staff members of NUHS, I collected documents from the service and other places, I interpreted and evaluated all this data to ultimately produce this report. Stake (1995) describes this as a storytelling approach. I was very conscious as the research progressed of being true to what I was hearing rather than interpreting it through the lens of my previous employment.

The use of interviews as the primary data source provided a current description of the model of midwifery care, as viewed by the group of midwives as well as the multidisciplinary team. Although this form of data was highly beneficial, achieving the interviews was time consuming in view of a busy workforce. Nevertheless, interviews allowed multiple voices for the process of building up the case which documents did not provide. The processes of triangulation, member checking and providing a chain of evidence gave rigour to the study. Ethical considerations related to my work in the field 
covered anonymity, informed consent and ownership of the data which kept all the participants safe and gave the service ownership of the findings.

The case study method and the processes in the research, described in this chapter, revealed the findings of the research set out as the NUHS model of midwifery care in the following chapter. 


\section{CHAPTER FOUR: FINDINGS - The NEWTOWN UNION HEALTH \\ SERVICE MODEL of MIDWIFERY CARE}

In this chapter I present the findings of the research which describe the model of midwifery care within NUHS. Midwifery is an integral feature of the service. The interrelationships of the community and its population with the service and all those who work for NUHS form an interwoven tapestry which creates this multidisciplinary PHC service. While a PHC service in a PHO can function without midwives, the NUHS emphasis on family care means the service would be incomplete without midwifery. Thus the midwives and the women they attend, being components of this tapestry, play a role in both shaping and being shaped by the service. To use an analogy that one of the participants used, all these features 'complete the jigsaw' not only providing a 'one stop shop' but producing a description of NUHS midwifery.

Material from the interviews, the documentation and some observations from my log book are used as the evidence supporting these findings. The voices of the interviewees in italics are heard throughout this chapter within vignettes taken directly from the interview transcripts (see Table 4.1 for identification of the voices). Italics are used also to identify the documentation used as part of the findings in this chapter to distinguish it from the general literature informing this research.

Table 4.1. Key to Interviewee Vignettes

\begin{tabular}{|l|l|}
\hline MIDWIVES & MDT MEMBERS \\
\hline Midwife 1; MW1 & Manager 1; M1 \\
\hline Midwife 2; MW2 & Manager 2; M2 \\
\hline Midwife 3; MW3 & Nurse 1; N1 \\
\hline Midwife 4; MW4 & Nurse 2; N2 \\
\hline Midwife 5; MW5 & Doctor; D \\
\hline & Receptionist; R \\
\hline & Social Worker; SW \\
\hline
\end{tabular}

The model is discussed under five major headings: the community, NUHS, the midwives in the multidisciplinary team, the midwives and finally the women. These 
five headings were the outcome of the data analysis. In order to present this model I have constructed a graphic illustration which sets these areas out within a series of circles which attempt to portray their relationship to each other, see Figure 4.1.

The community as context and setting for the service is positioned in the outer circle. As the service arose within the community it serves, this concept is important in the model and is the first to be discussed. The discussion includes a description of the Newtown suburb drawn from my observations, the census data, various reports on the service and particular websites. It closes with a short discussion on the midwifery link to the community.

The inner side of the community circle contains 'NUHS'. A description of NUHS forms the second section of this chapter which includes the setting up of the service, how it is currently governed, organised, funded and its kaupapa. The kaupapa constitutes a noteworthy part of the discussion as it is a distinguishing feature and of central importance to NUHS.

The next circle contains three elements: the midwives and the multi-disciplinary team, the midwives and the women. They are positioned on the rim of this inner circle to represent their close relationships within NUHS and as central aspects of the model. The inner circle represents the coming together of all components to constitute the model. In this representation the model is constructed to enable NUHS midwifery to be seen as part of an integrated cohesive service. The midwives and the MDT, the midwives and the women as components of the inner circle are discussed under their respective headings to complete this chapter. 
Figure 4.1: A Representation of the Newtown Union Health Service Model of

\section{Midwifery Care}

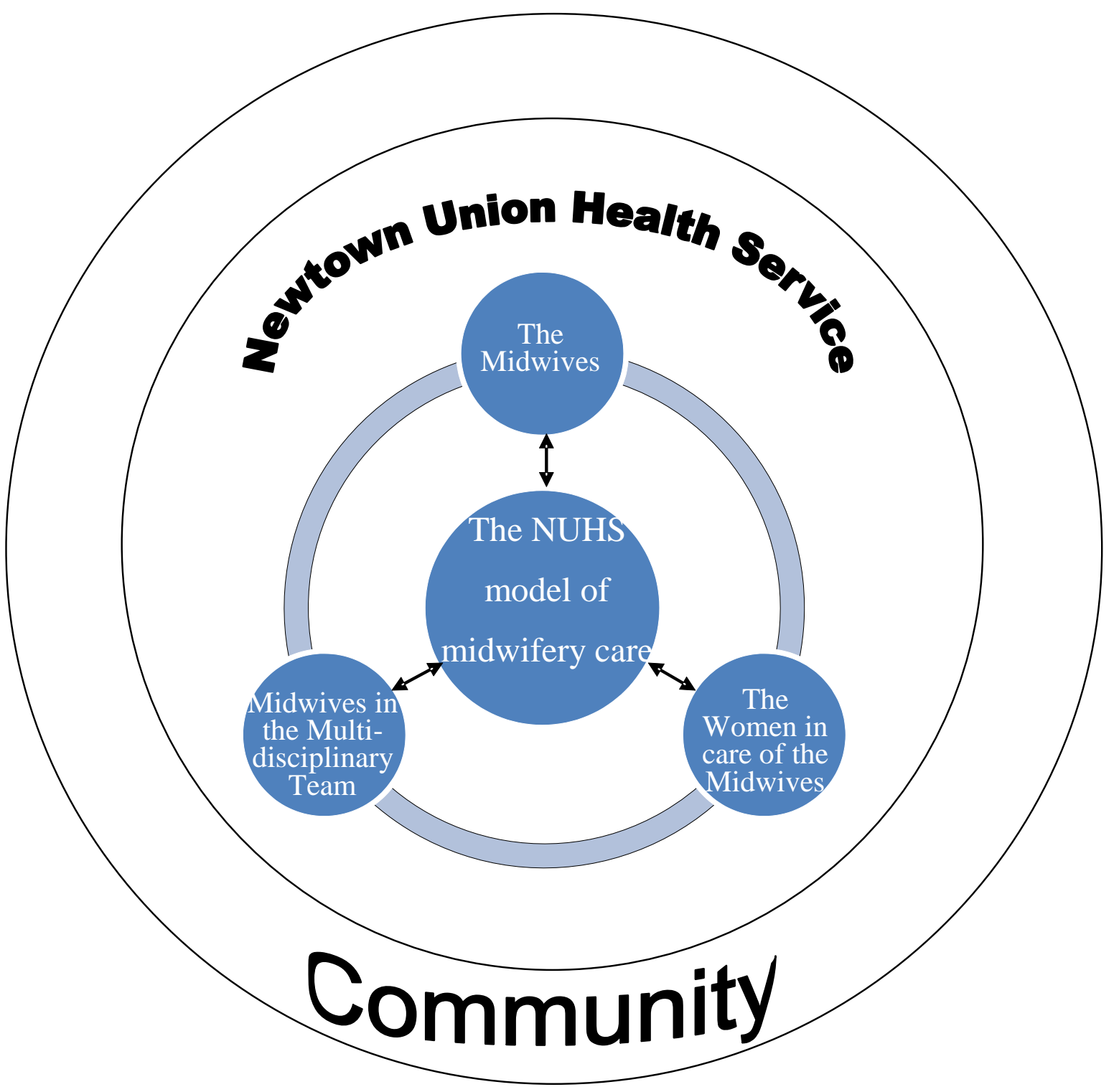

\section{The Community}

The map (Figure 4.2) places Newtown in the middle of Wellington and indicates its surrounding suburbs. The NUHS building is on a side street, two minutes walk from the main road and five minutes walk from the hospital. It also has outreach services in the Newtown Park Flats and in Strathmore which is highlighted on the map. Newtown is close to central Wellington. The map shows the distance between Newtown and suburbs on its periphery. 
Figure 4.2: Map of Newtown and its Surrounding Suburbs

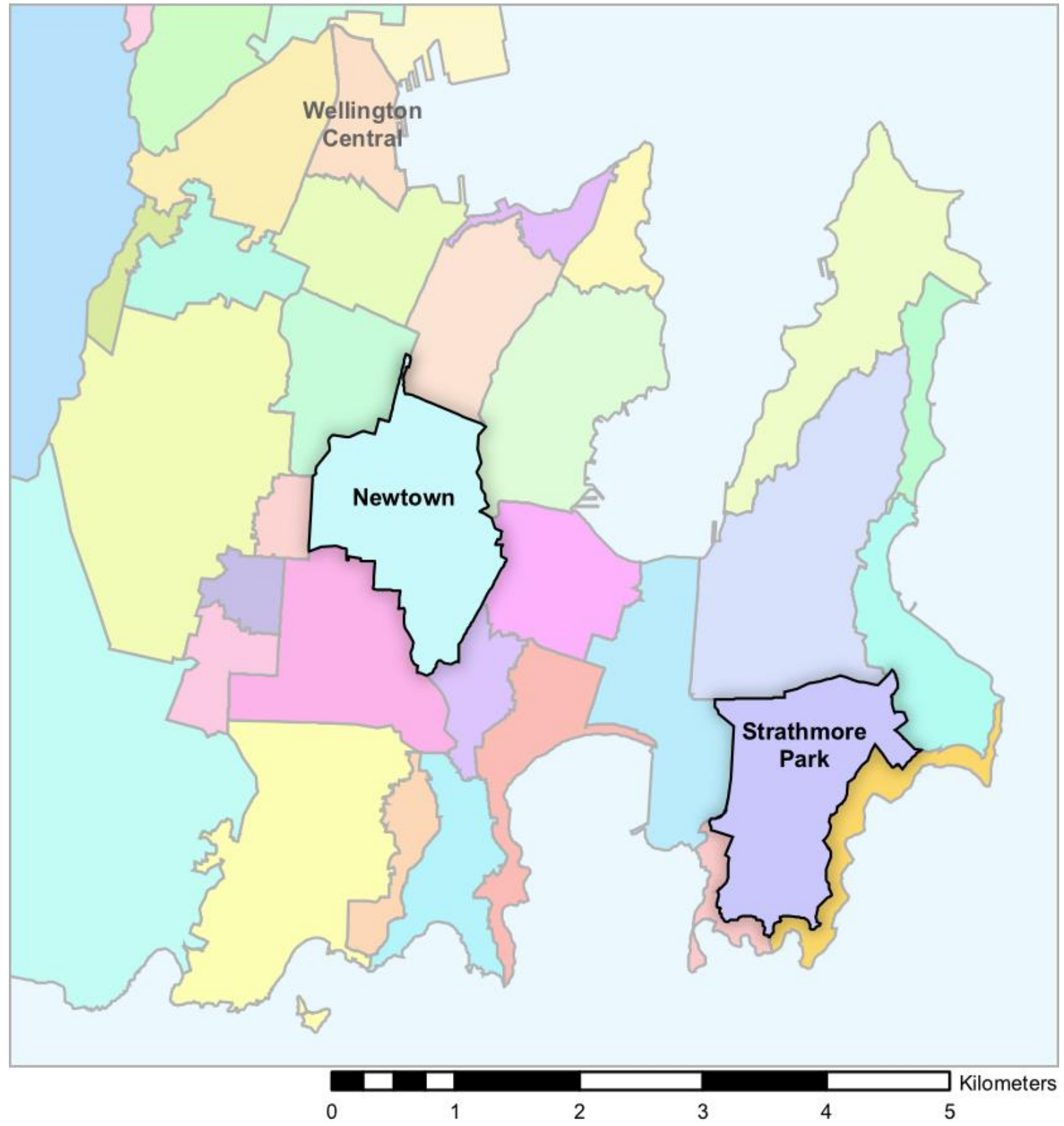

NUHS is housed in a large relatively new wooden building with wheel chair access. A sign clearly states opening times which are adhered to in my experience. The service closes for lunch and upon arriving at the end of this break I observed a queue had gathered waiting for it to reopen. The reception area is large with seating around the edges and a television on a wall playing health promotional videos on a loop. Several receptionists are present just through the main door behind an area closed off to the public. This closed off area provides security to staff and documentation. Patients and visitors are required to sign in and sign out. Staff and visitors pass through another locked door to gain entry to clinics and offices. At the end of a corridor is a large staff 
room where folding doors separate the area into a meeting room when required. The comments recorded in my logbook, found that the building suited its purpose and met the needs of the staff and the population it serves.

The present Newtown community evolved from one of the early suburbs situated in the south-east of Wellington. Historically, Newtown was a place which attracted working people, immigrants and others of lower socioeconomic means as housing in this area was affordable. Today it is a vibrant and bustling multicultural suburb. In the last 20 years more professional people and students have moved into the suburb and a gentrification process has occurred. Gentrification takes place when wealthier people buy houses in a lower socioeconomic suburb and upgrade them. This process often results in the displacement of the less wealthy residents of the suburb who can no longer afford the increased rent and property prices (Merriam-Webster, 2012). During these 20 years services and amenities of Newtown have developed as Newtown's population has changed and expanded. As part of the gentrification process, the changing businesses and retail outlets have begun to cater for the more affluent customers, increasing the appeal for these families to move into the suburb. This decreases this suburbs accessibility for people on lower incomes. According to the Wellington City Council District Plan, Newtown is recognised as a suburb with an "identifiable or distinct character". Such recognition has resulted in resource consent being necessary for two or more household units to go on one site in certain areas (Wellington City Council, 2012).

Some notable buildings, including the main hospital and Government House, are situated in Newtown. The hospital which serves the Wellington region, has been located in this suburb since 1881. It has been rebuilt several times. The most recent opening of a new hospital on this site was in 2010 (Easthope, 2007). The hospital is a short walk from the NUHS office. There are other GP practices, alternative health care businesses and also two other self-employed midwifery services in Newtown. The suburb has two primary schools and an intermediate school. One of these primary schools has served the Newtown community for 127 years and is bi-cultural with a Māori immersion class (Doyle, 1998). Three secondary schools are located on its northern boundary.

The shopping area is in Newtown's main road. This is also a main thoroughfare to surrounding suburbs making it a very busy road. There is a wide variety of retail shops 
including second hand shops, money lending facilities, cafes, restaurants, fast food outlets, a supermarket and an after-hours medical centre and pharmacy. Many of the buildings housing these facilities look old in relation to other Wellington suburbs and appear to be in need of an upgrade. At the end of the main road there are a number of light manufacturing businesses, a large park consisting of sports fields and the Wellington Zoo. On the northern boundary is a university. Other eastern suburbs of Wellington, where NUHS has 'outreach clinics', can be accessed by driving through Newtown, although there are more direct routes from the city centre. However, there is a regular bus service from the city centre to outer suburbs which goes through the main shopping area of Newtown.

Newtown has many large buildings hosting a number of apartments. The majority of these are council estates. Some of them appear run down, while others are in good condition or in the process of being upgraded. The houses are a mixture of small and large villas, cottages and regular wooden houses. Some are in need of repair while others appear well maintained. There are some large houses which could have belonged to wealthy families in the past, and now where middle class families who can afford their upkeep, insurance and rates, may still reside. Some of these large houses, however, look to hold several flats and thus several families. There are churches of many denominations, some catering specifically to Pasifica congregations. My logbook notes from conversations with NUHS staff that some well known local celebrities live in Newtown.

From watching the people in the shopping area there seemed to be a wide range of ages and ethnicities. No one ethnic group stood out to me more than any other and Europeans seemed to be in the minority. My overall impression was that the inhabitants of Newtown and the patients of NUHS were a strongly multicultural community with a high representation of people from the lower end of the socioeconomic scale. This was also supported in my conversations with the NUHS staff. In order to establish whether these impressions are an accurate representation of the Newtown and the NUHS population I initially concentrated on the ethnic variation of this population in the 2006 census which is followed with an investigation into economic status.

I examined this census data comparing it with the population statistics from the NUHS annual reports, the Midwives MMPO data and James (2009). Table 4.1 demonstrates 
the range in ethnic groups in the New Zealand, Wellington and Newtown population together with the NUHS patients and the women who attend the midwives. I found that the ethnic groups in Newtown are not an exact representation of Wellington or New Zealand as a whole. There is a smaller percentage within the NUHS clientele of the women in the European category than for Newtown, Wellington and New Zealand. The Pacific population amongst NUHS users is higher than their proportion of the population in New Zealand, Wellington and Newtown. It is higher than the Māori population who use NUHS. However, the number of both Pacific and Māori women who use the midwifery services are lower than those of other ethnicities using NUHS. Further, there is a much higher percentage of Middle Eastern, Latin American, African and Asian women using the midwifery service in relation to their proportion within the population of New Zealand or Newtown. The figure for the Middle Eastern, Latin American, African and Asian group is not recorded in NUHS statistics. It is possible this group under the NUHS column has been classified under 'other'. It is notable that the midwives also provide care to pregnant women not enrolled with NUHS and it could be this category of women that are influencing the statistical picture. NUHS midwives report that there are 45 different ethnic variations of women they provide care to that fit within these five broad groupings of ethnic classifications. For example the African groupings include women from Somalia, Eritrea and Sudan. Ultimately the figures from Table 4.2 suggest that Newtown, as well as the population served by NUHS and its midwives, is an ethnically diverse group. This is consistent with my observations of the Newtown community.

\section{Table 4.2: Ethnic Population}

\begin{tabular}{|l|c|c|c|c|c|}
\hline Ethnicity & $\begin{array}{c}\text { Ethnicity } \\
\text { of New } \\
\text { Zealand in } \\
\mathbf{2 0 0 6}\end{array}$ & $\begin{array}{c}\text { Ethnicity } \\
\text { of } \\
\text { Wellington } \\
\text { in 2007 }\end{array}$ & $\begin{array}{c}\text { Ethnicity } \\
\text { of } \\
\text { Newtown } \\
\text { in 2006 }\end{array}$ & $\begin{array}{c}\text { Ethnicity } \\
\text { of NUHS } \\
\text { patients } \\
\text { in 2007 }\end{array}$ & $\begin{array}{c}\text { Ethnicity of } \\
\text { NUHS women } \\
\text { who use NUHS } \\
\text { midwives in 2009 }\end{array}$ \\
\hline European & $68 \%$ & $70 \%$ & $61 \%$ & $19 \%$ & $27 \%$ \\
\hline Māori & $15 \%$ & $13 \%$ & $10 \%$ & $15 \%$ & $10 \%$ \\
\hline Pacific & $7 \%$ & $8 \%$ & $11 \%$ & $22 \%$ & $13 \%$ \\
\hline Asian & $9 \%$ & $8 \%$ & $15 \%$ & $15 \%$ & $24 \%$ \\
\hline Middle East, Latin & $1 \%$ & & $6 \%$ & & $26 \%$ \\
America, Africa & & & & & \\
\hline Other & $11 \%$ & $1 \%$ & $8 \%$ & $29 \%$ & \\
\hline
\end{tabular}


*Columns that add up to over $100 \%$ are due to people relating to more than one ethnic group.

An exploration of the socio-demographics of the Newtown community and NUHS is the second aspect I examined. I focussed on the New Zealand Deprivation Index and the Census data. I found that of the registered patients of NUHS in $2007,70 \%$ were classified in the fourth and fifth quintile of this index. Quintile five is the classification given to the most deprived and lowest socio-economic population (James, 2009; Salmond, Crampton, \& Atkinson, 2007). This finding also correlated with my observations of the Newtown inhabitants and patients seen in the waiting room of NUHS. It is for these people that NUHS exists.

Figures 4.3 and 4.4 demonstrate the income of Newtown inhabitants compared to the Wellington population to give a picture of the economic status of this community. According to the 2006 Census (New Zealand Government, 2006), 23.6\% of the Wellington region inhabitants compared to $18.7 \%$ of the 8,409 residents of Newtown earn over $\$ 50,000$ per annum. The average income of those living in Newtown is $\$ 24,300$ per annum whereas the average earnings for those in the Wellington region per year is $\$ 28,000$. Those in Wellington earning under $\$ 20,000$ a year total $38.8 \%$ as opposed to $44.1 \%$ of Newtown inhabitants in the same category. In summary Newtown has a higher proportion of its population earning less than the average income, and a lower percentage of its people in the higher earning bracket. The census reports that $7 \%$ of Newtown inhabitants are unemployed compared to the Wellington average of $5.2 \%$. Notably these census figures do not differentiate between the 15 year olds and above not working, for example, those in education or the elderly (New Zealand Government, 2006). 
Figure 4.3. Income for People Aged 15 Years and Over

Newtown West and Wellington Region, 2006 Census

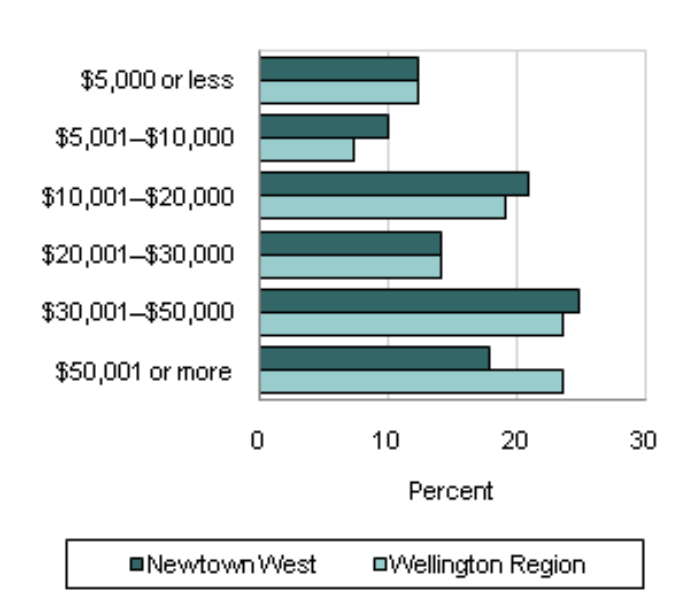

Figure 4.4. Income for People Aged 15 Years and Over.

Newtown East and Wellington Region, 2006 Census

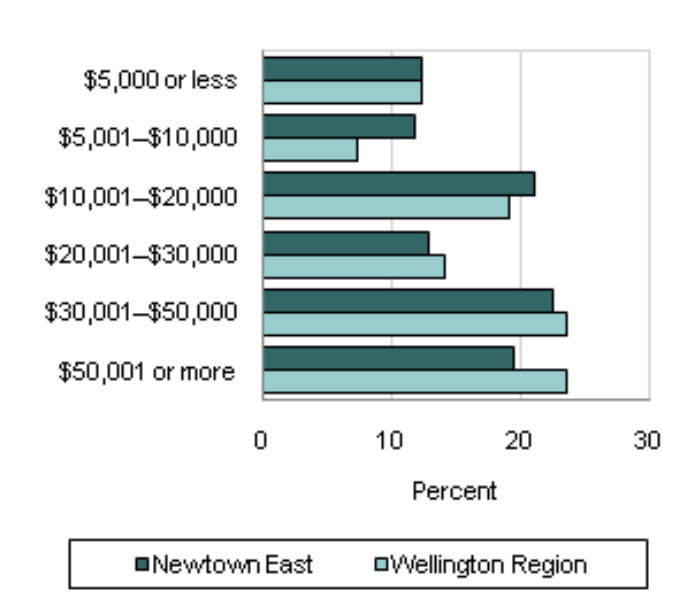

The deprivation figures correlate well with the census data and confirm the low incomes of many Newtown inhabitants. However the women attending the NUHS midwifery service appear to have quite a different profile.

The NUHS patient register in 2007 revealed it had 5800 patients (James 2009). The Newtown population according to the census in 2006 (New Zealand Government, 2006) recorded that it had 8409 inhabitants. The interviews and documents revealed that NUHS accepts people who are beneficiaries, refugees, unemployed or on low incomes living in Wellington South and other suburbs. Therefore the NUHS enrolled patients come from further afield than Newtown alone. For example, on the northern boundary of Newtown there are several large council buildings where apartments house refugee families and other people with low incomes. I was told that these families are often enrolled at NUHS. I could not locate statistics that gave the proportion of NUHS patients that came from within Newtown as opposed to those from neighbouring suburbs. This would be interesting information to obtain in view of the gentrification that has occurred in Newtown and its community over recent years.

\section{Midwifery in the Community}

Midwives are connected with the community in several ways. They are there visiting the families and attending meetings with other agencies that are working with the 
NUHS families. The MDT members felt that the midwives were a necessary part of the service to engage the people and families within the community. An MDT member commented that the midwives who can get that frontline access are very beneficial, even more beneficial to the service as a whole, because they're the link (N2). The midwives can then engage the other MDT services for these women and their families as they are needed.

Midwives living in the community drew mixed responses from the midwives interviewed. One midwife commented that the NUHS midwives should be visible within the community. She felt the community needed to know who its midwives were. Living in the community she works in she found that walking around the streets here in Newtown people will always say 'Hi', how are you going, ... they stop because we were with them during a really important time (MW4). Nevertheless, another midwife expressed amazement about her colleague living where she worked. She felt living away from the community gave her some separation between her personal life and her work life which was important to her given the nature of the job.

A potentially negative reason for living and working in the same community relates to poor outcomes. Another midwife aptly stated that it's all good when it's good but when it's bad it still has to be good (MW4). She recounted a story where there had been less than favourable outcomes. In some instances they don't talk to us... they don't acknowledge us up the street (MW4). Whereas in another particular case when a baby died, the midwives and the family came together supporting each other within the community, and I felt welcomed by the family because I went to the funeral (MW3).

In summary the community of Newtown is a colourful but generally a low income community. A number of people from diverse ethnic groups live there and possibly others do their shopping and business there. Although the profile of women attending the NUHS midwives differs from the Newtown profile it does include many women of non-European origin. This community is the home of NUHS.

\section{Newtown Union Health Service}

NUHS began in 1987 to serve a particular population of the Newtown Community. This section is divided into two subheadings: the origins and development of NUHS and NUHS today. 


\section{The Origins and Development of Newtown Union Health Service}

A description of the origins of NUHS is important in understanding its development and how it is currently structured. The need for a health service focusing on the needs of low income families, arose from concerns held by members of the Northern and Wellington Hotel and Hospital Workers Labour Union, prior to the election of the Labour Government in 1984. Ryall (2009) reports that this Union had strong links with the Labour Government, and had campaigned regularly against the former National Government, who wanted to privatise public hospital services. The unions believed that the private fee for service model used by GPs prevented them from considering an alternative system that would offer low income families better access to medical care. The union workers' main concern at the time was the high cost of health care for their children. Hence they were pleased when their concerns regarding this were taken up by Labour Government's Minister of Health; Michael Bassett. He introduced a scheme in which GPs were to be largely subsidised if they contracted with the government to charge children under six years $\$ 2$ per visit. According to Ryall few GPs took this up and ultimately a group of them took the Minister of Health to the High Court and had the $\$ 2$ per visit contract overturned as being a breach of the Social Security Act.

Ryall (2009) states that some time later, members of the various unions approached the Minister of Health again with suggestions about employing GPs for areas that had a low income population. The Minister was reportedly sympathetic but did not want more conflict with the Medical Association. After further discussions the Minister encouraged the Unions to set up their own Health Service based on a capitation model employing their own doctors. He told them that the Government would support them if a pilot project was successful.

After some internal debate around the issues of being responsible for initiating and funding a health service the unions concluded that this would be the only way, at that stage, to achieve their desire for employed GPs (Ryall, 2009). They decided that their proposed service would use a funding model that emphasised wellness rather than sickness and that the service would ultimately provide low cost health care to union members, beneficiaries and their families. The next stage was to finalise where the first service would be located. Meetings occurred with the then Newtown Health Care Association and the Porirua Community Health Project. It appears that the Newtown 
group proposed the best case, which incorporated multiple contacts in the community, a hospital funded health promotion worker, and their desire to include the beneficiaries and their families. Financial loans from 19 of the Trade Union Organisations (Crampton \& Brown, 1998; McGrath, 1989) enabled the Unions to begin with the Newtown option. A building was found and two GPs with PHC experience and knowledge of the Alma Ata Declaration were employed as well as a practice nurse and a manager. In May 1987 the Newtown Union Health Service began. According to NUHS (2010) the first year proved successful and the Government then commenced funding it as a three year pilot project under the primary care division of the then Department of Health. The following statement sums up the beliefs of the present staff about the service's origins. It was a need, and a want but more a need (M1). NUHS' foundational philosophy, which was derived from the Alma Ata Declaration and introduced by the two GPs, made it a leader in the New Zealand PHC movement. It became a flagship service.

NUHS together with other union health services have played a pivotal role in the development of current New Zealand PHC policy and structures. NUHS began as a not for profit non governmental organisation (NGO). It became a model for other union health community governed PHC services. NUHS was and still is community governed (Ryall, 2009). Community governance is made up of a Board consisting of patients, members of staff and members of the community which is consistent with the Primary Health Care Strategy (King, 2001). It was also an early model that demonstrated capitation finding. Soon after the union health movement was implemented a new group called Health Care Aotearoa (HCA) was created (Gauld, 2008). This was a network of representatives from community governed primary care provider services. It provided an umbrella group to assist each union service to develop quality programmes through development of standards and management processes. HCA believed in a multidisciplinary team approach that was dedicated to "providing quality health care for those hardest to reach" (Health Care Aotearoa, 2010). The HCA took the Treaty of Waitangi as a founding principle and thus developed a bicultural philosophy. It extended its services to Māori PHC organisations as they developed in the 1990s. Further the union health services provided a model for the PHC strategy, as the PHC strategy came many years after NUHS began (Gauld, 2003; Hefford et al., 2005). The group of access PHOs which followed the implementation of the strategy kept most 
faithfully to the union health model. HCA remains in existence to assist the access PHOs.

In 2003 NUHS changed from its NGO status to being attached to a PHO. NUHS became part of the South East Community Primary Health Organisation (SECPHO) which was one of the first PHOs to establish. According to the Ministry of Health (2005a, 2005b) this PHO uses 'access formula' funding and in 2005 was catering for an enrolled population of just under 10,000 people. This change in status led to NUHS becoming an integral component of the health care system.

\section{Newtown Union Health Service in 2011}

NUHS still aims to provide low cost access, quality PHC to vulnerable populations as it has done for more than 20 years. The patients include unemployed people, low income people often on a benefit, people of all age groups and ethnicities including European, Māori, Pacific, African and Asians (James, 2009; Newtown Union Health Service, 2008, 2009). One interviewee reported that they cater for 45 ethnicities, many of whom are refugees. These patients often have high health needs which frequently include multiple complex chronic conditions.

The service is open seven days a week from $8 \mathrm{am}$ until $7 \mathrm{pm}$ with a doctor remaining on call until 11pm (Newtown Union Health Service, 2010). Clinics include those that have booked appointments and those where patients can just drop in to 'on the day clinics'. With the introduction of the latter the requirement for home visits lessened which was ultimately financially beneficial to the service. Referrals are made as necessary to different members of staff. Two 'outreach clinics' are also held weekly. The following excerpt demonstrates the community focus and involvement and thus the philosophy and reason for NUHS:

It's a way of kind of keeping in touch with vulnerable people you know.

There's a lot of elderly people, a lot of very low income people there, families, young families, so it's a way of just keeping an eye on them, letting them know that we are around if they want to come in. (N2)

NUHS remains funded by a capitation model. The money is allocated from the $\mathrm{MoH}$ which then comes through the Wellington DHB as marked funds for the PHOs (Newtown Union Health Service, 2010). It has various contracts and additional streams 
of funding specifically relating to the low income and high needs populations they serve. The patients are charged $\$ 10$ to see the GP, but seeing the nurse is free. The cost to see the doctor in the outreach clinics is five dollars. Allowances are made if people cannot pay. Pregnant women do not pay for their appointments with the midwives as funding for midwifery services is through the third party payment system from the Ministry of Health via Section 88 of The Health and Disability Services Act 2000 payment schedule and the 'Whanau Ora' contract. The latter is an additional funding stream specifically for low income high needs population.

There is a common belief within the service that NUHS is financially viable although 'money' was seen by six of the interviewees as a stressor on the service. The financial side can outweigh you if you let it, but we haven't let it. A manager believed that if we can't show value for money and how we're managing our funding then we're going to get the funding taken away (M1). He commented that this was particularly pertinent now with the National Party being back in power. Ultimately if you don't play the game on their terms, you'll lose it. It's simple politics!(M1). It was concluded by one MDT member that it's a good model and I think there needs to be more funding and resourcing around that $(S W)$.

Policy changes aimed at decreasing the number of PHOs led to SECPHO merging with Porirua Health Plus PHO in 2010 to become Well Health PHO. Porirua Health Plus PHO had incorporated Porirua Union Community Health Service, or PUCHS which is another union health service that incorporates a midwifery team. The following quote from the SECPHO chief executive depicts their shared philosophy.

By merging we recognize there is an opportunity to strengthen our voice on behalf of those who need lower cost access to PHC. Through our combined network of more than 30 community primary health and social service providers we are well positioned to provide a level of innovation and community development for Māori, Pacific, Refugee, youth and low income populations that larger, more commercial PHOs are unlikely to be as focused on.

(Wellington PHOs, 2010, p. 1) 
A manager in describing this merger of PHOs expressed it was jump before you were pushed under this government (M2). He added it was seen as better to align between like-minded PHOs rather than being forced into bed with Compass (an organisation providing management services to other interim PHOs) (Compass, 2010). According to this manager, the latter kind of merger would not have worked. Relating these changes to NUHS he concluded;

what would be nice is to be able to be supported by a system that recognised the value of how we do things instead of having to fight against a system that is pretty much increasingly tailored at commercial private practice, and big PHOs that are basically companies... we have enjoyed being supported very much by the South Eastern City PHO ... Our PHOs won't save any money by merging, but it ticks a box for the Minister of Health. (M2)

Newtown Union Health Service continues to both thrive and struggle today to maintain its values. One MDT member stated you wouldn't work this way of working unless you're passionate for it (N1). Forty-four multidisciplinary members of staff work for this service. A midwife saw it as a model of integrated PHC, that model of having linked services across not just GPs but allied health, including midwifery (M2). Expanding on this a participant added that it is about the patient being in the middle, whose needs can be met by a whole range of people within one organisation without necessarily having to refer out (N2).

As the service grew, its management became more complex. The Governance Board became more formalised consisting of members of the community, the enrolled patients and the NUHS employees and met monthly to discuss pre-organised agendas. The kaupapa of NUHS, set out by the Board, is informed by the Alma Ata. This philosophy became embedded within the service and remains strong today.

\section{Kaupapa}

Kaupapa, as described earlier, is a Māori word used to describe the philosophy and spirit of the service. Such a word provides a unique New Zealand flavour to the findings. The staff interviewed revealed that the kaupapa was about providing a service to vulnerable families. The kaupapa was seen as a key reason for wanting to work at 
NUHS with its supportive multidisciplinary environment that aimed to make care more affordable and accessible to this population.

The MDT aspect of the kaupapa is commented on by a MDT member. You are treated as a colleague and as a peer here and I think that is part of what the service is about, that is utilising individual skills and making the most of it for the patients really (SW). Some of the staff commented positively that their roles within this service were often more autonomous and allowed greater flexibility than what they could achieve in employment outside the service. One nurse explained that she had always worked in a traditional GP practice. She said you are limited as to what you can do because the GP owned the whole - he owned the patients, he owned the practice... whereas here, nursing, we're doing so much more... we're doing what we were trained to do really (N2). The other nurse added that it probably is a unique model here. I think when you are working here, you just get so tied up in the day to day stuff that you forget that not everybody does it the same and I'm often surprised when I go to meetings and things and talk to other nurses about what we are doing and they're often amazed at what we are doing (N1).

Whilst some staff interviewed appeared to embody the kaupapa of the service, others seemed quite in awe of it as one midwife articulated that a staff member would not last long if they were there just for the 'employment package'.

I think about Newtown Union Health and I think that the philosophical side of it, you grow into it... and as the time goes on you think there's more about the philosophy and you may not necessarily understand it or might not agree with it but I think you kind of grow into it..., it's more than the package... there's something unique and different about the place that keeps you there really or attracts you to it and its challenging, it grows on you, its so dynamic. (MW3)

However, one MDT member predicted that a business like model would be more appropriate in maintaining the longevity of NUHS in the following comment. In the last 12 months the organisation has been driven on a purely philosophical basis... there has not been a real understanding of the business constraints of delivering a service (M1). This manager believed a business model would work well alongside the existing 
kaupapa. Another interviewee spoke on how the word 'kaupapa' was over used and was applied when it suited certain staff.

The word kaupapa...kind of means philosophy....it was bandied around a lot at Newtown Union but it could have been more of a weapon than a tool...as of late if a suggestion was put on the table and somebody didn't agree with it then it was easy to blanket that with....well that's not our kaupapa. What's our kaupapa? Who defines it?, and given that culture is dynamic, not static, how do we allow change....how do we allow it to grow? (MW4)

Nevertheless many of the interviewee's reiterated that NUHS has strong philosophical underpinnings which make it an attractive place to work: The relationships that we have in our multidisciplinary team... are a real positive. We and everyone here have got that philosophy, here in work (MW2). Another MDT member conveyed that there is some research done that shows the value of this model of PHC, both in deflecting patients away from emergency services but also between that interface between primary and secondary care (M1).

As time went by this model of PHC became more widely known and the number of employees within the service grew. The organisational structure then evolved to accommodate the expansion. It's a matrix from hell, on lots of levels, but it works, because we want it to! (M2). The kaupapa is deeply embedded in the structure and highly regarded by most staff. However, in the expanding of the service it does appear that more dialogue could take place about the kaupapa and its day to day application.

\section{Structure}

Initially the smaller service consisted of a very flat structure with collective decision making and consensus. One of the managers commented that it's much easier when you have a much smaller staff like this started as, where the passions were probably more closely aligned (M2). The management structure came as the result of a growing organisation. A middle line of management was added in 2007 consisting of team leaders who were to be a conduit of information sharing for clinicians to and from the manager and the Board. The role of the team leaders also included dealing with any challenges and defusing any tensions that did not need manager involvement. This was seen as the implementation of a hierarchical model. The service had initially prided itself on not having such a model. 
This hierarchy was met with resistance by some staff. A midwife expressed that she understood that Newtown Union became big... in terms of amount of staff...the amount of contracts, but it wasn't big enough to have team leaders because then you become micromanaged (MW4). A MDT member added that the midwives had no team leader and over the last couple of years, that's come in as a structure to make it a lot easier on the manager himself (N1). The managers did see it as a positive change. One manager believed that from an accountability point of view it was good (M1), whereas the other manager asserted that without team leaders we can't operate, you want to manage fortyfour people? (M2). Even with the change in management structure a MDT member asserted we are such a large and complicated organisation now and the structures to support that haven't really caught up $(S W)$. Interestingly one of the managers commented that prior to the introduction of team leaders, team members had the tendency to turn towards someone in particular within their team for guidance. He observed that particular team members took on individual roles without the title (M1). He described this as an almost default hierarchical model. The team leaders constitute what is known as the 'core group'.

The 'core group' is the level of management which makes decisions on organisational issues including strategic concerns, IT, research applications, staffing solutions, incidents and complaints. It does not cover clinical issues. When it is appropriate or required they recommend or refer to the board. As a MDT member mentioned, on some things the Board has to give ultimate approval, not all (D).

\section{Future of Newtown Union Health Service}

Some interviewees commented on the future of NUHS. In justifying the service's ability to remain on the 'landscape', an interviewee noted, that their location gave them a distinct advantage, being over the road from the hospital. One of the managers felt that the more the organisation was recognised, talked about and promoted the better the chances of survival in the long term. He used an analogy to describe this;

a year ago we were an oak on the landscape, you know a number of people said 'you'll still be there'. But we may not be an oak we maybe an elm or we maybe some other plant. Not at the same size, not at the same scale. That concerns me because an oak's a pretty strong tree, a large oak's been around for a couple of hundred years. (M1) 
On a positive note most NUHS members interviewed felt that they belonged to an exemplary practice that could lead the way. There is great potential to show the world...or show New Zealand...how primary health looks...in a community. I don't know how that's going to happen but I still believe in that (M1).

It is apparent that over the last 25 years NUHS has held to its original intentions and produced a service for a low income vulnerable population. It has evolved into a complex PHC service with a particular kaupapa that both attracts and challenges the staff. However, since NUHS commenced, the structure within which the staff work has changed significantly to accommodate expansion in staff numbers.

\section{The Midwives in the Multidisciplinary Team}

Working collaboratively as a multidisciplinary team is integral to the way that NUHS works. The NUHS staff include teams of midwives, doctors and nurses. In addition to these are social workers, a community health worker, and support staff including receptionists, clerical staff and cleaners. Together the staff provide comprehensive and holistic care that includes going into other community institutions such as hospitals and housing agencies, and into patients' homes. Their work includes but is not limited to: refugee health, maternal and child health/immunisations; mental health, management of chronic conditions, sexual health, diabetes, social advocacy and social work (Hefford et al., 2005; James, 2009). One staff member aptly described it as the concept of a 'one stop shop' or 'super clinic'.

All the interviews elicited positive responses regarding NUHS being formed by many different teams of health professionals. The multidisciplinary team works as the axis for the service. One MDT member commented that Newtown Union Health is a really perfect model of intra-professional relationships talking between the disciplines (N1). Another added that it's a strength having the different professionals on board and having these different perspectives $(S W)$.

The MDT members agreed that the midwives were an integral part of a MDT in a PHC service. For a population where it's really hard to access, it's really crucial that you have midwives on board (N2). Another added that Midwives can see things that otherwise we mightn't pick up. They're visiting in homes a lot more, so it's a frontline access, which is a good thing because then they can refer to other services within, the 
social worker for example $(R)$. In stressing the nature of how NUHS midwives work and the importance of them being included in the MDT, an MDT member expressed that a lot of good things are happening out there due to the midwives being on board. Not only one, but a team (M1).

When a MDT member was asked his view on NUHS incorporating a midwifery team, his reply inferred it was necessary. He expressed amazement about how self-employed midwives could provide adequate care for the complex needs of some women without the back up of a PHC service including a full team of health professionals like those of NUHS. Working in a PHO has a big advantage with funding for interpreters etc, how do self-employed midwives manage, when they work with women with little English, how do they access interpreters when necessary? (D).

The interviews revealed that not all team members knew much about each other's professional roles, even though there were occasional presentations to educate each other. Some members found the midwives role difficult to understand, as they were not highly visible at the clinic or always able to make MDT meetings as a lot of their work is predominantly off the site in the homes and delivery suite or they might not be there because they are on annual leave or they have got days off so they are still part of the wider Newtown Health team but just still a bit on the periphery because of the nature of the demands and the hours of work which completely highlights how hard they work (N1). There is a feeling sometimes that the midwives are something else. And that can be mutual but they are very much part of what we do and it's a model that they think works (M1).

All midwives interviewed had positive things to say about working in a multidisciplinary team. They considered that when a lower socioeconomic, complex needs group have instant access to allied health professionals, their care is optimised and it is less likely that those at risk will miss out on care. Access to internal services and those outside of NUHS for this group was expressed as a necessity by the midwives. They felt this was particularly important and valued its provision as part of the NUHS environment. The midwifery team found NUHS to be an interesting comprehensive service where pregnancy was generally seen as a part of life's journey.

GPs returning to care for pregnant women, as had been common in the past, was another issue raised. A midwife noted that we're always aware that there are 2 or 3 
doctors there that are obstetrically trained and would like to do part of our job if they could (MW2). This was topical at the time of interviewing due to a recent change in government and political events. Ultimately it was felt by one of the midwives that they can't because they're just so busy with what they're doing already and they haven't got the time (MW3).

All interviewees supported the midwifery service and saw that it was a necessary part of NUHS. The midwives have a unique model and there are benefits of retaining that (M1). It's [the midwifery model] been the creation of Newtown Union Health, there's always been maternity care. It brings a kind of uniqueness and it's bringing new life into the service and it would be a huge loss to the service and to the women if it went (MW5). Two midwives expressed surprise that no one else was using their model. A MDT member believed that somehow the boat's been missed to capture midwives to be part of that wider primary healthcare sector $(S W)$. This person felt that midwifery is primary care which did not explain why there were only two primary health services in the country incorporating a midwifery team. In reaction to this another MDT member commented it had to kind of be out there...published...to say look this is a different model and it's one that can work (MW5).

\section{Multidisciplinary Team Communication}

Working successfully as a multidisciplinary team requires effective communication systems. Three forms of communication were described by the interviewees. These included direct encounters, via their computer system and through meetings.

Approaching each other directly was talked about favourably by all MDT members and midwives as an optimal way of communicating. Such communication enabled a dialogue with appropriate team members about clinical and social issues which increased the likelihood of a better outcome for the patient. A midwife gave a specific example of this direct communication.

You can just step out of the room. If you've got a client that's got for example fungal toes, you can just pop out and see if there's a doctor available to look. A classic example just recently is the flu vaccinations, swine flu... you talk to them about it... 'this is health regulations and we recommend it' and they say 'oh yeah, when can I get it done', 'well hang on 
a minute, I'll just pop out and see if one of the nurses can do it right now'... you get this ability to catch staff for other health things. (MW3)

NUHS uses an up to date computer programme called 'med tech' to record patient files which all staff members can access which aids interdisciplinary communication. It incorporates an application in which the staff can communicate with each other via 'tasks', or personal messages. Within this system some of the different teams have created templates specific to their speciality. This form of communication is talked about positively by the staff. For example - everyone in NUHS has access to the computer system [therefore] everyone involved with a client should know what's going on $(D, S W)$.

Multidisciplinary team meetings including NUHS Board meetings, core group meetings and the weekly two hour meeting over lunch on a Wednesday were all reported as helpful in communicating with each other. MDT meetings for all staff occur weekly and the staff value these meetings. These meetings are good as we all work different hours, we are all kind of stuck in these rooms, you don't really get to liaise much with others, so it's a good way to touch base with people $(S W)$. All the interviewees stated that these meetings were a good place to discuss issues or concerns around particular clients or families. A MDT member emphasised that other staff have a lot of history around the families and they give input... it is not just an individual approach (SW).

Many other meetings occur at NUHS including each team of health professionals holding their own meetings with each other. The midwives for example, meet on Fridays. An additional child maternal health meeting occurs twice a month. Included in this is the doctor whose focus is in this area, the midwifery team leader and the 'maternal and child health' nurse who is often the first health professional to see the pregnant women. The social worker and community worker are also involved. These meetings discuss all the pregnant NUHS women as this MDT member states; it would be a time to, look you know... oh this woman's coming to you... if there are any concerns or any ways that we can support them. $(S W)$.

A particular aspect of communication is dealing with conflict. The interviewees commented on tensions within the teams and service caused by the many different personalities and passions of the staff but refrained from expanding on the issue. The organisation has processes in place for dealing with conflict which some interviewees 
elaborated on. Initially staff members are to manage tensions between themselves. If this is unsuccessful their team leader is to attempt to find a solution. If no conclusion is reached, the manager then becomes involved. One manager described it when you've got passionate people, skilled people, quite strongly opinionated people working together in a confined space, you're going to get friction. It's normal... a big part of my job is managing the passions (M2). The other manager suggested that one of the strategies for dealing with tensions was having a higher tolerance of different views. The following excerpt uses a metaphor to elaborate on the importance of accepting each others' points of view when working in a MDT.

Somebody told me once that you look from different mountain tops, and everyone is sitting on different mountain tops which is good because their truth is just one truth, there are different perspectives from each other, So its not necessarily what the other person says is true, it's just that no one's wrong. $(S W)$

\section{Choosing to be Part of a Multidisciplinary Team}

The most significant rationale described by all the interviewees for wanting to be a part of the multidisciplinary team was the support they received from each other when dealing with challenging issues. Some members of the MDT expanded on this stating that it was an integrated model where, for example, midwifery is part of the wider health picture. A particular MDT member believed there was a collegial sense of belonging and support $(D)$.

The second most popular reason for working at NUHS was the cultural diversity of the population and the team approach to caring for them. One midwife commented that $I$ was blown away by the diversity of the clientele we had to look after, their life history and humbled by people who had had the most horrific things happen to them (MW1). Another midwife spoke about her particular attraction to the service that came from observations she made from working as a core midwife in the hospital. She said they [the NUHS midwives] seemed to have an interesting clientele, they were very visible midwives (MW2).

NUHS employees are renumerated for providing this model of care with a salaried employment package. Yet many participants felt that for the midwives in particular this was not necessarily an attraction to the service. I don't think it's the dollars, if it was the 
dollars most midwives would practice privately (M1). This was the general feeling among the midwives as well.

It was observed by some of the midwives and MDT members that the type of environment, the complexities of the population served, the team and camaraderie do not appeal to everyone. A MDT member commented that in the past midwives have come for different reasons to what the service operates and they either adapt or don't stay long (N1). Another expressed that some midwives are there for the love (R). She noted the midwives often went the extra mile to give families the support they needed. People could drop off clothes here for babies, the midwives will scoop them up knowing very well which households would like them $(R)$.

\section{Future of Midwifery}

Two factors were seen to threaten the viability of the midwives within the service. These were funding and policy changes. Three MDT members and three midwives specified that there needed to be more funding, resourcing and support for the model to keep working. One of the midwives felt that in the past we have always had highly political activists in our community who have supported us (MW5). She was not convinced that the next generation of young people could be counted on for that sort of activism. It was concluded by this midwife however that we have got generations now of commitment to the service and I think that's a strength. She added that we are known around the country and it's really interesting how within other networks, the Union Health Service is known and I think a small success grows and keeps the things intact really.

Midwives as members of the MDT are fully integrated into the team. All other MDT members saw their contribution as completing the service and found it hard to imagine a service without them. Midwives themselves found working within the MDT particularly helpful in relation to the women and families they attended.

\section{The Newtown Union Health Service Midwives}

The amendment to the Nurses Act of 1977 allowed independent practice and midwifery to emerge as an autonomous profession. With their new found autonomy and statutory equivalence to doctors providing maternity care many New Zealand midwives chose to work independently in small groups as self-employed practitioners. The new situation 
also meant that midwives could practice independently while working as part of a primary care maternal and child health team (James, 2009, p. 66).

By the late 1980s the NUHS team incorporated a midwife, a PHC nurse, a GP and later a social worker providing an 'integrated model of care' to pregnant NUHS women. This was prior to the law changes affecting the midwives so at this stage the midwife assisted the GP with antenatal and postnatal care of women. Together they provided a high level of care for women with high and complex needs. According to James (2009) the midwife loved the team model and being employed. When the law changed in 1990 she began practising autonomously and was supported as necessary by two local selfemployed midwives. One of the present midwives remembers these times.

It was about the $3^{\text {rd }}$ year of the [NUHS] service that the midwifery law change happened, in fact, it might have been earlier than that. I was actually on the steering group and went down to parliament to speak for the law change and I think I was still working for union health then. Anyway,[name] came onboard at that stage as a midwife and the function was autonomous practice and then gradually over the years it evolved in terms of a team. (MW4)

By the mid 1990s NUHS GPs no longer practised maternity care and by 2006 the number of midwives had increased to four. The NUHS midwifery service funding that had been via Section 51 of The Health and Disability Services Act 1993 changed to come under Section 88 of The Health and Disability Services Act 2000. One midwife comments on how she perceives they were seen as a group.

For a lot of years we have just been 'oh the union health service midwives', 'they deal with a rough group of people' and 'they do this and they do that but they are not real midwives and they don't occupy centre space',... centre space has changed and the goal posts have changed and its PHC now and we have been doing it for a long time, we know what we are doing. (MW4)

However, another midwife commented that there's six of us or eight of us in the country employed as midwives in this situation, we actually occupy a really small part of the general PHC service picture. (MW5) 
The values or kaupapa that inform the midwives practice are demonstrated in the way they are with their women and in their team work. Midwives told stories where the women were prioritised and home visits revealed their needs and highlighted the health problems of other family members who could be referred back into the MDT service. Such comments reinforce the family nature of the service.

\section{Team Practice}

In 2007 a significant change was made to the way the midwives organise themselves to care for their women. The change involved shifting from working on a one-to-one basis with each midwife having a caseload of women to working as a team with all the midwives looking after all the women and running antenatal clinics from their rooms. It was noted by a MDT member that when the midwives worked one-to-one with each woman they were less visible at the service than in the present time. The midwives said reasons for the change related to 'burnout' and difficulties in finding and retaining new midwives. The shift in how they organised their work is summed up by the following midwife:

One of the midwives thought there must be a better way to do this, to guarantee us time off because that's the bit that people don't quite get, is the never being off call and that can mean not being able to say yes to a glass of wine or go to a movie. (MW3)

The new way of working required the creation of some form of roster. The resulting roster is described by some of the midwives as being based on the old 'psychiatric hospital' nursing roster. It is a three week roster allowing the midwives two days off a week. It is a different two days each week. If it is excessively busy and because the midwifery team has a finite number of midwives then occasionally midwives have to return from days off to work.

The midwives take turns at being first on call and second on call for the women they look after. The 'on call' responsibility runs in 24 hour blocks. In addition, the midwives alternate between running the antenatal clinic, assisting births at the hospital and doing the home visits on a three month rotation basis. Some women we start to do home visits at 30 weeks, generally it's more like 34, or 36 weeks so, depending on the women, it's a negotiated thing (MW2). If midwives are not busy with their allocation of work they help each other. For example, the home visits might be divided up between the 
midwives who are available to do them that day. To accommodate two days off a week and busy times two midwives provide backup when needed. One midwife commented that I found I was doing a bit of everything which was good in some ways (MW2). All midwives carry a pager which is the number the women call to get the midwife on call. This way of working as a team and helping each other demonstrates team loyalty, an aspect of their kaupapa.

On the whole the midwives seemed to think their unique way of working as a team worked well. One midwife commented the roster is great, fantastic, having that regular time off and paid vacations is brilliant (MW1). Another midwife compared the way they worked to the hospital midwives way of working and expressed that further refinements to the roster would be appreciated. She reflected rhetorically:

Even though we've got the generous weekends, 4 days and 2 days, it's probably not enough. ... nothing stops the fact that when you're that first on call and second, that it interferes with your life and you do think sometimes the 8 hour shift that the core midwives do... and you see them going off at the end of day when you're still there..., and you know you're going to be there for the next 24 hours, you just think 'bugger, is it finished yet? (MW5)

Although team practice was seen as advantageous one midwife missed the one-to-one approach that encourages continuity of carer. This midwife also felt that some of the women they provided care to also favoured the continuity of carer approach more. $I$ think it's because you've delivered their other babies, they've come to the team but they're still hoping to get you, even though they know they might not get you and then the next person becomes their favourite person (MW1). This demonstrates that even working as a team, some midwives can still develop a special bond with certain women and their families, wanting to see their care all the way through and likewise the women can also want care from certain midwives in the team.

In view of the particular population of women the midwives care for they believed that it was an advantage working as a team. Support from each other as well as working with a MDT on site, with whom they could talk directly and refer to as necessary, was considered important. A negative aspect of working as a team and rotating through the different areas of practice every three months was the potential to result in a midwife 
assisting a woman in labour she does not know. One midwife discusses this concept. It's about continuity of care and continuity is seeing the women, even though the team sees them, I mean it's very rare, like just before I went off I said to the girls, it's really lucky that *** hasn't delivered, I said, because I actually haven't met her the whole way through (MW2). A MDT member noted that when she receives referrals from a member of the midwifery team, that midwife might not be on when she comes to deal with it, in which case she consults their team leader. This member expressed that it then relies on their team communication for the original issues not to be missed.

The midwives provide continuity of care and attempt continuity of carer as best they can. Continuity of care is dictated by their organisation and the team's philosophy and the protocols, policies and guidelines of the hospital where they attend the births of these women. Continuity of carer is provided in that the women will meet all the midwives at some point in their pregnancy and postnatal period. One of these midwives will attend their birth. The care of these women is discussed weekly where all midwives are alerted to any significant issues the women have. However, as seen in an above comment, there was one woman not known to all the midwives. This could be related to the woman registering for midwifery care at a later stage in her pregnancy or not attending many of her appointments. Continuity of carer by one midwife for one woman throughout her pregnancy is not achievable in the current structure.

\section{Relationships with Other Midwives}

The NUHS midwives felt that their relationships with other local teams of selfemployed midwives were satisfactory. Competition for women was denied. In fact, two of the NUHS midwives said they often referred women to the other groups of midwives when they had reached their maximum number of women per month. It was not known if this was reciprocated.

All midwives believed the relationship was also good with the staff at the hospital where they hold access agreements to attend their women during birth. Three believed they were well respected, one said they seem to be pretty positive about us, and another thought they were quite happy with us. A third perceived they realise we work hard. Nevertheless there was a 'problem area' expressed by three of the midwives. It was thought at times that they were let down by the hospital. This was to do with a breakdown in communication with the hospital referring women back to the midwives' 
care after they had had been referred to them or after the women had been discharged from hospital care. Issues they described pertained to 'lack of reports or notification' and the assumption that the midwives would want to have these women back for the postnatal period when the original relationship had ceased much earlier.

Two midwives talked positively of how they are often approached by other midwives and doctors for their expertise and experience in caring for women of different ethnicities and diverse cultural backgrounds which is acquired from working at NUHS. However one of the midwives felt that some self-employed midwives thought that NUHS midiwves should be looking after all of these women. It was almost as if there was this expectation that they were ours somehow (MW2). She felt however that this view had eased a bit since the introduction of the 'primary team' [at the hospital]. The 'primary team' was set up at the hospital to cater for women in the community with low risk pregnancies who could not find a self-employed midwife to care for them. It is run by either a group of specifically assigned hospital midwives or all midwives are rostered and rotated through this area.

Three midwives expressed with pride the role the NUHS midwives had assumed as educators. One of the midwives uses her knowledge and specialist expertise in holding workshops on 'female genital mutilation' and 'domestic violence' which are well attended by other midwives and health professionals. Two members of the MDT also spoke highly of these sessions. These are issues that the midwives encounter in the families who seek care from NUHS which other midwives seldom encounter. Because of this certain midwives have been interested enough to develop added expertise on these issues and share this with others.

The kaupapa of the service is embedded in the way the midwives work and is demonstrated in their way of being with families and being with each other as a team. In recent years they have structured their work to have a team focus, regular time off and remain in a particular practice area for three months. With this change came a complex system of rosters. Amidst this the midwives retain a women/family centred approach in their care. 


\section{The Women in Care of the Midwives}

The women who seek midwifery care at NUHS come from two main groups. The major group is from families already enrolled at the service. The second group are from women outside the service who seek out NUHS midwives. According to the midwives the NUHS enrolled pregnant women comprise $50 \%$ of their workload. These women are described as coming from low socioeconomic backgrounds with complex needs which is consistent with the purpose of NUHS. A MDT member commented that this group is a seriously dynamic population including refugees with trauma in their background $(S W)$.

The second group of women are referred to as 'casual clients' by the midwives. They are not enrolled with the NUHS and do not access other services within NUHS. These women have contracts with the midwives for their pregnancy, birth and postnatal care only. One midwife stated that 10 to 20 percent of these women came from other services within SECPHO and were women living in poor circumstances. A midwife described the remaining 30 percent of this group of women being at the other end of the spectrum living in more affluent areas and of a higher economic status (MW1).

The interviews elicited many reasons as to why the midwives care for this second group of women. These included the national midwifery shortage alluding to the idea that it was not so much a choice but whichever midwife a woman could get. This was seen as mutually beneficial for the midwives when they had spaces available to take these women as it in turn assisted them to meet the monthly quota they required. One midwife commented that they were attracting some local celebrities and believed this to be because the service and its midwives had a good name and reputation. It was further suggested by a midwife that their midwifery services were sought after by some of the non-European pregnant women due to their experience of caring for women from many cultures. We are approached by particular women including 'Indian, Phillipino, the Irish and those from the UK' because they recognise or hear about the diversity of cultures and tend to come towards us (MW2).

The contrast in the socio economic status is depicted in the following midwife's experience. 
They're [the second group of women are] well informed, a woman recently asked; could she go to a pop concert, at 8 weeks, would that affect her baby, the sound, so when you get a question like that it's very serious, it's very sensible, it shows the woman's thinking and caring about her unborn child. But it does put it in stark contrast to the woman who has been beaten, who's got no food in the cupboard, has 3 kids under foot and facing eviction. So [each group of women's] needs differ and [their] context set them apart and every concern is real. (MW5)

While it is well documented that the NUHS women were likely to have issues with lack of money, food and transport, domestic violence, drugs and alcohol and Children and Young Persons Service (CYPS) involvement, the women of higher socio-economic status were found by the midwives to have just as many problems but of a different nature. Issues described included isolation, lack of support and difficult transition to parenthood due to expectation versus reality. It was often said by the midwives that for the NUHS women, the pregnancy was just another thing going on in their life whereas with the more affluent women the pregnancy was the only thing going on in their life (MW2).

Occasionally the women registered with NUHS choose to go elsewhere for their pregnancy care. No statistics could be ascertained from the data on the percentage of these pregnant women who choose not to use the NUHS midwives. Reasons were assumed and varied. One midwife wondered if with their social background, they're actually trying to escape Newtown Union who know all of the ins and outs of their care (MW4), whereas another MDT member suggested some women liked to have midwives from their own cultures. However, this participant spoke of her daughter choosing NUHS midwives because it was in line with her own kaupapa. The GP interviewed articulated that when a woman chooses to go elsewhere for midwifery care, her care is fragmented, miscommunication can occur and when the women return to the service after the completion of their pregnancy care, it is like a 'gap' in their overall care. This was seen as unfortunate in view of the diversity of women NUHS midwives care for, in particular those with minimal English.

The diversity of those women in the midwives care is evident when the midwives see the women in their homes for an antenatal or postnatal visit. Here they obtain insight in 
to the diversity of cultures, values and the vast range of socio-economic status. The women and their homes become great learning environments for the midwives who held the belief that the home visits were where you get the laughter and the fun of knowing these women (MW3). One particular midwife provided an insight into the diversity of cultures and economic status of the women by the hospitality they provided on a day of home visits. She described having apple tea with an Iraqi family, a cup of chi with an Indian family and by the end of the day had also consumed a cup of regular tea and a herbal one as well. It's really interesting how when you walk into the homes [where] the distinct flavours [are evident] and I always used to say that, I can see what kind of cups of tea I'm going to be offered today and you pick your cups of tea, when you feel like drinking chi today (MW5). An observation that another midwife made was that often those with the least offer the most. You know there is very little in the cupboards, but that's their offering... it's a really important part of dealing with women $(M W 1)$.

As there was no direct input from the women who used the NUHS midwives an unpublished exploration of their feedback forms has been used. Stienmetz (2011) studied routinely collected consumer feedback forms from 2006 to 2010 of women who had used the NUHS midwives services throughout this time. These feedback forms requested material of what the women saw as strengths and weaknesses of the model and suggestions for improvements. This research found that consumer satisfaction for the midwifery service was high with strengths outweighing the weaknesses. Notably one of the strengths listed was 'having a team of midwives' with 'good collaboration'. However, it was acknowledged that the feedback forms were limiting and the overall return rate was low. According to Stienmetz, a positive outcome of the research was that a new feedback form was designed resulting in an invaluable tool for any further research on this model.

\section{Summary}

The model of midwifery care is integral to NUHS which arose out of the Newtown community's need for a PHC service designed to meet the health care needs of low income people. The community of Newtown still retains a population in need of low cost PHC but now NUHS serves low income people from other suburbs as well. The enrolled population is ethnically diverse. The service has a family approach and is open 
to people of all ages who often have high risk complex and chronic health conditions. It is now run by a Board that consists of the staff, patients and members of the community. It is a non profit service which began as an NGO but became part of a PHO when this system was introduced in 2002. NUHS has remained open over the last twenty five years and has expanded amidst radical changes to the New Zealand health system. Today it is a PHC service with forty four members of staff working in a semihierarchical structure with a manager and team leaders in each of the different disciplines.

NUHS as described above is not unique. There are other PHC services similar to this, both locally and nationally including ten other 'union health services'. What makes this service distinctive is the addition of the midwifery team. To my knowledge there is only one other service like this in New Zealand and as one MDT member said you have a very fragmented approach to health care if you didn't include midwifery (M2). The midwives were attracted by the established MDT practice, its kaupapa and the cultural diversity of the women.

The NUHS model of midwifery care is shaped by the features and kaupapa of the larger service in which it is embedded. As such the midwives are given all the benefits of the service. They relinquish direct funding for their work and are required to take an active part in the functioning of the MDT. Moreover they are accountable to a manager and a Governance Board. Nevertheless the midwives have designed the organisational details of their work which has changed over time to fit both the needs of the women and themselves.

The model of midwifery care as expressed within NUHS is distinguished primarily by it strong kaupapa or philosophy, its embeddedness within a comprehensive PHC service, by the nature of its relationship within a MDT, by the way it is organised and its employment status. The next chapter discusses these findings in relation to this model's distinguishing features and its relationship to other national and international models. 


\section{CHAPTER FIVE: DISCUSSION and CONCLUSION}

According to Stake (1995) a case study always produces a unique view of what is studied because it is a personal construction within a particular moment in time and includes all the personal, social and political happenings going on at that time. Thus the case is wholly unique. Nevertheless, a close inspection of the NUHS model identified that it has distinctive features but also has several features similar to other midwifery models which will be drawn out in this discussion. The distinctive features of the NUHS model of midwifery care are discussed in the first section of this chapter. The second section addresses the relationship of the NUHS model of midwifery to other national and international models of midwifery. This chapter closes with a reflection on the research process and a concluding statement to the research.

\section{Distinctive Features of the Model of Midwifery Care}

The distinctive nature of the NUHS model of midwifery care in relation to the literature set out in Chapter Two on PHC and on models of midwifery care emerged from a 'to and fro' process of determining what was similar and what was distinctive. The most distinctive features that emerged from this process were the model's situation in the service kaupapa, the union influence and midwifery as an integral discipline in a multidisciplinary team.

\section{Kaupapa}

As the NUHS midwifery team is embedded in a PHC service, it is influenced by all that goes on in the whole service. Midwives then, have become embedded in the kaupapa of the service which provides the philosophical underpinnings of their practice. It is most evident in how they interact with the women whom they attend, how they collaborate with their own team members and with the MDT. The kaupapa of the service essentially comes from the PHC philosophy which informed the origins of this service and is still practised today. The service adheres to primary care and its principles as outlined in the WHO's definition of PHC, Alma Ata Declaration, Ottawa Charter and the New Zealand PHC Strategy (King, 2001; World Health Organisation, 1978,1986). It follows the key principles of PHC from the Alma Ata Declaration: availability, accessibility, affordability and appropriateness for their high needs population. Low charges and sometimes no cost for services demonstrates availability and accessibility in their seven day a week service. Their position in the community and the 
establishment of out-reach clinics further promote availability and accessibility to the population they serve. In addition, NUHS also provides booked and drop in appointments at its three sites as well as home visits when necessary.

NUHS serves a large and diverse ethnic population. A midwife describes evidence of the cultural diversity in drinking different types of tea offered by the women of different cultures she had visited in a day. This midwife commented that it was at these home visits, sitting with the women, that she particularly learnt about who they were and how they lived thus learning about their culture and what was important to them. The information gathered from these encounters was then shared with the MDT when appropriate. It is the midwives then that assist the MDT in building up a culturally appropriate service.

As Matheson says "NUHS has kept the vision of PHC alive, and influenced the direction of the nations health services" (James, 2009, p. 10). Matheson, in writing the forward to James's book, states that implementing the Alma Ata in many countries proved difficult and goes on to say that "NUHS stands out both locally and internationally as an exception to this. It has consistently explored and developed a practical approach to delivering on the hopes and aspirations of the Alma Ata declaration" (James, 2009, p. 9). The practice of the PHC principles are particularly important in addressing inequalities of care which was a founding premise for setting up the service.

NUHS, its kaupapa and the work of Health Care Aotearoa (where NUHS has a representative) were instrumental in the shaping of the New Zealand PHC Strategy. This Strategy (King, 2001), now informs the organisation and delivery of all New Zealand PHC services to achieve six specific key directions which are now PHO requirements (2001). Consequently the PHC Strategy reflects what NUHS and its kaupapa initiated.

NUHS was one of the first PHC services to be part of a PHO. At the onset of this research, NUHS belonged to SECPHO where their kaupapa was felt to be well supported. However, two years later, at the time of completion of my data gathering, SECPHO merged with another PHO called Porirua Plus. This merger was not without challenges and tensions. It was felt that the merger would create a large PHO that could interfere with practising their kaupapa because business concerns would take priority 
over meeting the needs of their population. However Porirua Plus was a like minded PHO and it was hoped that the NUHS kaupapa would not be threatened. In the present state of flux of New Zealand health services with their business orientation and cost cutting mentality, maintaining a genuine PHC focus as set out in the Alma Ata Declaration (World Health Organisation, 1978), the Ottawa Charter (World Health Organisation, 1986) and the New Zealand PHC strategy (King, 2001), appears to be under threat.

The midwives value the access the women have to the service. The women enrolled at NUHS and other services within SECPHO are from a population that often only receive minimal antenatal care which can increase the morbidity and mortality rates of this high risk population. However, the NUHS midwives, by providing midwifery care at their clinic, the women's homes and the local hospital have achieved similar outcomes to other New Zealand midwives, whether practising in the hospitals or in self employment (Midwifery and Maternity Providers Organisation, 2008, 2009).

Community involvement in the organisation of PHC services is recommended in the Alma Ata Declaration (World Health Organisation, 1978) and the Ottawa Charter (World Health Organisation, 1986). In NUHS this is demonstrated by a community Governance Board which has representation from community members, patients and staff (Regan \& Clarke, 2007; Ryall, 2009). In fact, anyone from the community served by NUHS can make submissions to a Board meeting. The service covers a large geographic area and a mixed cultural population that is divided up into smaller communities which are represented at Board meetings. "Each member is expected to provide feedback from their community on experiences that their communities have had with the service, significant events for the communities and ideas for improving the service to its community" (Regan \& Clarke, 2007, p. 46). However the multiple voices on this board reflected the group present and not necessarily everyone from that culture within the community. It appears to me that community involvement in the organisation of the service adheres to the Alma Ata Declaration and the Ottawa Charter. Nonetheless multiple agendas within different cultural groups and within the community can make it challenging to have full representation.

Overall the staff are committed to the kaupapa. This is expressed by a midwife in $I$ think that the philosophical side of it, you grow into it... and as the time goes on you 
think there's more about the philosophy and you may not necessarily understand it or might not agree with it but I think you kind of grow into it ... there's something unique and different about the place that keeps you there. NUHS presents as an organisation deeply embedded in both international and national PHC philosophy but its day to day operation is an ongoing challenge as the service grows in its complexity. An indication of the challenge of keeping NUHS running is the four changes of permanently appointed managers during the time of this research. This complexity is also reinforced by a participant who commented that the service kaupapa was sometimes used in a controlling way. She found this difficult as she believed there should be a more open approach to permit the philosophy to be well understood and to allow for its growth.

For the needs of the population to be met, the service had to expand both in the number of employees to cover the growing population, and in its organisation of MDT members into teams with a team leader. The latter was a structure seen to aid management and was greeted with mixed views. With this growth, dynamics changed and the potential for tensions became evident. Noteworthy was a manager's reference to 44 passionate members of staff which inevitably resulted in challenges and at times tensions. It is human nature that all teams have tensions. There is little research on self-employed midwives, their teams and any conflict within, however in my experience it exists. A strength of this research is that personality tensions were disclosed in the interviews and not hidden away.

\section{The Union Influence}

The union influence brought NUHS into existence and 'union' remains central in its name maintaining that influence and demonstrating to the wider health system its prominent role in NUHS. There continues to be a union member on the governance board who is kept up to date on the changing context and who contributes to all the high level decisions made by the board. These decisions affect NUHS engagement with the Newtown community and all contractual, management and quality performance measures. All staff members are asked to belong to and fund membership to unions which give them an external channel to the governance board for grievances if this is ever needed. Further, unions are involved in the negotiation of pay rates and working conditions for all staff. Nowhere in the international literature I have read is there talk of union initiatives in health care with an integrated midwifery service. 
In the 1980s in New Zealand, the principles of PHC according to the Alma Ata Declaration (World Health Organisation, 1978) and Ottawa Charter (World Health Organisation, 1986) were beginning to be embraced in small ways in the health system. At the same time the Unions were concerned about the costs low income people incurred at most GP practices. NUHS, which was planned in the latter half of the 1980s and came to fruition in 1987 brought together these two movements. Hefford, Crampton and Foley (2005) discuss how the timing of NUHS beginnings was significant as basic Alma Ata principles were not being met for many of their identified population. The unions embraced the Alma Ata principles as they wanted to fund a health service that focussed on wellness which they believed would be beneficial and cost effective for their families. The Alma Ata saw midwifery as a critical component of PHC.

The context of 1987 was different to today. It was a struggle for the unions to set up NUHS in drawn out negotiations with the Minister of Health; the setbacks that occurred, the shift in mindset and the risks involved required to initiate and fund a service and form a NGO. There were no precedents for them to follow. Without this struggle it would not have come into being and it seems that the struggle has become a legend within NUHS today, influencing their new struggles to maintain their identity and kaupapa. One participant talked of the activism that arose in the community in recent times when there have been threats to the service's future and kaupapa. It is significant that the service has survived many changes in both government and in health service restructuring and remains in operation today.

Midwifery has been integral to NUHS since its early times. It is possible that the Union influence attracted some midwives but also likely that some midwives responded to the challenge of working with the NUHS families who were union families and beneficiaries. Another possibility relates to some midwives choosing an employment package over being self-employed while maintaining their independence in practice. The union influence in setting up NUHS gave midwives another option for the way they organised practice within employment.

\section{Midwifery as an Integral Discipline in a Multidisciplinary Team}

The multidisciplinary team is the core of NUHS. As King (2000, p.18) states "no single practitioner or type of practitioner can meet people's needs completely". Such a MDT working together provides a comprehensive family service that meets the requirements 
of the PHC strategy (King, 2001). This comprehensive service is referred to positively by one interviewee as a 'one stop shop'. Although a one stop shop is generally talked about in PHC as a positive attribute, this concept does not appear to suit all pregnant women registered with NUHS. Some of these women chose to have their pregnancy care elsewhere. When this happens, it suggests that some women value privacy over integrated family care available from NUHS. Although this was recognised as the right of all NUHS women the MDT saw there was a breach in the connectedness of their care.

Working in a MDT was advantageous for midwives choosing to look after this population. The NUHS population generally have complex social and health conditions and getting an appropriate member of the team involved in particular issues within one visit means a timely intervention can begin. Further the MDT member referred to is likely to already know this family. One NUHS midwife expressed that it's so handy being able to go down the hall and knock on the door of the health professional you need $(M W 1)$. This view was echoed by the MDT. Such timely access to appropriate input from other disciplines is not necessarily available to self-employed midwives. One MDT member expressed amazement that self- employed midwives working without the back-up of an MDT that could provide adequate care for the complex needs of some women. Self-employed midwives would certainly refer a woman with particular issues to the appropriate service but this may not be accessible to their women in such a timely fashion due to cost or other family demands. As one midwife stated pregnancy is only one part of these women's lives. It was felt by the NUHS MDT members that it was imperative to include midwives in their team. Therefore as recommended in the Alma Ata Declaration (1978) a functioning MDT like NUHS is more likely to successfully meet the needs of a high risk population.

Midwives are not an integral part of PHC teams which have developed since the implementation of the PHC Strategy (King, 2001). In this strategy, midwives and pharmacists are mentioned together as being a necessary part of a collaborative multidisciplinary approach to achieving good PHC. It appears that these two disciplines were not expected to be part of a team within a PHO practice but would make their contribution from their independent positions. In most PHOs, there is still an adherence to GP-owned practices which continue to employ other health professionals. Midwives became independent of GPs ten years prior to the implementation of the PHC Strategy 
via PHOs. Midwives at that stage had gained equivalence to doctors and chose to remain independent except in models like NUHS where GPs and midwives are both employees.

NUHS has a long tradition of all MDT members functioning from an equal powerbase i.e. they were all employed, however some were paid different salaries, but each disciplines' contribution to the patient's care was seen as equally important. They either made the decisions independently or communicated with each other to achieve the best outcome. No discipline was seen to be in charge of the other. This is important because historically PHC was predominantly provided by the GPs who owned their practices and employed their staff and were able to charge a fee for the service they provided. In this situation, the GP was responsible for all the care given by other disciplinary members who s/he employed and therefore was the main decision maker about all care. I believe that the equal power base was an attraction for the midwives to work as NUHS. They had already gained their independence so were unlikely to want to be employed by a GP.

The MDT has an active role in the welfare of NUHS. The financial and policy situation of the service is made transparent at Governance Board meetings where all members of staff can participate. They are expected to take a responsible part in any planned changes, community and staff issues and finding solutions to any problems that emerge. Within this structure all team members have an opportunity to have their voice heard in the running of NUHS and planning for its future. Midwives as members of this MDT carry this extra responsibility which is not expected of self-employed or hospital midwives. The NUHS midwives must also listen and accept contributions from other MDT members when these are offered. The transparency of these processes result in all members of the MDT being accountable for the survival of the service.

Functioning as a MDT requires that each member puts time into many levels of communication. This means much one-to-one discussion and the attendance at many meetings. However, taking part in much of this communication is not always possible for the midwives who are out in the community with their women or at the hospital attending deliveries which can be at any time of the day or night. This is further exacerbated by the midwives rostered time off which can occur on weekdays when most meetings take place. It is the role of the midwifery team leader to represent the 
midwifery contribution at the meetings. However this does not overcome the ‘invisibility' of midwives experienced by some team members.

In summary the three distinctive features discussed in this chapter demonstrate that the NUHS model of midwifery care has its own special character. Its kaupapa is informed by the international documents on PHC and it is described as having been true to what the documents describe as fundamental PHC throughout its existence. These documents recommend that PHC be given by a MDT and that midwifery is a component of PHC. These elements come together in the NUHS MDT to provide an integrated service. Further, NUHS initiated and has maintained an equal power base between all disciplines. The union influence is unique to NUHS and its history. All staff members of NUHS work together to meet the needs of patients, women and their families. As stated by James "to develop a model of true PHC has been satisfying. To see communities become empowered, to act and change, is inspiring" (James, 2009, p. 23).

\section{The Relationship of the Newtown Union Health Service Model of}

\section{Midwifery Care to other National and International Models of}

\section{Midwifery Care}

The NUHS Model of midwifery care is a distinctive model both within New Zealand and internationally. I will now outline the relationship of the NUHS model to other models in New Zealand and internationally. To give structure to this outline I will restate my description of a model of care as set out in Chapter Two. The key elements of this description are then used to demonstrate similarities and differences of the NUHS model in relation to other models. The description reads as follows:

A model of midwifery care embodies guidelines and policies for the provision of care to women and their families. Such a model includes the structure of a service designed by a group and the way it is funded. It can be set within a larger organisation which can be broader than the work of midwives. Where this occurs such an organisation will influence in overt or covert ways how midwives arrange their work and practice. Midwifery practice then either takes its values from the larger organisation or if the structure permits creates its own particular philosophy which shapes the interactions with women. A mixture of these combinations can exist. 
In terms of this description the NUHS model is set within a larger organisation. The philosophy and much of the structure is determined by this broader organisation. This includes the women and their families, to whom the midwives provide care, predominantly being from within the service or a like service. A specific amount of funding comes via the $\mathrm{MoH}$ and $\mathrm{DHB}$ which is specifically nominated for the midwifery service. However the funding goes directly to the service and the midwives are paid salaries. Although the kaupapa of the service influences how the midwives interact with the women they have been free to determine how they organise their team and their day-to-day way of working. They have the autonomy of practice under the New Zealand legislation governing midwives. Their way of working involves moving around specific areas of care on a three month basis and regular rostered days off. Midwives maintain continuity of care within their rostered time off system and attempt continuity of caregiver by having all midwives know the women via meeting them in the clinical situations and having meetings to discuss them and in documentation. This organisation of their team means that the midwives assist their women to give birth in the hospital settings. They do not generally facilitate home births.

The following discussion is limited to recently developed examples of midwifery that fit within the mainstream approach that is fostered within these countries. It excludes the private models that exist in the UK and Australia. The international shift to new models that began in the 1990s emphasised continuity of care as a central philosophical tenet of midwifery care.

\section{New Zealand}

The New Zealand partnership model provides the philosophical basis of most New Zealand midwifery. Guilliland and Pairman (1995) created this theoretical model which can be described as a philosophy grounded in practice. The main philosophical tenets are women centred care, continuity of care, belief in normal birth, equality, reciprocity and negotiation within the relationship (Guilliland \& Pairman, 2010). In this model continuity of care is achieved by stressing continuity of care-giver which necessitates that midwives take responsibility for one woman's care throughout the pregnancy, birth and postnatal period. Part of a woman's choice is to have a hospital or a home birth. Some groups of self employed midwives focus predominantly on a home birth service. 
The partnership model (Guilliland \& Pairman, 1995, 2010) is a different way of organising practice than is evident in NUHS. The philosophy in the NUHS model is primarily governed by their kaupapa. Nevertheless I believe that the NUHS midwives value normal birth, equality and reciprocity within the relationship they have with their women wherever this can be achieved. However, their primary focus is to provide a high standard of midwifery care to their group of women who may not otherwise receive it. The authors of the partnership model argue that their philosophical approach is an inherent ethical approach. Although an ethical approach was not mentioned by NUHS interviewees it is inherent in their kaupapa. From my experience it can take up to a woman's third or fourth pregnancy before the trust in the relationship/partnership has been gained. Griffiths (2002) sees these women as 'wary' and often with 'huge problems' which would be factors that interfere with a reciprocal relationship. In contrast, trust is generally achieved more rapidly in the partnership with more educated middle class women who are used to more choice in their lives. Skinner (1999) also found that women in lower socio economic groups were less able to enter into a reciprocal partnership due to their social circumstances.

Unlike the NUHS model embedded in the larger service the partnership model (Guilliland \& Pairman, 1995, 2010) sits within the structure of self-employed midwives. Within this structure the partnership model can be practiced in its purest form with continuity of care provided through continuity of care-giver. Although NUHS, in the past, has practised continuity of care via continuity of care-giver they made a change four years ago because it was believed that the midwives were becoming burnt out and recruitment and retention of midwives to the service was proving difficult under this way of organising their practice. Like self-employed midwives, NUHS midwives are in control of organising their day-to-day practice. While NUHS midwives have presently organised their practice as a way of avoiding burnout and attracting and retaining midwives, self-employed midwives organise their practice differently in relation to their philosophy.

The self-employed midwives are funded directly in relation to the number of women they care for whereas NUHS midwives receive a salary irrelevant of the numbers of women they care for. Both self-employed and NUHS midwives do control the numbers of women in their caseloads. While self-employed midwives can choose what women 
they book into their care NUHS midwives must give top priority to those already registered within the service.

While the emphasis in Guilliland and Pairman (1995) is on the partnership as a practice model, Guilliland and Pairman (2010) do use the term 'the partnership model of care'. In this second edition these authors see the self employed structure as integral to the partnership model. In this way the partnership model fits better with my definition of a model care than when the emphasis was only on practice.

Hospital or core midwives in New Zealand are challenged when endeavouring to practise the partnership philosophy (Wynn-Williams, 2004, 2006). This is due to the structure of a hospital setting. Through the allocation, wherever possible, of one midwife to the same woman over each consecutive day that the woman is in hospital an attempt is made to provide continuity. NUHS and the hospital midwives are similar in that they work to a roster to cover the 24 period, rotate through the different clinical areas and are paid salaries by the organisations for which they work. Nevertheless NUHS midwives have control over their roster. The NUHS midwives work as a team to be responsible for the women they care for over the 24 hour period and one midwife can work up to twenty four hours at a time. In lieu of this they get eight weeks annual leave a year whereas the hospital midwives get four weeks annual leave a year but work no more than 8 or 12 hour shifts. Hospital midwifery in the United Kingdom and Australia is similar to that in New Zealand and therefore the similarities and differences to the NUHS model are the same.

\section{United Kingdom}

In the UK the main tenets of the midwives' philosophical approach are 'continuity, choice and control' for women and the view that pregnancy is a normal life event. These are set out in the Changing Childbirth document (Department of Health, 1993). As such, they came from a national perspective or 'top down' which led to policies that enabled new models of care to be set up in numbers of different situations where this philosophy could be practised. These new models were called by different names: oneto-one midwifery, case loading midwifery and team midwifery (Benjamin et al., 2001; Homer, Brodie, \& Leap, 2008; Flint, 1993a; Flint, Poulengeris, \& Grant, 1989 Bates, 2004; McCourt et al., 2000; Reed, 2002a, 2002b). 
These models are similar to the NUHS model in that these midwives are employed and subject to the policies of the employing organisation. However, the NUHS midwives take their philosophy from the kaupapa of their service and work with a MDT. It also appears that the UK midwives, like the NUHS midwives, organise their day-to-day practice and maintain continuity of care within their rostered time off system. They endeavour to maintain continuity of caregiver within their team. Continuity of care is imperative in the UK philosophy and in the 'know your midwife' schemes they endeavour to achieve continuity of caregiver as well. However, in both NUHS and the UK system some organisational facets interrupt this at times. All the UK groups have small differences in their structure but generally an on-call system over night is part of their service. The latter is similar to the NUHS model. Both the NUHS midwives and these UK midwives receive salaries from particular funding streams in their organisation. The autonomy of the NUHS midwives practising under the New Zealand legislation is greater than that of the UK midwives. Moreover NUHS midwives are members of a MDT.

\section{Australia}

In Australia there is no state or national document instigating changes to the philosophical approach of midwives. Hospital midwifery remains the dominant way of practising. However, with the international shift there was a groundswell among midwives who wanted to improve midwifery care. It was a 'ground up' initiative similar to the partnership model in New Zealand (Rowley, Hensley, Brinsmead, \& Wlodarczyk, 1995). The goal of the shifts that did occur in Australia was to improve women centred care by offering more choice, continuity and control and promote pregnancy as a normal life event. To achieve this, particular teams were set up and attached to hospitals (Cornwell et al., 2008; Homer, 2005; Rowley et al., 1995; Walker et al., 2004).

The Australian team models are similar to NUHS in that there is a team approach with an emphasis on continuity of care. Wherever possible in Australia efforts are made to provide continuity of caregiver within the structural constraints. This is not attempted in NUHS. NUHS and Australian models have systems for the women to meet all the midwives. Both models work to a roster however NUHS' embodiment of the service kaupapa and its position within a multidisciplinary team is quite different. Like NUHS the Australian teams mainly organise their own practice. The midwives in Australia and 
NUHS are paid salaries by the services that employ them. Further NUHS midwives' practice is different in that it also has more autonomy under the New Zealand legislation. Midwives within the NUHS model and Australian models attend the birthing of their women in hospitals.

In summary all the national and international models discussed have particular philosophies, structure, organisational and funding mechanisms. They meet the description of a model of care as set out at the beginning of this discussion. The philosophies have many similar facets but the structure in which they are embedded and the funding mechanisms differ in relation to whether they are attached to specific organisations. The kaupapa of NUHS midwives is different to all other models. The self-employed midwifery model of New Zealand is the only model not attached to an organisation. NUHS is attached to a PHC service and the UK and Australian models are attached to hospitals. Being situated within an organisation brings with it both advantages and disadvantages which affect the midwifery care given.

In all these models ways of organising practice vary. Within NUHS alone the organisation of their day to day practice has changed over time and could change again. Their present organisation came out of specific events and developed as an attempt to retain the midwifery service which could have been lost. Threats to the closure of the midwifery service could arise again which may require another reorganisation of their day to day practice. Nevertheless I believe that the findings of this research show that having midwifery as an integral discipline in a multi disciplinary team in a primary health care service is a very valuable feature.

\section{Reflections on the Research Process}

Stake $(1995,2000)$ and Yin's $(2003,2008)$ case study method was appropriate for this research. It specifically allowed different expressions of context to emerge in the research. These contexts included the social, historical and political context of NUHS, the context that the interviewees who contributed to the findings brought to the case and the context that I brought into the research with prior experience of working in a similar service.

Although I have no doubts that case study was the most appropriate method, the process of its implementation was both complex and time consuming. Even though this is a 
small case study it required great effort and persistence to achieve the outcomes described in this report. As a small case study it makes a small but significant contribution to the literature on models of midwifery care. Both the data gathering and organisation of the findings were the most time consuming aspect for me of the case study method, taking much longer than I anticipated. This was due to my status as a novice researcher, the busyness of all the interviewees and my own busy work schedule as a self-employed midwife. A qualitative survey, for example, would have been a less time consuming way of collecting data. If I had been a full time researcher I believe the whole process would have been much smoother.

I learnt that implementing a study design can appear achievable on paper but can be challenging to achieve in reality. Nevertheless one advantage I had was in not having to search for participants as once the service gave me permission to carry out the study key people helped me to contact the interviewees. I came very close to not obtaining the interviews with two key people. I believe that without these the breadth of the study would have been reduced. Upon reflection, although my access to the midwifery interviewees was relatively smooth, it was much more difficult gaining access to the seven MDT members. I have wondered if access to the interviewees would have been easier if I had been better known to the organisation, for example, a past employee or if I had spent more time at the service making myself visible. 


\section{Concluding Statement}

This research has described the NUHS model of midwifery care using Stake (1995, 2005) and Yin's case study method $(2003,2008)$. Data were gathered from interviews, documents and logbook entries, and was analysed to produce the findings that are set out as the NUHS model of midwifery care. The main headings used to describe this model of care are the Community, NUHS, the midwives in the MDT, the midwives and the women in the care of the midwives. These headings are set out in a graphic illustration to demonstrate their relationship to each other. The discussion of this model includes what I extrapolated as three distinctive features, the kaupapa, the union influence and the midwives in the MDT. In addition this discussion covers the relationship of the NUHS model of midwifery care to other national and international models.

The limitations of this research are threefold. Firstly it is a small study undertaken by one person within a limited timeframe. It was set up for me to learn the research process and to gain an academic qualification. One person can only achieve so much unlike a group of researchers who may study a case within different periods of time. Secondly, the case study method specifies that the description of this model pertains to a particular context of time and place. If the study had been spread out over a longer period, all the policy and political changes of the time embodied in the model of care, would not have seemed so significant. For example, the three changes of manager recorded in the findings over the time span of the research would not have created such an impact if they had have been viewed over a five year period as the first manager who resigned had been there for five years. Thirdly, not having the women's point of view limits the description of this case. In a time when it can be difficult to gain ethical approval to study vulnerable patients, i.e. complex pregnant women, I already had that approval but was unable to access the women.

The significance of this research, I believe, is the description of a New Zealand model of care not presently described elsewhere in the literature. It is different to the more dominant model practised in New Zealand. Descriptions of the dominant model are readily available in the literature. It is significant to the NUHS midwives who provide this model of care to have it articulated so that they can see how they work in relation to other models. It is also important that all midwives know that such a model exists so 
that it can inform the creation of new models which may be being constructed. Overall having another model that midwives can read about can help them reflect on their own model of care particularly relating to the philosophy, the structure they work in and the funding mechanisms which apply. It may provide assistance to midwives in articulating their own models of care.

Growing up in New Zealand contributed to my background knowledge of PHC, midwifery and its models of care. However a knowledge deficit, current in this area, resulted after many years spent abroad. Undertaking this research had the additional benefit of filling this void. I asked myself if having this knowledge prior to working at a union health practice would have made a difference. I concluded that it would not have affected my clinical practice. However at an organisational level it would have enabled me to have a deeper understanding of how that service worked and its model of midwifery care.

I conclude this research report in the words of Guilliland and Pairman (1995, p 51) "Any model which arises from practice is accessible and meaningful to all practitioners". 


\section{APPENDICES}

\section{Appendix One: Ethics approval}

Health
and
Disability
Ethics
Committees

25 September 2009

Amended 21 March 2012

Ms Siobhan Connor

18 Aurora Street

Petone

Wellington

\section{Dear Ms Connor}

CEN/09/39/EXP - Midwifery as a Model of Care within a Multi-Disciplinary Primary Health Care Service: A Case Study of Midwifery as Practiced within the Newtown Union Health Service

The above study has been given ethical approval by the Central Regional Ethics Committee.

Approved Documents

Appendix 1a: Information Sheet for NUHS Midwives

Appendix 1b : Information Sheet for NUHS Staff

Appendix 1c : Information Sheet for Women Who Have Received NUHS Midwifery Care

Appendix 2a: Consent Form for NUHS Midwives

Appendix $2 b$ : Consent Form for NUHS Staff

Appendix 2c : Consent Form for Women who have Received NUHS Midwifery Care

Appendix 3 : Contract for Research Proposal between Newtown Union Health Service and Siobhan Connor

Appendix 4 : Research Proposal

Accreditation

The Committee involved in the approval of this study is accredited by the Health Research Council and is constituted and operates in accordance with the Operational Standard for Ethics Committees, April 2006.

\section{Final Report (for studies less than 1 year)}

The study is approved until 1 January 2010. A final report is required at the end of the study. The report form is available on http://www.ethicscommittees.health.govt.nz and should be forwarded along with a summary of the results. If the study will not be completed as advised, please forward a progress report and an application for extension of ethical approval one month before the above date.

Amendments

It is also a condition of approval that the Committee is advised if the study does not commence or is altered.

All amendments to the study must be advised to the Committee prior to their implementation, except in the case where immediate implementation is required for reasons of safety. In such cases the Committee must be notified as soon as possible of the change.

Please quote the above ethics committee reference number in all correspondence.

The Principal Investigator is responsible for advising any other study sites of approvals and all other correspondence with the Ethics Committee. 
It should be noted that Ethics Committee approval does not imply any resource commitment or administrative facilitation by any healthcare provider within whose facility the research is to be carried out. Where applicable, authority for this must be obtained separately from the appropriate manager within the organisation.

Yours sincerely

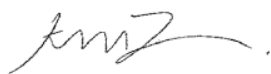

Kirsten Forrest

For Sonia Scott

Central Regional Ethics Committee Administrator

Email: central_ethicscommittee@moh.govt.nz 


\section{Midwifery as a model of care within a multidisciplinary primary health care service: A case study of midwifery as practiced within the Newtown Union Health Service.}

\section{Information Sheet for NUHS Midwives}

My name is Siobhan Connor. I am a practising Midwife employed by Hutt Union Community Health Service. I am currently a student at Victoria University undertaking a Masters of Midwifery. This study will be written up as a thesis and is supported by Dr Joan Skinner who is my supervisor.

The majority of Midwifery in New Zealand is practiced in a continuity of care and midwifery led maternity care model. This model arose at a time of great change within New Zealand midwifery practice. Working as I do in a group practice for a PHC service I have come to find that it is both unique and under studied. This model offers an alternative way for midwives to work in New Zealand. I have chosen to study the Newtown Union Health Service as it is the first of the three Union Health services to have a midwifery component.

The aim of the study is to describe the model of care that the Newtown midwives use, to see how this is positioned within a multidisciplinary team and within a PHC service. This will then be compared and contrasted with the self-employed midwifery model. I am using a case study method that will allow me to examine the work and perspectives of the NUHS (Newtown Union Health Service) midwives and the views of other members of the multidisciplinary team. In particular I am interested in having individual interviews with the midwives, a doctor, a nurse a community health worker and the Manager. I also intend to have a focus group with women who have received NUHS midwifery care. 
I invite you to participate in a one hour interview at a time and location convenient to you. The questions and areas I would like to explore are;

- How does Newtown Union Health Service Work and how do the midwives work with in it?

- Why do you work for Newtown Union Health Service?

- What are the challenges and benefits of working for Newtown Union Health Service?

- How do you perceive others (for example, midwives and consumers) view you and the way you work?

Your participation in the research would be based on your written consent and is voluntary. The interview will be taped and later transcribed. You will then have the opportunity read the transcript to confirm accuracy or to add any further thoughts. No one will see the transcripts except for me, my supervisor and the transcriber who will be asked to sign a confidentiality agreement. The tapes will be kept for five years and then destroyed. As NUHS will clearly be identifiable and with the Services negotiated permission, I may name it in my research report and in any future publications. With your permission I plan to introduce you in the research but comments made will not be attributed to you individually.

If you have any further queries I can be contacted on my mobile 0272894252 or through my pager 5666789. My supervisor Joan Skinner can be contacted on 4636654. 
Midwifery as a model of care within a multidisciplinary primary health care service: A case study of midwifery as practiced within the Newtown Union Health Service.

\section{Consent Form for NUHS Midwives}

- I have read and I understand the information sheet for taking part in the study designed to find out how the midwives at Newtown Union Health Service work, how they work as part of a multidisciplinary team and how this fits in a PHC service.

- I have had the opportunity to discuss this study. I am satisfied with the answers I have been given.

- I understand that taking part in this study is voluntary and that I may withdrawal from the study at any time after the analysis of the data and that this will not affect my employment at NUHS in anyway.

- I understand that my participation in this study is confidential and that the contributions from the individuals and the group will not be divulged to any other participant.

- I understand that the written report of this study and in any future publication of this material that as NUHS is easily identifiable, it will be named and that that makes me more identifiable. I give my permission that in the written report of this study and in any future publication of the material that my name will be used to introduce me in the research but comments made will not be attributed to myself.

- I understand that the researcher will take all reasonable steps to maintain the good name and status of NUHS and its staff.

study.

Signature

Date

Researcher

Date 


\section{Midwifery as a model of care within a multidisciplinary primary health care service: A case study of midwifery as practiced within the Newtown Union Health Service.}

\section{Information Sheet for NUHS Staff}

My name is Siobhan Connor. I am a practising Midwife employed by Hutt Union Community Health Service. I am currently a student at Victoria University undertaking a Masters of Midwifery. This study will be written up as a thesis and is supported by Dr Joan Skinner who is my supervisor.

The majority of Midwifery in New Zealand is practiced in a continuity of care and midwifery led maternity care model. This model arose at a time of great change within New Zealand midwifery practice. Working as I do in a group practice for a PHC service I have come to find that it is both unique and under studied. This model offers an alternative way for midwives to work in New Zealand. I have chosen to study the Newtown Union Health Service as it is the first of the three Union Health services to have a midwifery component.

The aim of the study is to describe the model of care that the Newtown midwives use, to see how this is positioned within a multidisciplinary team and within a PHC service. This will then be compared and contrasted with the self-employed midwifery model. I am using a case study method that will allow me to examine the work and perspectives 
of the NUHS (Newtown Union Health Service) midwives and the views of other members of the multidisciplinary team. In particular I am interested in having individual interviews with the midwives, a doctor, a nurse a community health worker and the Manager. Your view is necessary and will assist in giving the study context.

I invite you to participate in a half an hour interview at a time and location convenient to you. The questions and areas I would like to explore are;

- How does Newtown Union Health Service Work and how do the midwives work with in it?

- Why do you think midwives ant to work for Newtown Union Health Service?

- What are the challenges and benefits of having midwives working in the Newtown Union Health Service?

Your participation in the research would be based on your written consent and is voluntary. The interview will be taped and later transcribed. You will then have the opportunity read the transcript to confirm accuracy or to add any further thoughts. No one will see the transcripts except for me, my supervisor and the transcriber who will be asked to sign a confidentiality agreement. The tapes will be kept for five years and then destroyed. As NUHS will clearly be identifiable and with the Services negotiated permission, I may name it in my research report and in any future publications. With your permission I plan to refer to you by your profession and not by name.

If you have any further queries I can be contacted on my mobile 0272894252 or through my pager 5666789. My supervisor Joan Skinner can be contacted on 4636654. 
Midwifery as a model of care within a multidisciplinary primary health care service: A case study of midwifery as practiced within the Newtown Union Health Service.

\section{Consent Form for NUHS Staff}

- I have read and I understand the information sheet for taking part in the study designed to find out how the midwives at Newtown Union Health Service work, how they work as part of a multidisciplinary team and how this fits in a PHC service.

- I have had the opportunity to discuss this study. I am satisfied with the answers I have been given.

- I understand that taking part in this study is voluntary and that I may withdrawal from the study at any time after the analysis of the data and that this will not affect my employment at NUHS in anyway.

- I understand that my participation in this study is confidential and that the contributions from the individuals and the group will not be divulged to any other participant.

- I understand that the written report of this study and in any future publication of this material that as NUHS is easily identifiable, it will be named and that that makes me more identifiable. I give permission, that in the written report of this study and in any future publication of the material, for my profession to be identified. I understand that my name will not be used.

- I understand that the researcher will take all reasonable steps to maintain the good name and status of NUHS and its staff.

I (full name) hereby consent to take part in this

study.

Signature

Date

Researcher

Date 


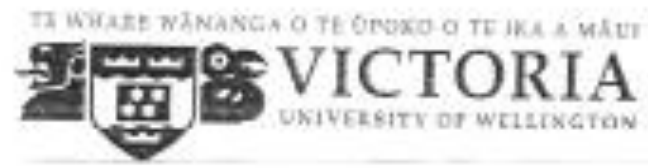

\section{Contract for Research Proposal between Newtown Union Health Service and Siobhan Connor.}

This agreement is made this Sorknt

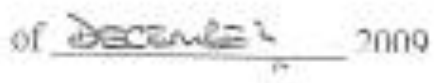

Between

NUHS

And

Siobhan Connor

\section{Research}

1.1 The researcher will earry out a case study evaluation of the Newtown Union Health Service.

1.2 The researcher will provide a detailed research proposal to NUHS prior to the commencement of the research.

1.3 The case study will involve staff interviews, data review and members input.

1.4 The case study will describe the health service and in particular the way the midwives work.

1.5 The case study will provide festback to NUHS and sontribute to knowledge ou de model of care that the midwives use within the service.

\section{Indicative Time Frane}

2.1 The researcher will provide a Provisional Research frame work hy end of September 2009

2.2 NUHS will respond to this framework by the end of October 2009.

2.3 Research involving staff will commence in November 20009 .

2.4 NUHS data review will commence in November 2009 and be completed by the end of January 2010

2.5 Provisional findings will be available by the end of May 2010.

2.6 The thesis for which this case study is for will be completed by April 2011.

\section{Consultation}

3.1 The researcher and NUHS will work honestly and openly raising any issues and marters of concern with the otber party in a timely manner.

3.2 The reseurcher and NUHS will work to resolve any areas of conflict.

3.3 The receawher and NUHS will eonfer on mattera not specified in I cocarch proposal. 


\section{Participation}

4.1 The researcher and NUHS agree to work in partnership with respect to finalising the details of tie rescarch.

4.2 The researcher will have access to NUHS staff and data at a time and place convenient to NUHS.

\section{Ownership}

5.1 All the data (excluding the tapes and transcripts of the interviews) and the findings of the case study evaluation shall be and will remain the property of NUHS.

5.2 The researcher has the right to utilise the data and findings of the case study fur her Masters thesis.

5.3 All decisions, (e.g. Authorship, audience, content) regarding the dissemination of all findings shall be subject to the agreement of both parties.

\section{Confidentiality}

6.1 The researcher agrees to treat all service and member data confidentially according to the Expedited Ethics Committee requirements.

\section{Ternination}

7.1 Where for any reason, other than outlined in 7.3 , this contracted is terminated both parties agree to consult and give reasonable notice (1 month) regarding termination.

7.2 Where for any reason this contract is terminated prior to the completion of the study, agreement shall be reached as to the use of the findings to date.

7.3 NUHS shall bave the right to terminate this contract without notice if the researober acts illegally or in any way that might bring NUHS into disrepute.

This contract is between the Newtown Union Health Service and Siobhan Connor and both parties agree to participation in the case study under the terms and conditions mentioned above. 
Signed for the Newtown Union Health Service by

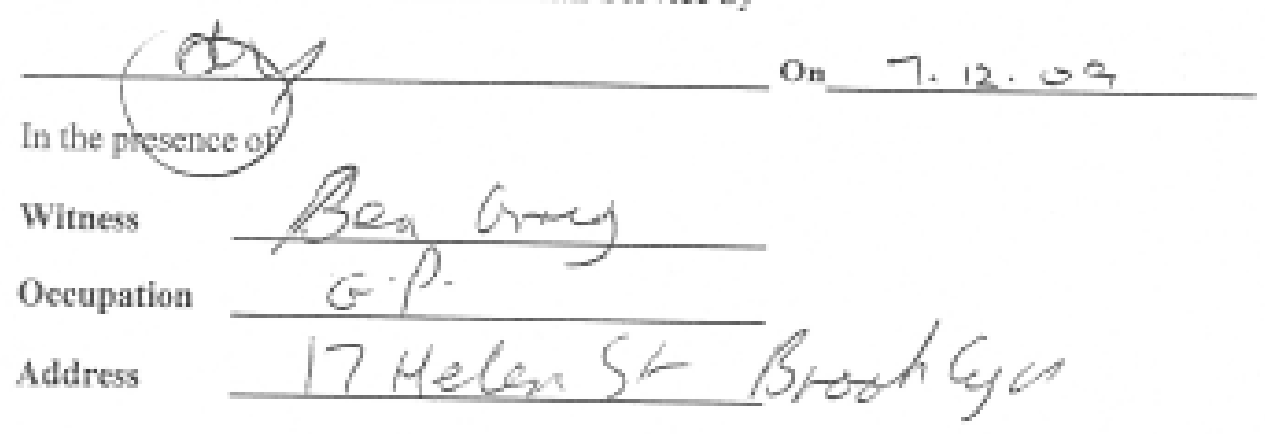

Signed by

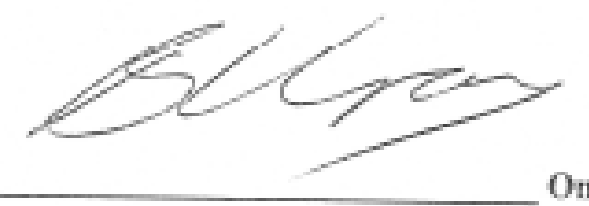

On

Sioblasa Caner

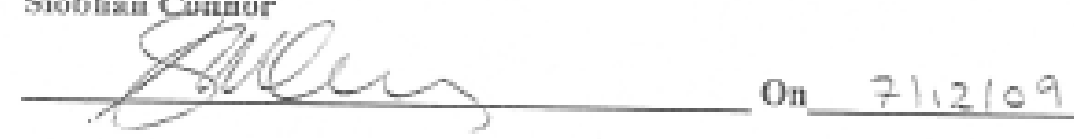

As the researcher in presence of

Witness

Occupation
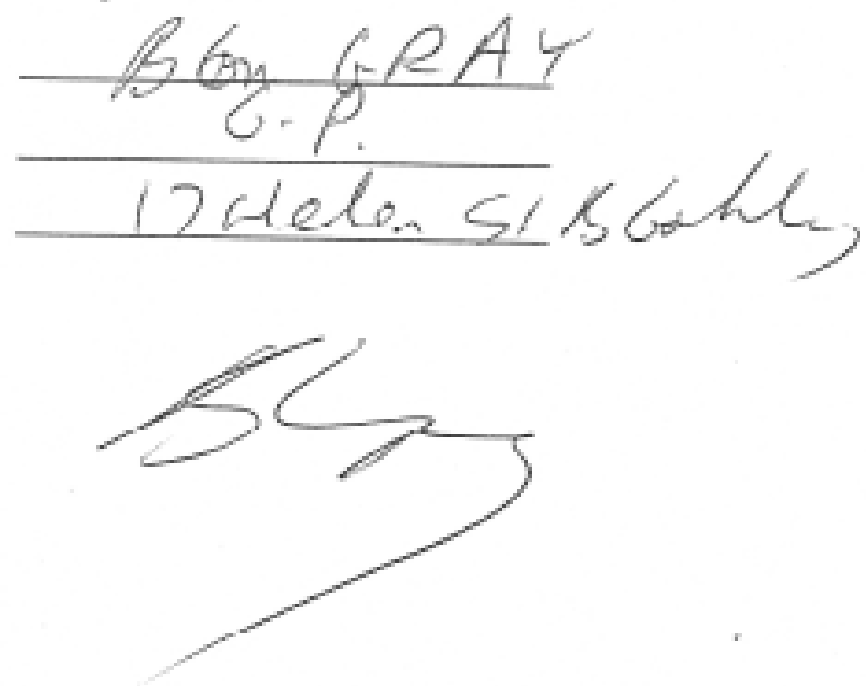

108 
Appendix Five: Research Summary and Agreement Between NUHS and Myself

\section{NUHS Research Agreement}

\section{Proiect ID:}

Title:

Midwifery as a model of care within a multi disciplinary primary health care service; A case study of midwifery as practiced within the Newtown Union Health Service.

\section{Name Contact Details of Principal Researeher:}

Slobhan Connor

Tel; 0212894252

siobhanconnornz@yahoo.co.nz

18 Aurora Street, Petone, Wellington

Organisation of Princinal Researcher:

N/A

\section{NUHS Internal Liaison Person:}

Mary-Clare Reilky (Midwife)

\section{What does the Research Require of NUHS?}

Interviews with key staff including the midwives, one each of the different disciplines ie, the Manager, Doctor, Nurse, Social Worker, Receptionist.

Documents; ie, annual reports, minutes to board meetings, orientation to NUHS package, anything else that may be beneficial.

\section{How Will the Research Findings be used? Eg, Publication, Presentation...}

Written thesis.

Summary of findings in an article, ie joumal publication.

Presentation of findings at conferences, workshops etc

\section{How will NUHS participation be acknowledged?}

In writing in the acknowledgements page of the thesis and in any publication. 


\section{Alsiraci of Plamed Resarchi:}

\section{Midwifery in a Multi Disciplinary Primary Health Care Service: A Unique Model of Care}

In New 7ealand, midwives work in two main contexts: salaried in a hospital. or as self employed, independently practising 'lead maternity carers', A minority way of practising is in a team. Some of these teams work in multi-disciplinary primary health care, family oriented services under the umbrella of Primary Health Organisations. These teams work within a continuum of comprehensive primary health care to families of high socio economic need, underserved populations. Such services are consistent with the aims of the New Zealand Primary Health Care Strategy. I previously worked in this type of service as a midwife. There is minimal research on midwives working within this team model of care, therefore I chose to investigate it through a primarily qualitative case study design informed by the work of Robert Stake and Robert Yin. It is self-funded. The aim of the research is to examine and deseribe the model of care and model of proctioe devolopod by midwives employed in Newtown Union Health Service (NUHS). Key objectives include exploring the challenges and benefits of the service, the midwives in the service, and to explore the views of its community. Ethical approval for the research came from the regional health ethics committee where NUHS is situated. The main data comes from individual interviews with midwives, multidisciplinary team members, and with five women who have birthed with these midwives. Other data includes demographic and midwifery practice outcome data from NUHS. All data is undergoing content analysis directed at answering the fesearch question. The systematic description of this model of midwifery care is significant in New Zealand as it does not presently exist. At the intemational level it will provide an alternative model of midwifery care for use with under-served populations.

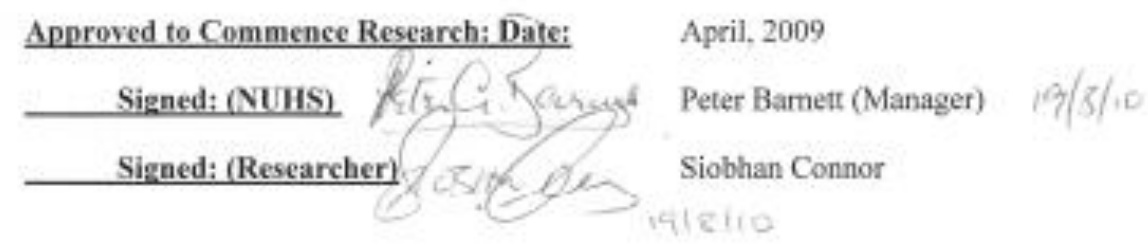

\section{Poxt Seript:}

My aim of this thesis is to meet the requirements to obtain a Masters in Midwifery, I am doing this part time, which is over two years at Victoria University in Wellington. I aim to have this completed by July $31,2011$. 


\section{REFERENCES}

Anderson, T. (2007). Is this the end of independent midwifery? Practising Midwife, 10(2), 4-5.

Armstrong, G. (2009). Ryall set to cut deep into PHO's, Sunday Star Times. Wellington.

Ashton, T., Cumming, J., McLean, J., McKinlay, M., \& Fae, E. (2004). Contracting for health services; Lessons from New Zealand. Regional Office for the Western Pacific

Ashton, T., Mays, N., \& Devlin, N. (2005). Continuity through change: The rhetoric and reality of health reform in New Zealand. Social Science and Medicine, 61, 252-262.

Barnett, J., \& Barnett, P. (2008). Reinventing primary care: The New Zealand case compared. In A. Crooks \& G. Andrews (Eds.), Primary health care: People, practice and place (pp. 122). Aldershot: Ashgate Press.

Barnett, P., \& Barnett, R. (2005). Reform and change in health service provision. In K. Dew \& G. Davis (Eds.), Health and Society in Aotearoa New zealand (2nd ed., pp. 219-234). Auckland: Oxford University Press.

Barnett, P., Smith, J., \& Cumming, J. (2009). The Roles and Functions of Primary Health Organisations. Wellington: Health Services Research Centre. Victoria University of Wellington.

Bassett, M. (2006). Health for All in the 21st Century (Publication. Retrieved 30/08/2009, from American Journal of Public Health 2089: http:/www.ajph.org/cgi/content/full/96/12/2089

Bates, C. (2004). Midwifery practice: Ways of working. In M. Stewart (Ed.), Pregnancy, birth and maternity care (pp. 121-142). London: Books for Midwives.

Benjamin, Y., Walsh, D., \& Taub, N. (2001). A comparison of partnership caseload midwifery care with conventioal team midwifery care: Labour and birth outcomes. Midwifery, 17(3), 234-240.

Benn, C. (1999). Midwifery partnership: Individualism contractualism or feminist praxis? New Zealand College of Midwives Journal, October, 18-20.

Berry, H. (2005). Briefing paper: The one-to-one caseload midwifery project. London: Guy's and St Thomas' NHS Foundation Trust.

Biro, M., Waldenstrom, U., Brown, S., \& Pannifex, J. (2003). Satisfaction with team midwifery care for low and high risk women: a randomized controlled trial. Birth, 30(1), 1-10.

Boseley, S., \& Domokos, J. ( 2009, Monday, 7 December). Celebrated Albany Midwifery Practice loses King's College Hospital contract. The Guardian.

Boulton, A., Simonsen, K., Walker, T., Cumming, J., \& Cunningham, C. (2004). Indigenous particpation in the 'new' New Zealand health structure. Journal of Health Services Research and Policy, 9(2), 35-40.

Bowden, J. (2006). Using health promotion models and approaches in midwifery. In J. Bowden \& V. Manning (Eds.), Health promotion in midwifery: Principles and practice (2nd ed., pp. 36-48). London: Hodder Arnold.

Brodie, P., Davis, G., \& Homer, C. (2008). Effective collaboration with medical colleagues: Making it happen. In C. Homer, P. Brodie \& N. Leap (Eds.), Midwifery continuity of care: A practical guide (pp. 89-106). New South Wales: Churchill Livingstone.

Burgess, M. (1993). A guide to the law for nurses and midwives. Auckland: Longman Paul Ltd.

Chinn, P., \& Jacobs, M. (1983). Theory and nursing: A systematic approach. St Louis: Mosby.

Clark, H. (1996). Address to the New Zealand College of Midwives National Conference. New Zealand College of Midwives Journal, October, 11-12.

Compass. (2010). Compass Health PHOs. Retrieved 20/02/2012, from http://www.compasshealth.org.nz/phos/

Connor, S., \& Skinner, J. (2011a). Midwifery as a model of care within a multi disciplinary primary health care service: Newtown Union Health Service. Paper presented at the International Confederation of Midwives Conference. 
Connor, S., \& Skinner, J. (2011b). Midwifery as a model of care within a multi disciplinary primary health care service: Newtown Union Health Service. Paper presented at the Joan Donley Midwifery Research Forum.

Connor, S., \& Skinner, J. (2011c). Midwifery as a model of care within a multi disciplinary primary health care service: Newtown Union Health Service. . Paper presented at the New Zealand College of Midwives Wellington Region.

Cooper, M. (1999). Mirroring the present in the past: Interpreting a midwifery casebook 19071913. In P. Watson \& M. Woods (Eds.), NZNO Waiora: Nursing research in Aotearoa/New Zealand. Wellington.

Cornwell, C., Donnellan-Fernandez, \& Nixon, A. (2008). Planning and implementing mainstream midwifery group practices in a tertiary setting. In C. Homer, P. Brodie \& N. Leap (Eds.), Midwifery Continuity of Care: A Practical Guide (pp. 107-126). New South Wales: Churchill Livingstone.

Crotty, M. (1998). The foundations of social research: Meaning and perspective in the research process. London: Sage.

Croxson, B., Smith, J., \& Cumming, J. (2009). Patient fees as a metaphor for so much more in New Zealand's primary health care system. Wellington: Health Services Research Centre. Victoria University of Wellington.

Cumming, J. (2009). Still challenges ahead for enhancing primary health care. Wellington: Health Services Research Centre: Victoria University of Wellington.

Cumming, J., Barnett, P., \& Powell, M. (2004). Governance in District Health Boards in New Zealand: A report on progress. Public Sector, 27(1), 5-9.

Davidson, P., Halcomb, E., Hickman, L., Phillips, J., \& Graham, B. (2006). Beyond the rhetoric: What do we mean by a model of care. Australian Journal of Advanced Nursing 23(3), 47-55.

Department of Health. (1993). Changing childbirth: Report of the expert maternity group. London: HMSO.

Dimond, B. (2002). Professional indemnity and the midwife. British Journal of Midwifery, 10(8), 641-644.

Donley, J. (1986). Save the midwife. Auckland: New Women's Press Ltd.

Donley, J. (1998). Birthrites. Natural vs unnatural childbirth in New Zealand. Auckland: The Full Court Press.

Donley, J. (Ed.). (1995). Independent midwifery in New Zealand. Edinburgh: Churchill Livingstone.

Doyle, M. (1998). Newtown! Community in a Wellington suburb Wellington: Wellington City Council.

Durham, R. (2002). Autonomy and commitment to life outside midwifery: Women, work and midwifery. In R. Maunder \& V. Fleming (Eds.), Failure to progress: The contraction of the midwifery profession (pp. 122-132).

Easthope, R. (2007). A pictorial history of the public hospital in Wellington. Retrieved 15/02/2012, from http://www.ccdhb.org.nz/History/Pictorial\%20index/Pictorial\%20Index.htm care

Engel, C. (2000). Towards a sustainable model of midwifery practice in a continuity of setting. The experience of New Zealand midwives. Unpublished Masters Thesis. Victoria University of Wellington.

Farquhar, M., \& Camilleri-Ferrante, C. (2000). Continuity of care in maternity services: Women's views of one team midwifery scheme. Midwifery, 16(1), 35-47.

Fleming, V. (1998). Autonomous or automatons? An exploration through history of the concept of autonomy in midwifery in Scotland and New Zealand. Nursing Ethics, 5(1), 43-51. 
Fleming, V. (2000). The midwifery partnership in New Zealand: A past history or a new way forward. In M. Kirkham (Ed.), The midwife-mother relationship. London: MacMillan Press.

Fleming, V. (2002). Statutory control. In R. Mander \& V. Fleming (Eds.), Failure to progress: The contraction of the midwifery profession. London: Routledge.

Flemming, E. (1998). Women and midwives in partnership: A problematic relationship. Journal of Advanced Nursing, 27, 8-14.

Flint, C. (1993a). Know your midwife. Continuity of care provided by a team of midwives. In S. Robinson \& A. Thompson (Eds.), Midwives research and childbirth (Vol. 2). London: Chapman and Hall.

Flint, C. (1993b). Midwifery teams and caseloads. Oxford: Butterworth-Heinnemann.

Flint, C. (2010). The birth centre. Retrieved 10/11/2010, from http://www.birthcentre.com/About-Us-Professor-Flint

Flint, C., Poulengeris, P., \& Grant, A. (1989). The 'Know Your Midwife' scheme: A randomised trial of continuity of care by a team of midwives. Midwifery, 5(1), 11-16.

Foureur, M., \& Sandall, J. (2008). The challenges of evaluating midwifery continuity of care. In C. Homer, P. Brodie \& N. Leap (Eds.), Midwifery continuity of care. A practical guide (pp. 165-180). Sydney: Churchill Livingstone.

Frohlich, J. (2007). Independent midwifery: A model of care on the brink of extinction. MIDIRS Midwifery Digest, 17(3), 313-318.

Gauld, R. (2003). One country, four systems: Comparing changing health policies in New Zealand. International Political Science Review, 24(2), 199-218.

Gauld, R. (2008). Report from the field: The unintended consequences of New Zealand's primary health care reforms. Journal of Health Politics., Policy and Law, 33(1), 93-115.

Godfrey, E. (2002). Birth centres: A return to the natural way. Midiwives, 5(11), 368.

Griffiths, C. (2002). An exploration of the care processes used by midwives in their work with women living in areas of high deprivation: A grounded theory study. Massey University, Palmerston North.

Guilliland, K. (1998a). A demographic profile of independent (self employed) midwives in New Zealand Aotearoa. Unpublished Masters Thesis. Victoria University of Wellington. New Zealand.

Guilliland, K. (1998b). Shared care in maternity services: With whom and how? New Zealand College of Midwives Journal, 14, 1-4.

Guilliland, K. (1999). Autonomous midwifery practice in New Zealand: The highs and lows. Birth Issues, 8(1), 14-17.

Guilliland, K. (2004). A hundred years of midwifery and what have we learnt about ourselves? Midwifery News, September(34), 4-6, 28-29.

Guilliland, K., \& Hassenn, J. (1990). Women in Partnership. New Zealand College of Midwives, November 3.

Guilliland, K., \& Pairman, S. (1991). Midwifery education - A national perspective. New Zealand College of Midwives, May 1991, 5-9,15.

Guilliland, K., \& Pairman, S. (1994). The midwifery partnership- a model for practice. New Zealand College of Midwives Journal, October, 5-9.

Guilliland, K., \& Pairman, S. (1995). The midwifery partnership. A model for practice. Monograph Series 95/1. Wellington: Department of Nursing and Midwifery, Victoria University of Wellington.

Guilliland, K., \& Pairman, S. (2010). The midwifery Partnership - A model for practice (2nd ed.). Christchurch: New Zealand College of Midwives.

Guilliland, K., \& Pairman, S. (2011). The demise of midwifery as a profession. In K. Guilliland \& S. Pairman (Eds.), Women's Business. The story of The New Zealand College of Midwives. Christchurch: The New Zealand College of Midwives. 
Hart, A., Pankhurst, L., \& Sommerville, F. (1999). An evaluation of team midwifery. British Journal of Midwifery, 7(9), 573-578.

Hatem, M., Sandall, J., Devane, D., Soltani, H., \& Gates, S. (2008). Midwife-led versus other models of care for childbearing women. Cochrane Database System Review. 8(4).

Health Care Aotearoa. (2010). Transforming social inequalities through community inspired health services. Retrieved 15/02/2012, from http://www.hca.org.nz/home/ourhistory/

Hefford, M., Crampton, P., \& Foley, J. (2005). Reducing health disparities through primary care reform: The New Zealand experiment. Health Policy, 72, 9-23.

Hendry, C. (2008). Understanding your context: Preparing for change. In C. Homer, P. Brodie \& N. Leap (Eds.), Midwifery continuity of care: A practical guide (pp. 47-66). New South Wales: Churchill Livingstone.

Hinton, B. (1999). Maternity care - A decade of change [Electronic Version]. Womens Health Action Trust, 3-6. Retrieved 08/12/10 from http://www.womensHealth.org.nz/index.php?page=maternity-care-a-decade-of-change.

Homer, C. (2005). Laying the foundation: The STOMP study. In P. Luanaigh \& C. Carlson (Eds.), Midwifery and Public Health: Future directions and New Opportunities. (pp. 129-152). Edinburgh: Elsevier Churchill Livingstone.

Homer, C., Brodie, P., \& Leap, N. (2008). Getting started: What is midwifery continuity of care? In C. Homer, P. Brodie \& N. Leap (Eds.), Midwifery continuity of care: A Practical guide (pp. 1-24). New South Wales: Churchill Livingstone.

International Confederation of Midwives. (2005). Definition of the Midwife. Retrieved 10/03/2012, from www.internationalmidwives.org

James, K. (Ed.). (2009). Health for the people - Newtown Union Health Service 20 years on. Wellington: Steele Roberts.

King, A. (2000). The New Zealand Health Strategy. Wellington: Ministry of Health.

King, A. (2001). The Primary Health Care Strategy. Wellington: Ministry of Health.

Lauchland, M. (1996). The shared journey: Models in midwifery practice. New Zealand College of Midwives Journal, 14, 24-27.

Leap, N., Homer, C., \& Brodie, P. (2008). Introducing continuity of care in mainstream maternity services: building blocks for success. In C. Homer, P. Brodie \& N. Leap (Eds.), Midwifery continuity of care. A practical guide (pp. 67-88). Sydney: Churchill Livingstone.

Learner, S. (2004). Independent midwifery. Midwifery matters, 103, 22.

Lester, A. (2005). The argument for caseload midwifery. MIDIRS Midwifery Digest, 15(1), 2730.

Libberton, P. (2007). Nursing theory and models for practice. In J. Brown. \& P. Libberton (Eds.), Principles of Professional Studies in Nursing (pp. 25-43). Hampshire: Palgrave Macmillan.

Malcolm, L., \& Powell, M. (1996). The development of Independent Practice Associations and related groups in New Zealand. New Zealand Medical Journal, 109, 184-187.

Mander, R., \& Purdue, D. (2002). Preface. In R. Mander \& V. Fleming (Eds.), Failure to progress. The contraction of the midwifery profession. London: Routledge.

McCourt, C., \& Page, L. (1996). Report on the Evaluation of One-to-One Midwifery Practice Wolfson School of Health Sciences, Thames Valley University, London.

McCourt, C., Stevens, T., Sandall, J., \& Brodie, P. (2000). Working with women: developing continuity of care in practice. In L. Page (Ed.), The new midwifery: Science and sensitivity in practice. (pp. 141-165). Edinburgh: Churchill Livingstone.

McGrath, F. (1989). The union health centres initiative - An evaluation. Wellington: Health Services Research and Development Unit Department of Health. 
Merriam-Webster. (2012). Gentrification. Retrieved 22/03/12, 2012, from www.merriamwebster.com/.../gentrification

Midwifery and Maternity Providers Association. (2008). Midwifery Statistics. Christchurch: Author.

Midwifery and Maternity Providers Association. (2009). Midwifery Statistics. Christchurch: Author.

Milan, M. (2005). Independent midwifery compared with other caseload practice. MIDIRS Midwifery Digest, 15(4), 439-449.

Ministry of Health. (2003). Minimum requirements for primary health organisations. Wellington. Author

Ministry of Health. (2004). A portrait of health: Key results of 2002/03 New Zealand. Retrieved 12/09/2009, 2009, from www.health.govt.nz/.../portrait-health-survey

Ministry of Health. (2005a). A difference in communities: What's happening in PHOs. Wellington. Author.

Ministry of Health. (2005b). PHO Yearbook: 2004. Wellington Ministry of Health in association with District Health Boards. Author.

Newtown Union Health Service. (2010). Orientation information for NUHS staff. Wellington.

Osten, F., \& McKillop, M. (2007). Midwifery, maternal and child health. In K. James (Ed.), Health for the people. Newtown Union Health Service - 20 years on. Wellington: Steele Roberts .

Page, L. (2004). The independent midwife. British Journal of Midwifery, 12(6), 360.

Page, L., Beake, S., \& Vail, A. (2001). Clinical outcomes of one-to-one midwifery practice. British Journal of Midwifery, 9(11), 700-706.

Pairman, S. (1998). Women-centred midwifery: Partnership or professional friendships. New Zealand College of Midwives Journal, October, 5-10.

Pairman, S. (2011). Educating midwives for autonomous practice. In K. Guilliland \& S. Pairman (Eds.), Womens Business. Christchurch: The New Zealand College of Midwives.

Papps, E., \& Olsen, M. (1997). Doctoring childbirth and regulating midwifery in New Zealand. A Foucauldian perspective. Palmerston North: The Dunmore Press.

Raymont, A., \& Cumming, J. (2009). Status and activities of general medical practices. Wellington. Wellington: Health Services Research Centre. Victoria University of Wellington

Reed, B. (2002a). The Albany midwifery practice. MIDIRS Midwifery Digest, 12(1), 118-121.

Reed, B. (2002b). The Albany midwifery practice (2). MIDIRS Midwifery Digest, 12(2), 261-264.

Regan, T., \& Clarke, C. (2007). Community Participation. In James (Ed.), Health for the people: Newtown Union Health Service - 20 years on (pp. 45-50). Wellington: Steele Roberts.

Rooks, J. (1999). The midwifery model of care. Journal of Nurse-Midwifery, 44(4), 370-374.

Rowley, M., Hensley, M., Brinsmead, M., \& Wlodarczyk, J. (1995). Continuity of care by a midwife team versus routine care during pregnancy and birth: A randomised trial. Medical Journal of Australia, 163(6), 289-293.

Ryall, J. (2009). Introduction. In K. James (Ed.), Health for the people. Newtown Union Health Service - 20 years on. Wellington: Steele Roberts.

Salmond, C., Crampton, P., \& Atkinson, J. (2007). NZDep2006 Index of Deprivation. Wellington: University of Otago.

Sandall, J. (1996). Moving towards caseload practice: What evidence do we have? British Journal of Midwifery, 4(12), 620-621.

Sandall, J., Davies, J., \& Warwick, C. (2001). Evaluation of the Albany midwifery practice. Final report March 2001. London: Florence Nightengale School of Nursing and Midwifery, Kings College of London. 
Sandall, J., Page, L., Homer, C., \& Leap, N. (2008). Midwifery continuity of care: What is the evidence? In C. Homer, P. Brodie \& N. Leap (Eds.), Midwifery continuity of care: A practical guide (pp. 25-46). New South Wales: Churchill Livingstone.

Sargent, L. (2002). Practice and autonomy. In R. Mander \& V. Fleming (Eds.), Failure to progress. The contraction of the midwifery profession. London: Routledge.

Skinner, J. (1999). Midwifery partnership: Individualism, contractualism or feminist praxis? NZ College of Midwives, 21, 14-17.

Smith, J., \& Cumming, J. (2009). Taking the temperature of Primary Health Organisations: A briefing paper. Wellington: Health Services Research Centre. Victoria University of Wellington.

Smithies, J., \& Webster, G. (1998). Why is community involvement in health important now? In J. Smithies \& G. Webster (Eds.), Community involvement in health (pp. 59-76). Ashgate, VT: Aldershot/ Brookfield.

Stake, R. (1978). The case study method of social inquiry. Educational Researcher, 7(2), 5-8.

Stake, R. (1995). The art of case study research. Thousand Oaks: Sage Publications.

Stake, R. (2005). Qualitative case studies. In N. Denzin \& Y. Lincoln (Eds.), Sage handbook of qualitative research (pp. 443-466). Thousand Oaks: Sage.

Steinmetz, M. (2011) Team-based midwifery care: Consumer satisfaction with a service embedded in primary health care. Unpublished summer student research project. University of Otago.

Stewart, S. (2001). Midwifery in New Zealand. A cause for celebration. MIDIRS Midwifery Digest, 11(3), 319-322.

Thomas, P. (2002). The midwife you have called knows you are waiting... A consumer view. In R. Mander \& V.Fleming (Eds.), Failure to progress. The contraction of the midwifery profession. London: Routledge.

Tinkler, A., \& Quinney, D. (1998). Team midwifery: The influence of the midwife-woman relationship on women's experiences and perceptions of maternity care Journal of Advanced Nursing, 28(1), 30-35.

Todd, C., Farquhar, M., \& Camilleri-Ferrante, C. (2009). Team midwifery: The views and job satisfaction of midwives. Midwifery, 14(4), 214-224.

Walker, S., Moore, H., \& Eaton, A. (2004). North Queensland midwives' experience with a team model of midwifery care. Australian Journal of Midwifery, 17(1), 17-22.

Walton, I., \& Hamilton, M. (1995). Midwives and changing childbirth. Cheshire: Books for Midwives Press Ltd.

Welington City Council. (2012). Services and Information. Retrieved 03/03/2012, from www.wellington.govt.nz/services/

Wellington Primary Health Organisations. (2010). Two community-based Primary Health Organisations (PHOs) in Wellington region announce proposed merger [Electronic Version]. Retrieved 12/08/2010 from http://www.nzdoctor.co.nz/undoctored/2010/april-2010/01/two-community-based-primary-health-organisations(phos)--in-wellington-region-announce-proposed-merger.aspx.

Wood, G. (2005). An evaluation of a one-to-one midwifery team. MIDIRS Midwifery Digest, 15(3), 313-319.

World Health Organisation. (1978). Alma-Ata Declaration on Primary Health Care: Report on the International Conference on Primary Health Care. Geneva. Author

World Health Organisation. (1985). Health for all by the year 2000. Geneva. Author.

World Health Organisation. (1986). Ottawa Charter for Health Promotion. Health Promotion, 1(4), iii-v. Author.

World Health Organisation. (1995-2008). The World Health Reports. In World Health Organisation (Ed.). Author. 
World Health Organisation. (1998). The World Health Report 1998 - Life in the 21st century: A vision for all. Geneva. Author.

World Health Organisation. (2008). The World Health Report 2008 - Primary Health Care: Now More Than Ever Geneva: World Health Organisation. Author.

Wynn-Williams, B. (2004). Defining and delivering core midwifery care. Kai Tiaki Nursing New Zealand, April, 14-16.

Wynn-Williams, B. (2006). The lived experience of being a core midwife in a New Zealand maternity unit. Victoria University of Wellington, Wellington.

Yin, R. (2003). Case study research. Design and Methods (3rd ed.). Thousand Oaks: Sage Publications.

Yin, R. (2008). Case study research. Design and Methods (4th ed.). Thousand Oaks: Sage Publications. 